\title{
Eight new species of freshwater crabs (Decapoda: Brachyura: Potamidae) from Yunnan Province, China
}

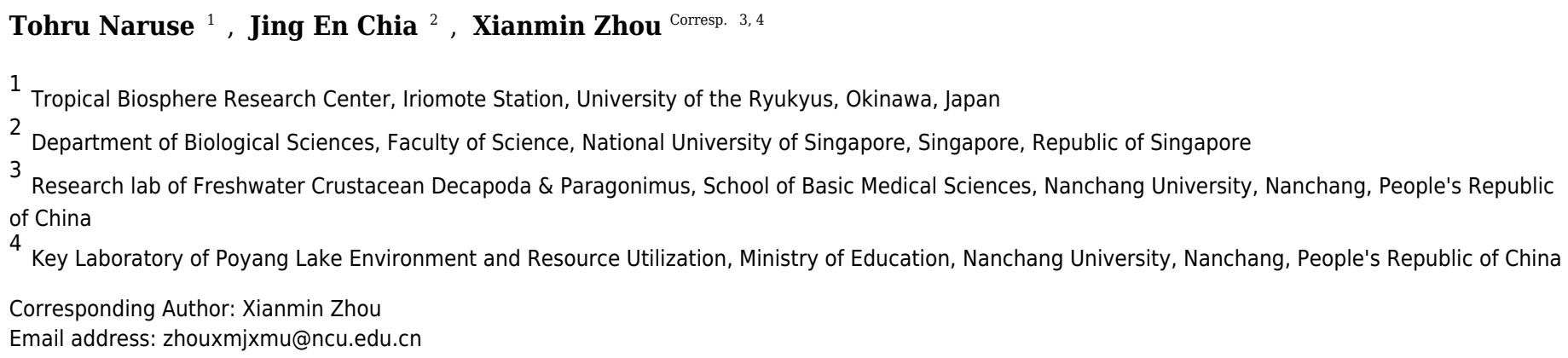

We describe eight new species of potamid freshwater crabs from Yunnan Province, China. These include four species of the genus Indochinamon Yeo \& Ng, 2007, two species of the genus Potamiscus Alcock, 1909, and one species each of the genera Pararanguna Dai \& Chen, 1985, and Parvuspotamon Dai \& Bo, 1994. The new species of Pararanguna and Parvuspotamon represent the second species of respective genera, which are here redefined. Detailed comparisons with morphologically allied species are provided. Photographs of the type specimens of their comparative species which are poorly illustrated in the literatureare also provided to allow better understanding of their morphology. 
1 Eight new species of freshwater crabs (Decapoda: Brachyura: Potamidae) from Yunnan

2 Province, China

3

4 Tohru Naruse ${ }^{1}$, Jing En Chia ${ }^{2}$ and Xianmin Zhou ${ }^{3,4}$

5

$6{ }^{1}$ Tropical Biosphere Research Center, Iriomote Station, University of the Ryukyus

7 2Department of Biological Sciences, National University of Singapore

$8{ }^{3}$ Research lab of Freshwater Crustacean Decapoda \& Paragonimus, School of Basic Medical

9 Sciences, Nanchang University

$10{ }^{4}$ Key Laboratory of Poyang Lake Environment and Resource Utilization, Ministry of Education,

11 Nanchang University

12

13 Corresponding author: Xianmin Zhou, zhouxmjxmu@126.com

ABSTRACT

We describe eight new species of potamid freshwater crabs from Yunnan Province, China. These

17 include four species of the genus Indochinamon Yeo \& $\mathrm{Ng}, 2007$, two species of the genus

18 Potamiscus Alcock, 1909, and one species each of the genera Pararanguna Dai \& Chen, 1985 , and Parvuspotamon Dai \& Bo, 1994. The new species of Pararanguna and Parvuspotamon represent the second species of respective genera, which are here redefined. Detailed comparisons with morphologically allied species are provided. Photographs of the type specimens of their comparative species which are poorly illustrated in the literature are also 23 provided to allow better understanding of their morphology.

\section{INTRODUCTION}

27 China is the world's most species-rich country for the freshwater crabs, with more than 200 species recorded from the country (Dai, 1999; Cumberlidge et al., 2009; 2011; Cumberlidge \& $\mathrm{Ng}$, 2009). Cumberlidge et al. (2011: 46) had made the observation that "(d)ozens of new species remain undescribed", and several recent discoveries have proven this to be true (Cheng, Lin \& Li, 2010; Zhu, Naruse \& Zhou, 2010; Huang, Huang \& Ng, 2012; Lin, Cheng \& Chen 2012; 
32 2013; Naruse, Zhu \& Zhou, 2013; Huang, Mao \& Huang, 2014; Do, Shih \& Huang, 2016;

33 Huang, Shih \& Mao, 2016; Chu, Sun \& Sun, 2017; Chu, Zhou \& Sun, 2017; Huang, Ahyong \&

34 Shih, 2017; Huang, Shih \& Ng, 2017; Ng, 2017; Huang, 2018).

35 Yunnan Province (Fig. 1) is located in southwestern China at the meeting point of the eastern

36 Asia monsoon region, the Tibetan Plateau region and the tropical monsoon region of southern

37 Asia and Indo-China. The significantly wide elevation range within the province ( $76.4 \mathrm{~m}$ to

$386,740 \mathrm{~m}$ ) and the presence of at least six major river systems (Irrawaddy, Salween, Mekong,

39 Yangtze, Red and Pearl) have contributed a wide range of habitats, topographies, and its rich

40 biota (Kunming Institute of Zoology, CAS 1999; Yang et al., 2004). Indeed, Yunnan hosts 50

41 species of the freshwater crab in 15 genera (Dai, 1999; Dai \& Cai, 1998; Naruse, Yeo \& Zhou,

42 2008; Chu, Zhou \& Sun, 2017), which represents the highest number of the freshwater crab

43 species in the provinces of China.

44 In 2004, a team from the National University of Singapore and Nanchang University started

45 to study the taxonomy and diversity of the freshwater crabs of Yunnan Province. Despite of the

46 short period of the collection, 25 species of the freshwater crabs were collected, of which 9

47 species were not be identified to any of described species (Jing En Chia, unpublished data). The

48 present study investigated the identities of 8 out of the above 9 species by comparing type

49 specimens, original descriptions and additional references of described allied species in detail.

50 As a result, the eight species treated in this study turned out to be undescribedspecies of four

51 genera, viz., Indochinamon Yeo \& Ng, 2007, Pararanguna Dai \& Chen, 1985, Parvuspotamon

52 Dai \& Bo, 1994, and Potamiscus Alcock, 1909. Indochinamon was established by Yeo \& Ng

53 (2007) for species distributed from southeast China (Yunnan and Guangxi), Vietnam, Laos,

54 Thailand, Myanmar, northeastern India to Himalaya (Alcock, 1909; Pretzmann, 1966; Yeo \&

55 Ng, 1998; Dai, 1999; Brandis, 2000; Ng \& Naiyanetr, 1993; Naiyanetr, 2001). They were

56

57

58

59

60

61

62 previously assigned to "Potamon", which was until then used as a "catch-all" genus for many

Asian potamid species (Yeo \& Ng, 2007). Recently four Vietnamese species have been added to the genus (Naruse, Quynh \& Yeo, 2011; Do, Nguyen \& Le, 2016). The present study describes additional four species that fit diagnostic characters of Indochinamon (see Yeo \& Ng, 2007: 283) but differs from any known species. Poorly known Pararanguna and Parvuspotamon are both monotypic genera and endemic to Yunnan Province. One species each are described for these two genera, and the two genera are redefined. Potamiscus is distributed from China (Guangxi, 
63 Yunnan, Tibet), Myanmar to northeastern India (Wood-Mason, 1871; Rathbun, 1904; Alcock, 64 1909; Kemp, 1913; Tuerkay \& Naiyanetr, 1987; Dai, 1999). Two new Potamiscus species are 65 also described in this study.

66 The ninth species not treated in this study will be described as a new species of a new genus

67 in a separate paper (Darren C. J. Yeo et al., in prep.).

68

\section{METHODS}

70 Specimens examined were collected by members of Chuxiong Medical College, Yunnan, and

71 National University of Singapore for our study and are deposited in the Department of

72 Parasitology, Medical College of Nanchang University, Nanchang (NCU MCP); the Zoological

73 Reference Collection (ZRC), Lee Kong Chian Natural History Museum (previously Raffles

74 Museum of Biodiversity Research), National University of Singapore; the Institute of Zoology,

75 the Chinese Academy of Sciences, Beijing (CB); and the Ryukyu University Museum, Fujukan

76 (RUMF), University of the Ryukyus, Okinawa. These collected specimens have been preserved

77 in $75-80 \%$ ethanol. Measurements provided are of the carapace length (CL) by the carapace

78 width (CW). Terminology used in descriptive accounts essentially follows Ng (1988) and Yeo \&

$79 \mathrm{Ng}$ (2007). The abbreviations G1 and G2 are used for the male first and second gonopods,

80 respectively.

81 Morphology of some comparative species were previously not well-illustrated, which

82 sometime makes difficult to conduct taxonomic work. A part of photographs taken by a team of

83 the third author (XZ) were shown in this study. Data of those specimens were as follows:

84 Indochinamon gengmaense (Dai, 1995), holotype, male (CB05192 YN6491119A), Mengding

85 Town, Dima County Yunnan Province, coll. 7 May 1964. Indochinamon chinghungense (Dai,

86 Song, He, Cao, Xu and Zhong, 1975), holotype, male (CB05166 YN 637507) (47.8 × 37.0 mm),

87 Tuanshanzai Town Jinghong County, Yunnan Province, coll. 9 Dec. 1963. Indochinamon

88 boshanense (Dai \& Chen, 1985), holotype, male (CB05160 HD8183031), Daojie Town, Baoshan

89 County, Yunnan Province, coll. 17 Oct. 1981. Indochinamon jianchuanense (Dai \& Chen, 1985),

90 holotype, male (CB05159 HD 8183030), Lingcheng Town, Jianchuan County, Yunnan Province,

91 coll. 28 Sep. 1981. Indochinamon menglaense (Dai \& Cai, 1998), holotype, male (CB05168 YN-

92 9496196A), (43.1 × 33.2 mm), Shangyong, Mengla County, Yunnan Province, coll., 23-26 Apr.

93 1994. Pararanguna semilunata (Dai \& Chen, 1985), paratype, male (CB05191 HD 8183034), 
94 Xiyi Town, Baoshan County, Yunnan Province, coll. 13 Oct. 1981. Parvuspotamon yuxiense Dai 95 \& Bo, 1994, holotype, male (CB05138 YN 9091116A), Xingping, Yuxi County, Yunnan

96 Province, coll. Aug. 1989. Potamiscus motuoensis Dai, 1990, holotype, male (CB05157

97 XZ6389084), Motuo County, Tibet, coll. 29 Jul. 1983. Potamiscus yongshengensis Dai \& Chen, 98 1985, holotype, male (CB05149 HD 8183035), Yongsheng County, Yunnan Province, coll. 22 99 Aug. 1981. Other comparative material are as follows. Indochinamon boshanense (Dai \& Chen, 100 1985), ZRC 1998.811, 1 male (50.1×36.8 mm), Boshan (Baoshan), Yunnan Province, China, 101 coll. A.Y. Dai, 20 Oct. 1981. Pararanguna semilunata Dai \& Chen, 1985, 1 male $(21.8 \times 16.7$ $102 \mathrm{~mm}), 1$ female $(20.0 \times 16.0 \mathrm{~mm})($ ZRC), Boshan (Baoshan), coll. 13 Oct. 1981.

103 The electronic version of this article in Portable Document Format (PDF) will represent a 104 published work according to the International Commission on Zoological Nomenclature (ICZN), 105 and hence the new names contained in the electronic version are effectively published under that 106 Code from the electronic edition alone. This published work and the nomenclatural acts it 107 contains have been registered in ZooBank, the online registration system for the ICZN. The 108 ZooBank LSIDs (Life Science Identifiers) can be resolved and the associated information viewed 109 through any standard web browser by appending the LSID to the prefix http://zoobank.org/. The

110 LSID for this publication is: urn:lsid:zoobank.org:pub:642C4FCB-905B-48DB-8E01-

111 96C87249D809. The online version of this work is archived and available from the following 112 digital repositories: PeerJ, PubMed Central and CLOCKSS.

113

\section{RESULTS}

115 Systematics

116 Family Potamidae Ortmann, 1896

117 Subfamily Potamiscinae Ortmann, 1896 (sensu Yeo \& Ng, 2003)

118 Indochinamon Yeo \& Ng, 2007

Potamon - Bott, 1967: 10 (part); Bott, 1970: 134 (part); Dai 1999: 157 (not Potamon Savigny, 121 1816).

122 Potamon (Potamon) — Rathbun, 1904: 247 (part); Alcock, 1910: 19 (part)

123 Potamon (Himalayapotamon) — Pretzmann, 1966: 4 (part).

124 Indochinamon Yeo \& Ng, 2007: 282; Ng et al., 2008: 163; De Grave et al., 2009: 40. 
Diagnosis. Body size large (largest Chinese individual with CW $59.4 \mathrm{~mm}$ ). Carapace relatively wide, low, with relatively flat dorsal surface, epigastric and postorbital cristae distinct, separated from each other by distinct groove, postorbital cristae not confluent with epibranchial tooth. Third maxilliped exopod with well-developed flagellum. Ambulatory legs relatively stout. Male sterno-pleonal cavity reaching imaginary line joining middle of bases of cheliped coxae. Male pleon narrowly triangular; G1 stout, terminal segment relatively short, stout, directed anterolaterally to laterally, lacking dorsal flap, with groove for G2 marginal in position.

Remarks. Indochinamon contains 38 species, including 4 new species described in the present study, from southeast China (Yunnan and Guangxi), Vietnam, Laos, Thailand, Myanmar, northeastern India to Himalaya. The type species of the genus is Potamon villosum Yeo \& $\mathrm{Ng}$, 1998, from northern Laos. Yeo \& Ng (2007: 283) raised 8 diagnostic characters for the genus: “i) carapace low, with relatively flat dorsal surface; ii) epigastric cristae separated from postorbital cristae by distinct groove; iii) postorbital cristae not confluent with epibranchial tooth; iv) third maxilliped exopod with well-developed flagellum; v) ambulatory legs relatively stout; vi) male pleon narrowly triangular; vii) male sterno-pleonal cavity reaching imaginary line joining middle of bases of cheliped coxae; and viii) G1 terminal segment relatively short and stout, with the groove for the G2 marginal in position, and lacking a dorsal flap".

In the key to the genera of Chinese Potamidae, Dai (1999: 85, in Chinese) characterized

144 Indochinamon (as Potamon) by the following characters: 1) the distance between mesial ends of thoracic sutures $4 / 5$ is shorter than the one-third distance between sternal press-button of locking mechanism; 2) the G1 terminal segment tapers, without any protrusion; 3) the exopod of the third maxilliped has developed flagellum; and 4) G1 terminal segment is stout, conical. It is, however, difficult to apply the first character to Indochinamon species. For example, the proportion of the distance between mesial ends of thoracic suture 4/5 to the distance between sternal press-button of locking mechanism is smaller than one-third in I. ahkense sp. n. and I. aozaoense, but that is larger than one-third in I. parpidum and I. lui. Inochinamon boshanense is also shown to have a larger value than one-third in this character (Dai, 1999: fig. 96(3)). This is probably because the mesial ends of the sutures are not always clear and mesially continued gradually as depression, so it is difficult to standardize the measurement. 
156

157

158

159

160

161

162

163

164

165

166

167

168

169

170

171

172

173

174

175

176

177

178

179

180

181

182

183

184

185

186

\section{Indochinamon ahkense sp. $\mathbf{n}$.}

urn:1sid:zoobank.org:act:98393C16-DDA8-4A13-A9A3-C8778C17E8E6

Figures 2-5.

Material examined. Holotype, male $(41.3 \times 32.0 \mathrm{~mm})(\mathrm{NCU}$ MCP 2013.0003), Shaping Village, Ahke Town, Guangnan County, Yunnan Province, China, coll. Chen Zeng Long, 1 Feb. 2004.

Paratypes: 7 males (largest $33.8 \times 26.3 \mathrm{~mm}$ ), 3 females (largest $43.3 \times 33.4 \mathrm{~mm})(\mathrm{NCU}$ MCP 2013.0004); 4 males (largest $38.4 \times 29.7 \mathrm{~mm}), 2$ females (larger $43.1 \times 33.2 \mathrm{~mm})($ ZRC 2013.0551), 2 males (larger $35.6 \times 27.4 \mathrm{~mm}$ ), 2 females (larger $32.5 \times 24.9 \mathrm{~mm}$ ) (RUMF-ZC2366), same data as holotype.

Diagnosis. Carapace (Fig. 2A) broader than long, CW 1.29-1.31 times (mean 1.30, n=7) CL; dorsal surface (Fig. 2B) flat, regions demarcated, with short, indistinct setae on metabranchial region; cervical groove distinct, deep, reaching postorbital cristae; epigastric cristae rounded, not sharp, distinctly anterior to postorbital cristae, separated from postorbital cristae by distinct groove; postorbital cristae rounded, not reaching epibranchial tooth; regions behind epigastric and postorbital cristae rugose, branchial region weakly granulose; antennular fossae (Fig. 2B) rectangular in anterior view; external orbital angle broadly triangular, outer margin longer than inner margin, distinctly cristate, with shallow notch demarcating it from epibranchial tooth; epibranchial tooth distinct; anterolateral margin convex, serrated, distinctly cristate, confluent with posterolateral margin. Epistome (Fig. 2B) posterior margin median tooth well-developed, laterally sloping downwards, only slightly arching. Third maxilliped (Figs. 2B, 3A) exopod with distinct flagellum exceeding two-third merus width. Ambulatory legs (Fig. 2A) with slender dactyli, carpi with well-defined median ridges; dactyli of last pair of ambulatory legs about same median length as propodi. Suture between sternites 3 and 4 (Fig. 3A) distinct, straight; sterno-pleonal cavity reaching imaginary line joining middle of bases of cheliped coxae. Male pleon (Fig. 3A) narrowly triangular; telson broadly triangular, proximal width about 1.2 times its median length; somite 6 trapezoidal, proximal width about 2.2 times median length. G1 (Fig. 4A-C) terminal segment slender, subconical, tapered tip, slightly curved, bent obliquely outwards $\left(\right.$ ca. $<30^{\circ}$ ), with rather broad neck between terminal and subterminal segments; subterminal segment with distinct cleft on upper part of outer margin. Vulva (Fig. 5) oval, large, 
187 opening directed mesioventrally, located mesial end of suture $5 / 6$, posterolateral end widely 188 produced as short eave, opening covered with membrane.

189 Etymology. The species is named after the locality in which it was first found.

190 Remarks. Indochinamon ahkense sp. n. closely resembles I. gengmaense (Dai, 1995) in its 191 general carapace morphology and in the slender, subconical, slightly curved G1 terminal 192 segment, which has a tapered tip and is bent obliquely outward. However, I. ahkense sp. n. can 193 be distinguished from I. gengmaense by the following characters: the external orbital angle is 194 blunt, with a shallow notch demarcating it from the epibranchial tooth (versus external orbital 195 angle acute, with deep notch demarcating it from epibranchial tooth); and the border between the 196 G1 terminal and subterminal segments is rather broad (versus border narrow) (Figs. 2A, 3A, 197 4A-C versus Fig. 6A, F; Dai, 1995: fig. 5 (4, 5), pl. 1 fig. 5; Dai, 1999: fig. 98 (4, 5), pl. 12 fig. 198 1).

199 The new species is also similar to I. tannanti (Rathbun, 1904) and I. orleansi (Rathbun, 1904) 200 in the shapes of the G1. Indochinamon ahkense sp. n. can be distinguished from I. tannanti by its 201 flatter carapace (versus slightly convex), having the epistome posterior margin divergent 202 posteriorly (versus almost straight), and the proportionally wider telson (versus telson 203 proportionally narrower) (Figs. 2A, B, 3A; versus Yeo \& Ng, 1998: fig. 1B, C). The new species 204 can be differentiated from I. orleansi by its straight lateral margins of telson (versus lateral 205 margins concave), and sharp and distinct epibranchial tooth (versus epibranchial tooth low) 206 (Figs. 2A, 3A versus Rathbun, 1904: fig. 20; Yeo \& Ng, 1998: fig. 6B).

207 Distribution. Shaping Village, Ahke Town, Guangnan County, Yunnan Province, China. 208

209 Indochinamon parpidum sp. $\mathbf{n}$.

210 urn:lsid:zoobank.org:act:FC1B9878-292C-4492-8A8D-44C7935A6904

211 Figures 7-10.

212

213 Material examined. Holotype, male $(47.1 \times 36.5 \mathrm{~mm})($ NCU MCP 2013.0015), Niujie Town, 214 Shiping County, Yunnan Province, China, coll. Li Hai Chun, 23 Feb. 2004.

215 Paratypes: 4 males (largest $29.1 \times 22.2 \mathrm{~mm}$ ), 10 females (largest $45.3 \times 33.0 \mathrm{~mm}$ ) (NCU MCP 216 2013.0016), 2 males (larger $43.4 \times 32.3 \mathrm{~mm}$ ), 2 females (larger $35.0 \times 26.2 \mathrm{~mm})($ ZRC 
217 2013.0558), 2 males (larger $39.3 \times 29.7 \mathrm{~mm}$ ), 2 females (larger $33.5 \times 25.6 \mathrm{~mm}$ ) (RUMF-ZC218 2371), same data as holotype.

219 Diagnosis. Carapace (Fig. 7A) broader than long, CW 1.29-1.37 times (mean 1.33, $\mathrm{n}=7$ ) 220 CL; dorsal surface (Fig. 7B) flat; cervical groove distinct, relatively deep, reaching postorbital 221 cristae; epigastric cristae strong, raised, rounded, distinctly anterior to postorbital cristae; 222 postorbital cristae sharp, breaking out into granules just before reaching epibranchial tooth, 223 slanting posterolaterally towards anterolateral margin, not confluent with epibranchial teeth;

224 branchial region and regions behind epigastric and postorbital cristae rugose; frontal margin 225 gently sinuous; antennular fossae rectangular (Fig. 7B) in anterior view; external orbital angle 226 broadly triangular, with shallow, weak notch demarcating it from epibranchial tooth;

227 epibranchial tooth present, very small, poorly developed; anterolateral margin convex, running 228 inwards posteriorly. Epistome (Fig. 7B) posterior margin with median tooth well-developed, 229 acutely triangular; laterally sloping downwards, almost straight. Third maxilliped (Figs. 7B, 8A) 230 exopod with distinct flagellum about two-thirds merus width. Suture between sternites 3 and 4 231 (Fig. 8A) distinct, straight; lateral margins of sternite 4 straight; sterno-pleonal cavity reaching 232 imaginary line joining middle of bases of cheliped coxae. Male pleon (Fig. 8A) narrowly 233 triangular; telson broadly triangular, lateral margins distinctly concave; somite 6 trapezoidal, 234 proximal width about 2.1 times its median length, lateral margins convex; lateral margins of 235 somites 3 straight. G1 (Fig. 9) terminal segment short, subconical, with bulge of constant width 236 that gradually tapers distally along inner margin, obliquely bent outwards (ca. $45^{\circ}$ ), curved 237 distally with narrowly tapered tip, groove for G2 marginal; subterminal segment gently sinuous, 238 slender, with cleft on upper part of outer margin. Vulva (Fig. 10) inverted narrow triangular, 239 opening directed mesioventrally, located posterior to mesial end of suture $5 / 6$, lateral end widely 240 produced as short eave, opening covered with membrane.

241 Etymology. The species name is an arbitrarycombination of par, Latin for "resemble", with 242 the species name Indochinamon hispidum (Wood-Mason, 1871), alluding to the similarity in the 243 shape of their G1 terminal segments.

244 Remarks. Indochinamon parpidum sp. n. closely resembles I. hispidum (Wood-Mason,

245 1871), in general carapace morphology and the short, subconical G1 terminal segment, which is 246 obliquely bent outwards and curved distally, with a low, broad bulge on extensor margin.

247 However, I. parpidum sp. n. can be distinguished from I. hispidum by the following characters: 
248 the bulge of the G1 terminal segment is gradually tapered distally along the extensor margin

249 (versus bulge narrow, with constant width along extensor margin); the G1 terminal segment is 250 strongly and obliquely bent outwards (ca. $45^{\circ}$ ), with a narrowly tapered tip (versus G1 terminal 251 segment obliquely bent outwards to a lesser degree (ca. $30^{\circ}$ ), with a broadly tapered tip); the G1 252 subterminal segment has a cleft on the distal part of the outer margin (versus G1 subterminal 253 segment without cleft on upper part of outer margin), and the shape of the vulva is inverted 254 narrow triangular (versus vulva oval) (Fig. 9A-C, 10 versus Dai, 1999: fig. $94(4,5,8)$ ).

255 Dai \& Chen (1985) described two subspecies of I. hispidum, i.e. I. h. jianchuanense (Dai \& 256 Chen, 1985) and I. h. boshanense (Dai \& Chen, 1985). The former was distinguished from I. $h$.

257 hispidum by its deeper grooves of the dorsal surface of the carapace, obtuse external orbital 258 angle, a greater degree of the bent of the G1 terminal segment, and convex ventrolateral margin 259 of the vulva, whereas the latter was differentiated from the type subspecies by a greater degree of 260 the bent of the G1 distal segment. Dai \& Chen (1985) indicated that the degree on the bent of the $261 \mathrm{G} 1$ terminal segment of $I$. $h$. boshanense is over $60^{\circ}$, but judging from the photograph of the G1 262 of the holotype (Fig. $6 \mathrm{H}$ ) and the original description, its degrees against the mesial margin of 263 the subterminal segment is ca. $80^{\circ}$. Although the two subspecies were erected to full species by $264 \mathrm{Ng}$ et al. (2008) without explanation, we consider the differences raised by Dai \& Chen (1985) 265 are significant to recognized them as full species.

266 Indochinamon parpidum sp. n. is morphologically similar to I. jianchuanense and I.

267 boshanense. The new species can be distinguished from I. jianchuanense by the following 268 characters: the extraorbital angle is sharp (versus extraorbital angle obtuse), and the G1 terminal 269 segment bends outwards to a lesser degree (ca. $45^{\circ}$ ) with a narrowly tapered tip (versus terminal 270 segment with stronger bend, ca. $60^{\circ}$ ), and the G1 subterminal segment is more slender (versus 271 more stouter) (Figs. 7A, 9A vs. Fig. 6D, I; Dai \& Chen, 1985: fig. 1(4, 5), pl. 1(1); Dai 1999: fig. 272 95(4, 5), pl. 11(6)). The new species can also be distinguished from I. boshanense by the 273 following characters: the G1 terminal segment bends outwards to a lesser degree (ca. $45^{\circ}$ ) 274 (versus terminal segment with stronger bend, ca. 80), and the G1 subterminal segment is 275 slenderer (versus stouter) (Figs. 7A, 9A vs. Fig. 6C, H; Dai \& Chen, 1985: fig. 2(4, 5), pl. 1(2); 276 Dai 1999: fig. $96(4,5)$, pl. 11(7)).

277 Indochinamon parpidum sp. n. is also morphologically similar to I. guttum (Yeo \& Ng, 1998), 278 but the former can be distinguished from the latter by the distal portion of the G1 subterminal 
279 segment being gradually bent laterally (versus distal portion of G1 sutermnial segment abruptly 280 bent laterally) (Fig. 9A-C versus Yeo \& Ng, 1998: fig. 4K-M).

281 Distribution. Niujie Town, Shiping County, Yunnan Province, China.

282

283

284

285

286

287

288

289

290

291

292

293

294

295

296

297

298

299

300

301

302

303

304

305

306

307

308

309

\section{Indochinamon tujiense sp. $\mathbf{n}$.}

urn:1sid:zoobank.org:act:B1E8716A-894F-44E6-8D41-7226FAF9BE28

Figures 11-14.

Material examined. Holotype, male $(45.3 \times 33.2 \mathrm{~mm})(\mathrm{NCU}$ MCP 2013.0005), Tujie Town, Nanhua County, Yunnan Province, China, coll. He Yong Gang, 23 Feb. 2004.

Paratypes: 3 females (largest $35.6 \times 26.7 \mathrm{~mm}$ ) (NCU MCP 2013.0006), same data as holotype.

Diagnosis. Carapace (Fig. 11A) broader than long, CW 1.33-1.36 times (mean 1.35, n = 2)

CL; dorsal surface (Fig. 11B) flat, short setae present on branchial and metabranchial regions, with regions distinctly demarcated; cervical groove distinct, relatively deep; epigastric cristae strong, raised, rounded, distinctly anterior to postorbital cristae, separated from postorbital cristae by shallow groove; postorbital cristae sharp, breaking out into granules just before reaching epibranchial tooth; branchial region and regions behind epigastric and postorbital cristae rugose; antennular fossae (Fig. 11B) rectangular in anterior view; external orbital angle broadly triangular, with distinct, shallow notch demarcating it from epibranchial tooth; epibranchial tooth distinct; anterolateral margin convex, granular, confluent with posterolateral margin; epistomal region narrow. Epistome (Fig. 11B) posterior margin with median tooth welldeveloped; laterally sloping downwards, gently arched. Third maxilliped (Figs. 11B, 12A) exopod with distinct flagellum about half merus width. Ambulatory legs (Fig. 11A) with short, stout dactyli, carpi with sharply defined median ridges, meri rugose; dactyli of last pair of ambulatory legs with median length about 5.7 times its proximal width, about same median length as propodi. Suture between sternites 3 and 4 (Fig. 12A) distinct, shallow, medially concave; lateral margins of sternite 4 distinctly concave; sterno-pleonal cavity reaching imaginary line joining middle of bases of cheliped coxae. Male pleon (Fig. 12A) narrowly triangular; telson broadly triangular, with lateral margins gently concave; somite 6 trapezoidal, lateral margins straight; lateral margins of somite 3 distinctly concave. G1 (Fig. 13A-D) terminal 
310 segment short, subconical, strongly bent obliquely outwards (ca. $70^{\circ}$ ), about 0.24 times the

311 length of subterminal segment, with tapering tip; extensor margin forming a bulge of constant

312 width; outer margin sinuous, with a cleft along upper part of outer margin; subterminal segment

313 with distinct cleft on upper part of outer margin, greatest width about 0.41 times its length. Vulva

314 (Fig. 14) oval, large, opening directed mesioventrally, located mesial end of suture 5/6, lateral

315 end widely produced as short eave, opening covered with membrane.

316 Etymology. The species is named after the locality in which it was first found.

317 Remarks. Indochinamon tujiense sp. n. closely resembles I. boshanense (Dai \& Chen, 1985),

318 in its general carapace morphology and in the short, subconical G1 terminal segment being

319 strongly bent obliquely outwards, with a slight hump along the outer margin at the proximal end

320 and a sinuous outer margin. However, I. tujiense sp. n. can be distinguished from I. boshanense

321 by the following characters: the epigastric cristae is strong (versus epigastric cristae relatively

322 weak); the lateral margins of male telson are gently concave (versus lateral margins of male

323 telson distinctly and widely concave); the G1 terminal segment has a broad bulge with constant

324 width along the extensor margin (versus G1 terminal segment with a relatively narrow bulge

325 along the extensor margin), and the shape of the vulva is oval (versus vulva narrow transversely)

326 (Figs. 11A, 12A, 13, 14 versus Fig. 4C; Dai \& Chen, 1985: fig. 2(4, 5, 7, 9), pl. 1 fig. 2; Dai,

327 1999: fig. $96(2,4,5,8)$, pl. 11 fig. 7).

328 The new species is also morphologically similar to I. jianchuanense (Dai \& Chen, 1985), but

329 the former can be differentiated from the latter by the greater degree of the bent of the G1

330 terminal segment (ca. $70^{\circ}$ ) (versus bent to a lesser degree, ca. $60^{\circ}$ ); and the relatively larger

331 bulge on the extensor margin of G1 terminal segment (versus bulge narrower); and the oval

332 vulval opening (versus the transversely narrow vulval opening) (Figs. 13, 14 versus Fig. 4I; Dai

333 \& Chen, 1985: fig. 1 (4, 5, 9); Dai 1999: fig. $95(4,5,8))$.

334 The new species can be distinguished from I. menglaense (Dai \& Cai, 1998) by the

335 anterolateral margin of the carapace being lined with rounded granules (versus anterolateral

336 margin lined with spine-like granules); the slightly concave lateral margins of male telson

337 (versus distinctly concave); the constantly wide bulge on the extensor margin of G1 terminal

338 segment (versus bulge more produced, rounded); and the oval vulval opening (versus

339 transversely wide vulval opening) (Figs. 11A, 12A, 13, 14 versus Fig. 4E, J; Dai \& Cai, 1998 :

340 figs. 12, 14, 15, 18). 
341 The new species differs from I. boshanense in the following characters: the mesial margin of

342 the G1 subterminal segment is more produced subdistally in dorsal view (versus mesial margin

343 straight, oblique, not produced subdistally); the G1 terminal segment bends to a lesser degree

344 (ca. $70^{\circ}$ ) (versus terminal segment with stronger bend, ca. $80^{\circ}$ ); the bulge on the extensor margin

345 of the G1 terminal segment is larger (versus smaller); and the shape of the vulva is oval (versus

346 vulva transversely narrow) (Figs. 13, 14 versus Figs. 6H; Dai \& Chen, 1985: fig. 2 (4, 5, 9); Dai, 347 1999: fig. 96(4, 5, 8)).

348 The new species also differs from I. dangi Naruse, Quynh \& Yeo, 2011, in the following 349 characters: the infraorbital margin is straight mesially and curves upwards laterally (versus 350 infraorbital margin almost entirely straight and oblique); the G1 terminal segment bends to a 351 lesser degree (ca. $70^{\circ}$ ) (versus terminal segment with stronger bend, ca. $90^{\circ}$ ); and the bulge on 352 the extensor margin of the G1 terminal segment is constant in width (versus bulge absent) (Figs. 353 11B, 13 versus Naruse, Quynh \& Yeo, 2011: figs. 9d, e, 11a).

354 Distribution. Tuzie Town, Nanhua County, Yunnan Province, China. 355

356

357

358

359

360

361

362

363

364

365

366

367

368

369

370

371

\section{Indochinamon lui sp. $\mathbf{n}$.}

urn:1sid:zoobank.org:act:3FAF5B0F-9963-4F00-9DBD-5FDE982DD04E

Figures 15-18.

Material examined. Holotype, male (43.0 × $32.9 \mathrm{~mm})($ NCU MCP 2013.0010), Mang Huai Town, Yun County, Yunnan Province, China, coll. Lu Yong Feng, 24 Feb. 2004.

Paratypes: 2 males (larger $30.8 \times 23.3 \mathrm{~mm}), 1$ female $(36.9 \times 27.5 \mathrm{~mm})(\mathrm{NCU}$ MCP 2013.0011), 2 males (larger $33.1 \times 25.0 \mathrm{~mm}), 1$ female $(31.4 \times 23.6 \mathrm{~mm})($ ZRC 2013.0555), 1 male $(25.5 \times 19.6 \mathrm{~mm}), 1$ female $(34.8 \times 26.2 \mathrm{~mm})($ RUMF-ZC- 2369), same data as holotype.

Others: 1 male $(40.3 \times 30.2 \mathrm{~mm}), 6$ females (largest $36.2 \times 28.1 \mathrm{~mm}), 5$ juveniles $(\mathrm{NCU}$ MCP 2013.0012), 2 males (larger $32.2 \times 24.9$ mm) (ZRC 2013.0556), Dashan Village, Xueshan Town, Fengqing County, Yunnan Province, China, coll. Yang Zheng Bing, 1 Feb 2004; 9 males (largest male $33.3 \times 24.4 \mathrm{~mm}$ ), 13 females (largest $41.7 \times 31.2 \mathrm{~mm}$ ) (NCU MCP 2013.0013), Xinfu Town, Yun County, Yunnan Province, China, coll. Shen Tian Juan, 26 Feb. 2004; 7 males (largest $39.3 \times 29.9 \mathrm{~mm}$ ), 9 females (largest $41.0 \times 30.2 \mathrm{~mm}$ ), 3 juveniles (NCU MCP 2013.0014), 2 males (larger $37.5 \times 28.8 \mathrm{~mm}), 2$ females (larger $38.6 \times 28.6 \mathrm{~mm})($ ZRC 
372 2013.0557), 3 males (largest $34.6 \times 25.7 \mathrm{~mm}$ ), 2 females (larger $38.5 \times 29.0 \mathrm{~mm}$ ) (RUMF-ZC-

373 2370), Mongku Town, Shuangjiang County, Yunnan Province, China, coll. Li Quan Cheng, 26

374 Feb. 2004.

375 Diagnosis. Carapace (Fig. 15A) broader than long, CW 1.29-1.36 times (mean 1.33, $\mathrm{n}=18$ )

376 CL; dorsal surface (Fig. 15B) flat, sparse and short setae on branchial and metabranchial regions,

377 with regions distinctly demarcated; cervical groove distinct, relatively deep, reaching postorbital

378 cristae; epigastric cristae rounded, distinctly anterior to postorbital cristae, separated from

379 postorbital cristae by shallow groove; postorbital cristae sharp, breaking out into few, weak

380 granules just before reaching epibranchial tooth; branchial region and regions behind epigastric

381 and postorbital cristae slightly rugose; antennular fossae (Fig. 15B) rectangular in anterior view;

382 external orbital angle broadly triangular, with outer margin longer than inner margin, with

383 distinct, shallow notch demarcating it from epibranchial tooth; epibranchial tooth distinct;

384 anterolateral margin convex, confluent with posterolateral margin. Epistome (Fig. 15B) posterior

385 margin with median tooth well-developed, obtusely triangular; laterally sloping downwards.

386 Third maxilliped (Figs. 15B, 16A) exopod with distinct flagellum about two-third merus width.

387 Ambulatory legs (Fig. 15A) with short, stout dactyli, carpi with sharply defined ridges, meri

388 rugose; dactyli of last pair of ambulatory legs with median length about 6.5 times its proximal

389 width, about 1.1 times as long as its propodus. Suture between sternites 3 and 4 (Fig. 16A)

390 distinct; lateral margins of sternite 4 slightly concave anteriorly; sterno-pleonal cavity just

391 exceeding imaginary line joining middle of bases of cheliped coxae. Male pleon (Fig. 16A)

392 narrowly triangular; telson broadly triangular, with lateral margins gently concave; somite 6

393 trapezoidal, lateral margins straight; lateral margins of somite 3 gently concave. G1 (Fig. 17)

394 terminal segment short, subconical, with a bulge of increasing distal width along the extensor

395 margin, bent obliquely outwards (ca. $70^{\circ}$ ), with straight tapering tip, without dorsal flap. Vulva

396 (Fig. 18) oval, large, opening directed mesioventrally, located mesial end of suture 5/6, lateral

397 end widely produced as short eave, opening covered with membrane.

398 Etymology. The species is named after its collector, Lu Yong Feng.

399 Remarks. Indochinamon lui sp. n. closely resembles I. boshanense (Dai \& Chen, 1985), in

400 general carapace morphology and in the short, subconical G1 terminal segment, which is

401 obliquely bent outwards, with a tapering tip and without a dorsal flap. However, I. lui sp. n. can

402 be distinguished from I. boshanense by the following characters: the epibranchial tooth is distinct 
403 (versus epibranchial tooth poorly developed); the G1 terminal segment has the straight, tapering 404 tip and a bulge of increasing distal width along the extensor margin (versus G1 terminal segment 405 with slightly curved, tapering tip and narrow bulge of constant width along the extensor margin); 406 and the shape of the vulva is oval (versus vulva transversely narrow) (Figs. 15A, 17, 18 versus 407 Dai \& Chen, 1985: fig. 2 (4, 5, 9), pl. 1 fig. 2; Dai, 1999: fig. 96 (4, 5, 8), pl. 11 fig. 7).

408 The new species is morphologically also similar to I. jianchuanense (Dai \& Chen, 1985), but 409 the former can be distinguished from the latter by the following characters: the G1 terminal 410 segment is shorter and stouter (versus G1 terminal segment longer and slender); the bulge on the 411 extensor margin of the G1 terminal segment is more produced distally (versus bulge more 412 gradually narrowed distally); and the shape of the vulva is oval (versus vulva transversely 413 narrow) (Figs. 15A, 17,18 versus Fig. 6I; Dai \& Chen, 1985: fig. 1 (4, 5, 9); Dai, 1999: fig. 95 $414(4,5,8))$.

415 The new species can be differentiated from I. dangi Naruse, Quynh \& Yeo, 2011, by the 416 lesser degree of the bend of the G1 terminal segment (ca. 70 ${ }^{\circ}$ ) (versus terminal segment with 417 stronger bend, ca. $90^{\circ}$ ); and the bulge on the extensor margin of G1 terminal segment with 418 constant width (versus bulge absent) (Fig. 17 versus Naruse, Quynh \& Yeo, 2011: fig. 9d, e).

419 Distribution. Yun, Fengqing and Shuangjiang Counties, Yunnan Province, China. The 420 collection site is located in the Lincang and Lancang Rivers Natural Reserve.

421

\section{Pararanguna Dai \& Chen, 1985}

423

424 Ranguna (Pararanguna) Dai \& Chen, 1985: 64.

425 Pararanguna — Dai, 1999: 370; Ng et al. 2008: 165; De Grave et al., 2009: 40.

426

Diagnosis. Body size relatively small (largest individual with CW $22.0 \mathrm{~mm}$ ). Carapace relatively high, with gently convex dorsal surface, epigastric and postorbital cristae very low, not continuous, postorbital cristae not confluent with epibranchial tooth. Third maxilliped exopod without flagellum. Ambulatory legs relatively slender. Male sterno-pleonal cavity reaching imaginary line joining middle of bases of cheliped coxae. Male pleon broadly triangular. G1 
4330.8 time that of subtemirnal segment, tip truncate, ventral layer produced outwards to form large 434 semicircular dorsal flap, groove for G2 marginal.

435 Remarks. Dai \& Chen (1985) used the name Ranguna (Pararanguna) semilunatum

436 consistently in the paper. The inclination is to assume the gender of the subgenus is neuter as the

437 species named is neuter. The Latin "lunatum" means crescent-shaped" and the gender is neuter

438 (masculine "lunatus", feminine "lunata"). The genus Ranguna Bott, 1966, on the other hand, is

439 clearly feminine even though Bott (1966) did not specify the gender when he recognised it as a

440 subgenus of Potamiscus Alcock, 1909. We, however, cannot extrapolate from Dai \& Chen's

441 (1985) paper that they wanted the gender of Pararanguna to be neuter; regardless of the fact that

442 it should be also feminine since it was based on Ranguna. The reason is that they only

443 established Pararanguna as a subgenus of Ranguna; and the Code (ICZN, 1999) mandates that

444 the gender of the species must match that of the genus - in this case, Ranguna, which already is

445 feminine. Dai \& Chen's (1985) used of the neuter "semilunatum" must thus be regarded as a

446 lapsus. The name "semilunatum" also cannot be regarded as a noun, it was neither stated or

447 etymologically correct. As such, it must be regarded as an adjective. In the present classification

448 were Pararanguna is treated as a full genus (Ng et al., 2008), it is thus necessary to treat this

449 name as derived from the feminine Ranguna, i.e. Pararanguna is also feminine. As such, the

450 gener of the constituent species is also feminine, i.e. Pararanguna semilunata.

451 When Pararanguna was established, Dai \& Chen (1985), compared it with Ranguna and

452 listed two diagnostic characters, i.e. 1) more prominent post-frontal lobe and post-orbital cristae, 453 and 2) the first pleopod being tapered and directed outwards, but they did not specify which

454 genus has these character states. Specimens of $P$. semilunata examined in this study, including

455 paratypes, have very low post-frontal crista and post-orbital crista (Fig. 19A), and subconical G1

456 terminal segment, with a bulge of increasing distal width along the extensor margin (Fig. 19E).

457 This indicates that the two diagnostic characters listed by Dai \& Chen (1985) were of Ranguna

458 sensu Bott $(1968,1970)$.

459 The genus Ranguna had taxonomic problems. Ranguna was established by Bott (1966) with

460 Potamon (Potamon) rangoonensis Rathbun, 1904, as type species, although he did not examine

461 the type specimen (see Türkay \& Naiyanetr, 1989; Ng, 1990; Holthuis, 1990). Bott (1970)

462 included 16 species and 2 subspecies in Ranguna. Türkay \& Naiyanetr (1987) redescribed the

463 holotype of Potamon rangoonensis, the type species of Ranguna, and found that it is not what 
464 they thought of "Ranguna" sensu Bott $(1968,1970)$ that was characterized by the presence of a 465 dorsal fold on the terminal segment of the G1 and the G1 subterminal segment being not466 noticeably narrowed distally. Potamon rangoonensis is now placed in Potamiscus ALcock, 1909, 467 therefore Ranguna is a junior synonym of Potamiscus (see ICZN 1991), whereas other ex468 Ranguna species have been transferred to 13 genera, i.e. Badistemon Yeo \& Ng, 2007, 469 Dromothelphusa Naiyanetr, 1992; Eosamon Yeo \& Ng, 2007, Hainanpotamon Dai, 1995, Iomon 470 Yeo \& Ng, 2007, Pilosamon Ng, 1996, Planumon, Yeo \& Ng, 2007, Pupamon, Yeo \& Ng, 2007, 471 Stelomon Yeo \& Naiyanetr, 2000, Stoliczia Bott, 1966, Thaipotamon Ng \& Naiyanetr, 1993, 472 Vietopotamon Dang \& Ho, 2002, and Villopotamon Dang \& Ho, 2003 (Ng et al., 2008). The G1 473 of Pararanguna clearly differs from those of all "Ranguna (Ranguna)" species recognized in 474 Bott (1970) in its truncate tip (versus tip tapering) (Bott, 1970; Bott \& Türkay, 1977; Ng 1991; 475 1998; Ng \& Naiyanetr, 1993; Brandis 2000; 2002; Yeo \& Naruse 2007; Yeo \& Ng 2007; Dang 476 \& Ho 2008; Yeo 2010).

477 In Dai's (1999) key to genera of Chinese Potamidae (p. 85, in Chinese), Pararanguna was 478 grouped with Aparapotamon Dai \& Chen, 1985, Tenuipotamon Dai, 1999, and Parvuspotamon 479 Dai \& Bo, 1994, by the following characters: 1) the distance between mesial ends of thoracic 480 suture $4 / 5$ is about equal to the one-third distance between sternal press-button of locking 481 mechanism, 2) the terminal segment of G1 is longer than half the length of G1 subterminal 482 segment; 3) the exopod of the third maxilliped lacks flagellum. The above first character in 483 Pararanguna semilunatum is 35.6 \% (calculated from Dai, 1999: fig. 200(3)), but this is difficult 484 to determin whether it is "about equal to the one-third". This character is also discussed for 485 Indochinamon (see remarks of Indochinamon). The differences between above four genera are 486 very distinct; the terminal segment of Pararanguna has a roundly truncate tip and well487 developed semicircular dorsal flap (versus terminal segment cylindrically stick-shaped without 488 dorsal flap in Aparapotamon, terminal segment gently incurved with distal dorsal lobe larger 489 than ventral lobe in Tenuipotamon, terminal segment tapered and distally curves inwards in 490 Parvuspotamon).

491

492 Pararanguna hemicyclia sp. n.

493 urn:Isid:zoobank.org:act:8D4F20E5-B08C-41C1-91AC-DADE13A58725

494 Figures 20-23. 
Material examined. Holotype, male $(14.3 \times 12.5$ mm) (NCU MCP 2013.0017), Dashan

497 Village, Xueshan Town, Fengqing County, Yunnan Province, China, coll. Yang Zheng Bing, 1

498 Feb. 2004.

499 Paratypes: 11 males (largest $10.6 \times 9.5 \mathrm{~mm}), 10$ females (largest $16.2 \times 13.6 \mathrm{~mm})(\mathrm{NCU} \mathrm{MCP}$

500 2013.0018), 3 males (largest $14.0 \times 11.9 \mathrm{~mm}), 2$ females (larger $15.1 \times 12.8 \mathrm{~mm})(\mathrm{ZRC}$

501 2013.0559), 2 males (larger $16.3 \times 13.5 \mathrm{~mm}$ ), 2 females (larger $15.1 \times 12.4 \mathrm{~mm})(\mathrm{RUMF}-\mathrm{ZC}$ -

502 2372), same data as holotype.

503 Others: 20 males (largest $12.0 \times 10.6 \mathrm{~mm}), 24$ females (largest $15.1 \times 12.9 \mathrm{~mm})(\mathrm{NCU} \mathrm{MCP}$

504 2013.0019), 2 males (larger $12.3 \times 10.7 \mathrm{~mm}), 1$ female $(12.9 \times 10.9 \mathrm{~mm})($ ZRC 2013.0560), 1

505 male $(12.3 \times 10.9 \mathrm{~mm}), 1$ female $(12.6 \times 10.5 \mathrm{~mm})($ RUMF-ZC-2373), Fengqing County,

506 Yunnan Province, China, coll. Yang Zheng Bing, Feb. 2004.

507 Diagnosis. Carapace (Fig. 20A) broader than long, CW 1.12-1.22 times (mean 1.17, $\mathrm{n}=13$ )

508 CL; dorsal surface (Fig. 20B) gently convex, with regions distinctly demarcated; cervical groove 509 present, shallow, weakly developed; epigastric cristae rounded, flat, distinctly anterior to

510 postorbital cristae; postorbital cristae weakly developed, gently sloping downwards anteriorly,

511 confluent with branchial and regions behind it; branchial region and regions behind epigastric

512 and postorbital cristae rugose; antennular fossae (Fig. 20B) subtriangular in anterior view;

513 external orbital angle acutely triangular, outer margin convex and longer than inner margin, with

514 obvious cleft demarcating it from epibranchial tooth; epibranchial tooth distinct, small;

515 anterolateral margin gently convex, confluent with posterolateral margin. Epistome (Fig. 20B)

516 posterior margin with well-developed, triangular median tooth that has a pointed median tip.

517 Third maxilliped (Figs. 20B, 21) exopod without flagellum. Carpi of chelipeds with well-

518 developed, acute spines on inner margin. Ambulatory legs (Fig. 20A) hairy, with very long,

519 slender dactyli. Suture between sternites 3 and 4 (Fig. 21) indistinct; sterno-pleonal cavity

520 reaching imaginary line joining middle of bases of cheliped coxae. Male pleon (Fig. 21) broadly

521 triangular; telson broadly triangular, lateral margins gently convex; somite 6 trapezoidal, lateral

522 margins convex, proximal width about 2.8-3 times its median length. G1 (Fig. 22A-C) relatively

523 slender, gently sinuous; terminal segment stout, straight, length about 0.6 time that of

524 subtemirnal segment, tip truncate, ventral layer produced outward to form semicircular dorsal

525 flap, dorsal flap well-developed, high, broad, but proximally not reaching to proximal end of 
526 terminal segment, groove for G2 marginal. G2 (Fig. 22D) terminal segment cylindrical, truncate,

527 less than half the length of basal segment. Vulva (Fig. 23) circular, large, opening directed

528 ventrally, located mesial end of suture 5/6, opening covered with membrane.

529 Etymology. The species name is derived from hemicyclium, Latin for semicircle, alluding to 530 the dorsal flap of the G1 terminal segment.

531 Remarks. Pararanguna hemicyclia sp. n. closely resembles the only congener, P. semilunata

532 (Dai \& Chen, 1985), in its general carapace morphology and in the stout, straight G1 terminal

533 segment which is rounded with a slight subdistal constriction, possessing a truncate tip and a

534 well-developed, high, broad dorsal flap. However, $P$. hemicyclia can be distinguished from $P$.

535 semilunata by the following suite of diagnostic characters: the anterolateral margin of the

536 carapace is less convex laterally (versus anterolateral margin strongly convex laterally); the

537 dorsal surface is gently convex with distinctly demarcated regions (versus dorsal surface convex

538 and inflated with weakly demarcated regions); the antennular fossae appear subtriangular in

539 anterior view (versus antennular fossae rectangular in anterior view); the external orbital angle is

540 acutely triangular with an obvious cleft demarcating it from the epibranchial tooth (versus

541 external orbital angle obtusely triangular with a slight cleft demarcating it from epibranchial

542 tooth); the median tooth of the epistome posterior margin has an acute tip (versus median tooth

543 with an obtuse tip); the carpi of the chelipeds have well-developed, acute spines on the inner

544 margin (versus chelipeds carpi with low, obtuse spines on inner margin); the male pleon is

545 broadly triangular with telson having gently convex lateral margins (versus male pleon relatively

546 narrowly triangular with telson having almost straight lateral margins); the dorsal flap of the G1

547 terminal segment has the median part being higher and the proximal end of the dorsal flap does

548 not reach the proximal end of the distal segment (versus dorsal flap with a lower apex in median

549 part and proximal end of dorsal flap reaching proximal end of distal segment). (Figs. 20-22A-C

550 versus Dai \& Chen, 1985: fig. 16 (4, 5, 7), pl. 1 fig. 5; Dai, 1999: fig. 200, pl. 25 fig. 1).

551 Distribution. Dashan Village, Xueshan Town, Fengqing County, Yunnan Province, China.

552 The collection site is located in the Lincang and Lancang Rivers Natural Reserve.

553

554 Parvuspotamon Dai \& Bo, 1994

555 
556

557

558

559

560

561

562

563

564

565

566

567

568

569

570

571

572

573

574

575

576

577

578

579

580

581

582

583

584

585

586

Parvuspotamon Dai \& Bo, 1994: 24; Dai, 1999: 406; Ng et al. 2008: 165; De Grave et al., 2009: 40.

Diagnosis. Body size relatively small (largest individual with CW $25.7 \mathrm{~mm}$ ). Carapace relatively high, with gently convex dorsal surface, epigastric cristae weak, postorbital cristae faint, not continuous, postorbital cristae not confluent with epibranchial tooth. Third maxilliped exopod without flagellum. Ambulatory legs relatively slender. Male sterno-pleonal cavity reaching imaginary line joining proximal portions of bases of cheliped coxae. Male pleon narrowly triangular G1 slender, sinuous; terminal segment slender, length, 0.4-0.6 time that of subterminal segment, distally digitiform, with truncate, narrowly rounded tip ending with dorsal apeature (visible from ventral view), with groove for G2 marginal.

Remarks. Dai \& Bo (1994) compared Parvuspotamon with Yarepotamon Dai \& Türkay, 1997, which has been known from Guangdon and Guanxi Provinces. They distinguished the two genera by the following characters: the carapace is more glabrous (versus finely rugose in Yarepotamon), the postorbital criste are blunt (versus sharp in Yarepotamon), the epibranchial tooth is blunt (versus prominent in Yarepotamon), the exopod of the third maxilliped lacks a flagellum (versus absent or with vestigial flagellum in Yarepotamon), and a groove for G2 on G1 placed laterally (versus medially in Yarepotamon). Furthermore, they recognized more morphological differences between $P$. yuxiense and $Y$. gracilipa in the length to width ratio of the telson (1.1 versus 1.4), and the G1 subterminal segment being 1.8 times as long as terminal segment (versus 2.1 in Y. gracilipa), and the G2 subterminal segment is about 1.4 times as long as terminal segment (versus 2 times in $Y$. gracilipa).

Parvuspotamon is morphologically more similar to Pararanguna, Aparapotamon and Tenuipotamon, which are exclusively or partially distributed in Yunnan Provice, in their low to very low postorbital and postfrontal cristae and the absence of the flagellum from the third maxilliped exopod. These genera can, however, be easilly distinguished from each other by the condition of the G1 terminal segment (see Remarks of Pararanguna).
According to the key to genera of Chinese Potamidae (Dai, 1999: 85, in Chinese), the abovementioned four Yunnan genera are supposed to have relatively long G1 distal segment (more than half the length of that of subteminal segment). This key should be amended to accommodate Parvuspotamon dixuense sp. n., G1 terminal segment of which is slightly shorter 
587 than half the length of the G1 subterminal segment (ca. 0.4). This change is also necessary for

588 Tenuipotamon, as T. huaningense has relatively short G1 terminal segment (Dai \& Bo, 1994: fig.

589 2(4); Dai, 1999: fig. 206(4)).

590

591 Parvuspotamon dixuense sp. $\mathbf{n}$.

592 urn:lsid:zoobank.org:act:1D4DBFB9-B5BB-49CB-90EA-4C862CD75859

593 Figures 24-27.

594

595

Material examined. Holotype, male $(25.7 \times 20.0 \mathrm{~mm})(\mathrm{NCU}$ MCP 2013.0020), Huaguo

596 Village, Dixu Town, Guangnan County, Yunnan Province, China, coll. Nong Guang Lin, 25 Feb. 5972004.

598 Paratypes: 8 males (largest $23.3 \times 17.4 \mathrm{~mm}$ ), 10 females (largest $23.3 \times 17.8 \mathrm{~mm})(\mathrm{NCU} \mathrm{MCP}$ 599 2013.0021), 5 males (largest $24.7 \times 18.9 \mathrm{~mm}), 1$ female $(21.3 \times 16.2 \mathrm{~mm})($ ZRC 2013.0561), 5

600 males (largest $23.6 \times 18.1 \mathrm{~mm}), 1$ female $(19.3 \times 14.6 \mathrm{~mm})($ RUMF-ZC-2374), same data as 601 holotype.

602 Others: 2 males (larger $16.7 \times 11.9 \mathrm{~mm}), 2$ females (larger $17.2 \times 12.5 \mathrm{~mm})(\mathrm{NCU} \mathrm{MCP}$ 603 2013.0022), Zhetu Village, Guangnan County, Yunnan Province, China, coll. unknown, 2 Nov. 604 2002; 1 male $(16.2 \times 12.5 \mathrm{~mm}), 1$ female $(15.8 \times 12.1 \mathrm{~mm})(\mathrm{NCU}$ MCP 2013.0023),

605 Xiyangjiang, base of Jiulongshan, Zhetu Village, Guangnan County, Yunnan Province, China, 606 coll. unknown, 2 Nov. 2002.

607 Diagnosis. Carapace (Fig. 24A) broader than long, CW 1.19-1.40 times (mean 1.32, $\mathrm{n}=11$ )

608 CL; dorsal surface (Fig. 24B) gently convex, with regions distinctly demarcated; cervical groove 609 indistinct, shallow; epigastric cristae rounded, weakly developed, separated from postorbital

610 cristae by shallow groove; postorbital cristae rounded, fairly straight, reaching epibranchial

611 tooth; branchial region and regions behind postorbital cristae weakly rugose; antennular fossae

612 (Fig. 24B) narrowly rectangular in anterior view; external orbital angle triangular, low, outer

613 margin gently convex, with distinct, shallow notch demarcating it from epibranchial tooth;

614 epibranchial tooth weakly developed, small, granular, appears part of anterolateral margin;

615 anterolateral margin convex, granular, confluent with posterolateral margin. Epistome (Fig. 24B)

616 posterior margin with median tooth broadly triangular. Third maxilliped (Figs. 24B, 25A)

617 exopod without flagellum. Ambulatory legs (Fig. 24A) with long, slender dactyli, carpi of first to 
618 third ambulatory legs with weak median ridges, meri slightly rugose. Suture between sternites 3

619 and 4 (Fig. 25A) weakly developed; sterno-pleonal cavity reaching imaginary line joining

620 proximal part of bases of cheliped coxae. Male pleon (Fig. 25A) narrowly triangular; telson

621 broadly triangular, proximal width about 1.3 times its median length, with lateral margins

622 convex. G1 (Fig. 26A-D) terminal segment long, slender, subconical, outer margin convex,

623 length ca. 0.4 times that of subterminal segment, gently bent but not curving obliquely outwards,

624 inner margin straight, with truncate, narrowly rounded tip ending with dorsal hole (visible from

625 ventral view), with groove for G2 marginal. G2 (Fig. 26E) subconical, terminal segment less

626 than half the length of basal segment. Vulva (Fig. 27) oval, large, opening directed

627 mesioventrally, located posterior to mesial end of suture 5/6, lateral end widely produced as short

628 eave, opening covered with membrane.

629 Etymology. The species is named after the locality in which it was found. Remarks.

630 Parvuspotamon dixuense sp. n. closely resembles the only congener, P. yuxiense Dai \& Bo,

631 1994, in its general carapace morphology and in the long, slender, subconical G1 terminal

632 segment with curved outer margin, truncate tip and slender subterminal segment. However, $P$.

633 dixuense can be distinguished from $P$. yuxiense by the following characters: the G1 terminal

634 segment is gently bent outwards, with a straight inner margin (versus G1 terminal segment

635 curved inwards, with a concave inner margin); the groove for G2 runs along the ventral side of

636 the G1 terminal segment (versus groove for G2 being marginal along the G1 terminal segment);

637 a shelf is present at the lateral margin between the G1 terminal and subterminal segments (versus

638 shelf absent); and the G2 terminal segment is less than half the length of the basal segment (G2

639 terminal segment more than half the length of the basal segment) (Fig. 26; versus Fig. 19F; Dai

640 \& Bo, 1994: fig. 3 (4-6); Dai, 1999: fig. 216 (4-6)).

641 Distribution. Xiyangjiang, Zhetu and Huaguo Village, Dixu Town, Guangnan County,

642 Yunnan Province, China.

643

644 Potamiscus Alcock, 1909

645

646 Potamiscus Alcock, 1909: 246; Bott, 1966: 479; Bott, 1970: 158; Dai, 1999: 186; Ng et al. 2008:

647 165; De Grave et al., 2009: 40.

648 Potamon (Potamiscus) - Alcock, 1910: 56. 
649

650

651

652

653

654

655

656

657

658

659

660

661

662

663

664

665

666

667

668

669

670

671

672

673

674

675

676

677

678

Potamon (Ranguna) Bott, 1966: 481.

Diagnosis. Body size midium (largest Chinese individual with CW $34.4 \mathrm{~mm}$ ). Carapace relatively narrow, high, with gently convex dorsal surface, epigastric cristae distinct, postorbital cristae low but clear, not continuous, postorbital cristae not confluent with epibranchial tooth. Third maxilliped exopod without or with vestigial flagellum. Ambulatory legs relatively stout. Male sterno-pleonal cavity reaching imaginary line joining middle to anterior portions of bases of cheliped coxae. Male pleon narrowly triangular; G1 stout, subconical, terminal segment relatively short, stout, distally tapering to roundly tapering, lacking dorsal flap, with groove for G2 marginal in position.

Remarks. Potamiscus contains 16 species, including 2 new species described in the present study, from China (Guangxi, Yunnan, Tibet), Myanmar, and northeastern India. The type species of the genus is Potamon (Potamiscus) annandali Alcock, 1909, from Assam, northwestern India. Potamiscus is diagnosed by the following characters: 1) carapace with moderate height, dorsal surface rugose; 2) third maxilliped without flagellum or with vestigial flagellum; 3) G1 subconical, with distally tapering tip; 4) G1 terminal segment without dorsal flap; and 5) groove for G2 on G1 terminal segment marginal (Wood-Mason, 1871; Rathbun, 1904; Alcock, 1909; Kemp, 1913; Tuerkay \& Naiyanetr, 1987; Dai, 1999). The two species described in this paper share these characters.

In the key to genera of Chinese Potamidae (Dai, 1999: 85, in Chinese), one of the characters that characterizes Potamiscus is: the distance between mesial ends of thoracic suture $4 / 5$ is shorter than the one-third distance between sternal press-button of locking mechanism. However, the mesial end of the suture $4 / 5$ is placed near the base of lateral slope of the sternopleonal cavity, which is nearly vertical, and the mesial end is not always clear and mesially continued gradually as depression, it is difficult to standardize the measurements.

\section{Potamiscus fumariatus sp. $\mathbf{n}$.}

urn:1sid:zoobank.org:act:0A9F4D94-7238-4780-8171-9D0D6DF36881

Figures 28-30. 
Material examined. Holotype, male $(24.1 \times 20.1 \mathrm{~mm})(\mathrm{NCU}$ MCP 2013.0024), Bailu Town,

680 Wuding County, Yunnan Province, China, coll. Liu Shao Yan, 25 Feb. 2004.

681 Diagnosis. Carapace (Fig. 28A) distinctly broader than long CW 1.20 times CL, dorsal

682 surface (Fig. 28B) relatively flat, cervical grooves indistinct, weakly developed, reaching

683 postorbital cristae; epigastric cristae rounded, rugose, appearing almost confluent with

684 postorbital cristae, weakly separated from postorbital cristae by indistinct groove, region

685 between epigastric cristae and frontal margin rugose; frontal region narrow; postorbital cristae

686 gently slanting posterolaterally towards anterolateral margin; regions behind epigastric and

687 postorbital cristae rugose; antennular fossae (Fig. 28B) slit-like in anterior view; cleft between

688 external orbital angle and epibranchial tooth narrow; epibranchial tooth distinct, developed,

689 spine-like; anterolateral margin convex, cristate, very weakly serrated being almost smooth,

690 running inwards posteriorly. Exopod of third maxilliped without flagellum. Suture between

691 sternites 3 and 4 absent (Fig. 29A); sterno-pleonal cavity reaching imaginary line joining middle

692 of bases of cheliped coxae. Male pleon (Fig. 29A) narrowly triangular; telson broadly triangular.

693 G1 (Fig. 30A-D) subterminal segment sinuous, broad; terminal segment short, columnar, with

694 broadly flattened truncate, coiled (when viewed dorsally) tip, shorter than half the length of

695 subterminal segment, with groove for G2 marginal.

696 Etymology. The species name is derived from an arbitrary combination of the Latin

697 "fumario" (=chimney) and -atus (a suffix to form adjective indicating the possession of a thing or 698 a quality), alluding to the possession of chimney-like G1s.

699 Remarks. Potamiscus fumariatus sp. n. is so far known by a single specimen collected 700 together with another species, Aparapotamon grahami (Rathbun, 1931). However, it can be 701 easily distinguished from the latter species by the absence of the flagellum on the exopod of the 702 third maxilliped and its distinct G1 structure.

703 It most closely resembles Potamiscus motuoensis Dai, 1990, in general carapace morphology 704 and in the G1 terminal segment being columnar-shaped and being shorter than half the length of 705 the subterminal segment. Nevertheless, $P$. fumariatus can be easily distinguished from $P$. 706 motuoensis by the following characters: the anterolateral margin of the carapace is less convex 707 laterally (versus anterolateral margin of carapace more convex laterally); the epibranchial tooth 708 is spine-like (versus epibranchial tooth triangular and low); and the G1 terminal segment has a 709 broadly flattened truncate tip (versus G1 terminal segment with a blunt tapering tip) (Figs. 28A, 
710 30A-D versus Figs. 19C, G; Dai, 1990: fig, 69-4, pl. 9 fig. 3; Dai, 1999: fig. 106 (5, 6), pl. 13 711 fig. 1).

712 Distribution. Bailu Town, Wuding County, Yunnan Province, China.

713

714 Potamiscus crassus sp. $\mathbf{n}$.

715 urn:lsid:zoobank.org:act:AA45FEE-505F-4C92-BA19-8D8E7AD3091E

716 Figures. 31-34.

717

718

719

720

721

722

723

724

725

726

727

728

729

730

731

732

733

734

Material examined. Holotype, male $(28.0 \times 23.6 \mathrm{~mm})(\mathrm{NCU}$ MCP 2013.0025), purchased

from a market near Kunmin by Yunnan Province, China, coll. local villager, purchased by Yang Chang Man, 10 June 2002.

Paratypes: 24 males (largest $26.3 \times 22.4 \mathrm{~mm}), 18$ females (largest $23.3 \times 18.9 \mathrm{~mm})($ ZRC 2013.0562), 5 males (largest $27.8 \times 23.4 \mathrm{~mm}$ ), 3 females (largest $25.1 \times 19.8 \mathrm{~mm})($ ZRC 2013.0563), 6 males (largest $25.4 \times 21.2 \mathrm{~mm}$ ), 4 females (largest $24.2 \times 19.4 \mathrm{~mm}$ ) (RUMF-ZC2375), same data as holotype.

Diagnosis. Carapace (Fig. 31A) broader than long, CW 1.17-1.27 times (mean 1.21, $\mathrm{n}=7$ ) CL dorsal surface (Fig. 31B) flat, cervical grooves indistinct, weakly developed, not reaching postorbital cristae; epigastric cristae rounded, slightly rugose, appearing almost confluent with postorbital cristae, weakly separated from postorbital cristae by indistinct groove; postorbital cristae gently slanting posterolaterally towards anterolateral margin; regions behind epigastric and postorbital cristae rugose; antennular fossae (Fig. 31B) slit-like in anterior view; orbital region broad; epibranchial tooth distinct, low, poorly developed, not triangular; anterolateral margin convex, weakly serrated, not confluent with posterolateral margin, running inwards posteriorly. Epistome (Fig. 31B) posterior margin lateral parts straight, with broadly triangular, obtuse median tooth. Exopod of third maxilliped without flagellum. Suture between sternites 3 and 4 distinct forming a shelf (Fig. 31B); lateral margin of sternum 4 straight; sterno-pleonal cavity reaching imaginary line joining middle of bases of cheliped coxae. Male pleon (Fig. 32A) narrowly triangular; telson narrowly triangular, shorter than proximal width, longer than sixth somite. G1 (Fig. 33A-D) subterminal segment strongly sinuous, broad, about 1.6 times longer than broad, with distinctive subdistal cleft along outer margin; terminal segment stocky, subconical, length about 1.5 times the proximal width, with truncate, broadly rounded tip, 
741 appearing longitudinally twisted, with groove for G2 marginal. Vulva (Fig. 34) oval, large,

742 opening directed anterior mesioventrally, located mesial end of suture $5 / 6$, psoterior end widely

743 produced as short eave, opening covered with membrane.

744 Etymology. The specific name is derived from the Latin "crassus" (= thick, fat), alluding its 745 very stocky $\mathrm{G} 1$.

746 Remarks. Like the previous species, Potamiscus crassus sp. n. was also found together with

747 Aparapotamon grahami (Rathbun, 1931). However, it can be easily distinguished from the latter

748 species by the narrowly triangular male telson, the absence of the flagellum on the exopod of the 749 third maxilliped, and its distinct G1 structure.

$750 \quad$ Potamiscus crassus sp. n. most closely resembles P. yongshengensis Dai \& Chen, 1985, in

751 general carapace morphology and in the subconical G1 terminal segment appearing

752 longitudinally twisted as well as possessing a truncate tip. However, P. crassus sp. n. can be

753 easily distinguished from $P$. yongshengensis by the following characters: the epibranchial tooth

754 is poorly developed and not triangular (versus epibranchial tooth more developed and

755 triangular); male telson is narrow, with the lateral margins being proximally narrowed abruptly

756 (versus male telson broadly triangular, with lateral margins of telson being only slightly

757 concave); and the G1 terminal segment has a broadly rounded tip (versus G1 terminal segment

758 with a narrowly rounded tip) (Figs. 31A, 32A, 33A-D versus 19D, H; Dai \& Chen, 1985: fig. 5

759 (4, 5, 7), pl. 1 fig. 6; Dai, 1999: fig. 102 (2, 4, 5), pl. 12 fig. 5).

760 Distribution. The type specimens were purchased by Mrs Yang Chang Man at a market in

761 the outskirts of Kunmin City.

762

763 CONCLUSIONS

764 The present study described eight new species of potamid freshwater crab of the genera

765 Indochinamon Yeo \& Ng, 2007, Pararanguna Dai \& Chen, 1985, Parvuspotamon Dai \& Bo,

766 1994, and Potamiscus Alcock, 1909. The present study added 4 species to the genus

767 Indochinamon, and the genus currently contains 38 species (Cumberlidge \& Ng, 2009; Naruse,

768 Quynh \& Yeo, 2011; Do, Nguyen \& Le, 2016; present study). Nineteen out of the 38 species are

769 distributed in China, of which 18 species are known from Yunnan. Potamiscus is also distributed

770 in Indochina and southern China (Cumberlidge \& Ng, 2009). The present study added two

771 species, and the genus now contains 16 species, 7 of which have been recorded from Yunnan. 
772 Pararanguna and Parvuspotamon were monotypic genera, but the present study described 1

773 species each for the 2 genera. Both genera are endemic to Yunnan Province. Yunnan was already

774 known to host the highest number of freshwater crab species in the provinces of China, and the

775 present study further added 8 species and brings the number to 58 . It is noteworthy that 7 out of 8

776 new species described in the present study were collected by local colleagues and students at our

777 request within a relatively short period in February 2004. Considering also the fact that more and

778 more species have been discovered from Yunnan as well as other provinces of China (see

779 Introduction), it is most probable that the species diversity of this group is still understudied.

780

781 ACKNOWLEDGEMENTS

782 We are grateful to Peter K. L. Ng for his support and encouragement of this study, and to Darren

783 C. J. Yeo and Ng Ngan Kee for their kind assistance and input to this manuscript. Students and

784 staff from Chuxiong Medical College, Yunnan, and Tan Heok Hui (National University of

785 Singapore) kindly helped collecting material for our study. We also thank Jun Chen and

786 Shuqiang Li for their help in accessing specimens in IZAS. Thanks are also due to Chunchao

787 Zhu and Jiexin Zou for their help during a course of this study. We appreciate valuable

788 comments from Jose Cristopher E. Mendoza and two anonymous reviewers, which greatly

789 improved this paper. Baidu Map kindly approved to use the map of Yunnan Province for this

790 paper.

791

792 REFERENCES

793 Alcock A. 1909. Diagnosis of new species and varieties of freshwater crabs. Nos. 1-3. Records 794 of the Indian Museum 3: 243-253.

795 Alcock A. 1910 Catalogue of the Indian decapod Crustacea in the collection of the Indian

796 Museum. Part I. Brachyura. Fasciculus II. The Indian fresh-water crabs - Potamonidae.

797 Calcutta: Trustees of the Indian Museum.

798 Bott R. 1967. Potamidae (Crustacea, Decapoda) aus Afghanistan, Westasien und dem

799 Mittelmeerraum (Eine Revision der Untergattung Potamon s. str.). Videnskabelige

800 Meddelelser fra Dansk Naturhistorisk Forening 130: 7-43.

801 Bott R. 1970. Die Süßwasserkrabben von Europa, Asien, Australien und ihre

802 Stammesgeschichte. Eine Revision der Potamoidea und der Parathelphusoidea (Crustacea, 
803

804

805

806

807

808

809

810

811

812

813

814

815

816

817

818

819

820

821

822

823

824

825

826

827

828

829

830

831

832

833

Decapoda). Abhandlungen der Senckenbergischen Naturforschenden Gesellschaft 526: 1338, pls. $1-58$.

Bott R, Türkay M. 1977. Nachtrag zur Revision der Süßwasserkrabben von Europa, Asien und Australien. Die Verwandtschaftlichen Beziehungen von Ranguna (Ranguna) longipes (A. Milne-Edwards 1869). (Crustacea: Decapoda: Potamidae). Senckenbergiana biologica 58(1/2): 93-96.

Brandis D. 2000. The taxonomic status of the genus Potamiscus Alcock, 1909 (Decapoda: Brachyura: Potamidae). Senckenbergiana Biologica 80: 57-100.

Brandis D. 2002. On the taxonomic status and biogeography of the Isolapotamidae Bott, 1970 (Decapoda, Brachyura). Journal of Natural History 36: 1291-1339.

Cheng YZ, Lin GH, Li YS. 2010. Two new species of freshwater crabs (Decapoda: Potamidae) serving as intermediate hosts of Paragonimus in Fujian, China. Chinese Journal of Parasitology \& Parasitic Diseases 28(4):241-245. (In Chinese with English abstract and figure legends)

Chu K, Sun Y, Sun H. 2017. Sinopotamon baokangense sp. nov., a new freshwater crab with spoon-tipped cheliped fingers from Hubei Province, P.R. China (Decapoda, Brachyura, Potamidae). Crustaceana 90(3):263-274.

Chu K, Zhou L, Sun H. 2017. A new genus and new species of freshwater crab (Decapoda: Brachyura: Potamidae Ortmann, 1896) from Yunnan Province, China. Zootaxa 4286(2):241253. DOI: $10.11646 /$ zootaxa.4286.2.7

Cumberlidge N, Ng PKL. 2009. Systematics, evolution, and biogeography of the freshwater crabs. In: Martin JW, Crandall KA \& Felder DL, ed. Crustacean Issues 18. Decapod Crustacean Phylogenetics. Boca Raton: CRC Press, 491-504. DOI: 10.1201/9781420092592c25

Cumberlidge N, Ng PKL, Yeo DCJ, Magalhães C, Campos MR, Alvarez F, Naruse T, Daniels SR, Esser LJ, Attipoe FYK, Clotilde-Ba F-L, Darwall W, McIvor A, Baillie JEM, Collen B \& Ram M. 2009. Freshwater crabs and the biodiversity crisis: Importance, threats, status, and conservation challenges. Biological Conservation 142:1665-1673.

DOI: 10.1016/j.biocon.2009.02.038

Cumberlidge N, Ng PKL, Yeo DCJ, Naruse T, Meyer KS, Esser LJ. 2011. Diversity, endemism and conservation of the freshwater crabs of China (Brachyura: Potamidae and 
834 Gecarcinucidae). Integrative Zoology 2011, 6:45-55. DOI: 10.1111/j.1749-

$835 \quad$ 4877.2010.00228.x

836 Dai AY, Song YZ, He LY, Cao WJ, Xu ZB, Zhong WL. 1975. Description of several new

837 species of freshwater crabs belonging to the intermediate hosts of lung flukes. Acta Zoologica $838 \quad$ Sinica 21(3):257-264, pls. 1-3.

839 Dai AY, Chen GX. 1985. A preliminary report on the freshwater crabs of Hengduan Mountains 840 Area. Sinozoologica 3:39-72, pl. 1, 2. (In Chinese with English summary)

841 Dai AY. 1990. On the zoogeographical distribution of freshwater crabs in southwestern China.

842 From Water to Land, Snake Research Institute 375-385, pl. 1. (in Chinese with English 843 summary).

844 Dai AY, Bo WF. 1994. A new genus and three new species of freshwater crabs of Yuxi area of 845 Yunnan Province (Crustacea: Decapoda: Brachyura: Potamidae). Memoirs of Beijing Natural $846 \quad$ History Museum 54:21-28.

847 Dai AY. 1995. Five new species of freshwater crabs of genus Potamon from Yunnan Province,

848 China (Crustacea: Decapoda: Potamidae). Journal of the Taiwan Museum 48(1):49-59.

849 Dai AY, Cai YX. 1998. Freshwater crabs of Xishangbanna, Yunnan Province, China

850 (Malacostraca: Crustacea: Parathelphusidae, Potamidae). Acta Zootaxonomica Sinica

851 23(3):245-252. (In Chinese with English summary and figure legends)

852 Dai AY. 1999. Fauna Sinica (Arthropoda. Crustacea. Malacostraca. Decapoda.

853 Parathelphusicae. Potamidae). Beijing: Science Press. (In Chinese with English summary)

854 Dang NT, Ho TH. 2008. On the taxonomy of freshwater crabs allied to the genus Potamon 855 (Potamidae) in Vietnam. Tap Chi Sinh Hoc 30(2): 12-17.

856 De Grave S, Pentcheff ND, Ahyong ST, Chan TY, Crandall KA, Dworschak PC, Felder DL, 857 Feldmann RM, Fransen CHJM, Goulding LYD, Lemaitre R, Low MEY, Martin JW, Ng PKL, 858 Schweitzer CE, Tan SH, Tshudy D. \& Wetzer R. 2009. A classification of living and fossil 859 genera of decapod crustaceans. Raffles Bulletin of Zoology, Supplement 21:1-109.

860 Do VT, Nguyen TC, Le HA. 2016. A new species of the genus Indochinamon Yeo \& Ng, 2007 861 (Crustacea: Brachyura: Potamoidea: Potamidae) from northern Vietnam. Raffles Bulletin of 862 Zoology 64:187-193. 
863 Do VT, Shih HT, Huang C. 2016. A new species of freshwater crab of the genus Tiwaripotamon 864 Bott, 1970 (Crustacea, Brachyura, Potamidae) from northern Vietnam and southern China. 865 Raffles Bulletin of Zoology, 64:213-219.

866 Holthuis LB. 1990. Comments on the proposed fixation of type species for Larnaudia and 867 Ranguna Bott, 1966 (Crustacea, Decapoda). Bulletin of Zoological Nomenclature 47: 45. 868 Huang C, Huang JR, Ng PKL. 2012. A new species of Nanhaipotamon Bott, 1968 (Crustacea:

869 Decapoda: Brachyura: Potamidae) from Zhuhai, Guangdong Province, China. Zootaxa $870 \quad 3588: 55-63$.

871 Huang C, Mao SY, Huang JR. 2014. Two new potamid crabs, Yuexipotamon arcophallus new 872 genus, new species and Minutomon shanweiense new genus, new species, (Crustacea:

873 Decapoda: Brachyura: Potamidae) from southern China. Zootaxa 3764(4):455-466.

874 DOI: $10.11646 /$ zootaxa.3764.4.5

875 Huang C, Shih HT, Mao SY. 2016. Yuebeipotamon calciatile, a new genus and new species of 876 freshwater crab from southern China (Crustacea, Decapoda, Brachyura, Potamidae). ZooKeys 877 615:61-72. DOI: 10.3897/zookeys.615.9964

878 Huang C, Ahyong ST, Shih HT. 2017. Cantopotamon, a new genus of freshwater crabs from 879 Guangdong, China, with descriptions of four new species (Crustacea: Decapoda: Brachyura: 880 Potamidae). Zoological Studies 56(41): 1-20. DOI: 10.6620/ZS.2017.56-41

881 Huang C, Shih HT, Ng PKL. 2017. A new genus and new species of Potamidae (Crustacea:

882 Decapoda: Brachyura: Potamoidea), the first stygomorphic cave crab known from China and 883 East Asia. Zootaxa, 4232(1): 71-84.Huang C. 2018. Revision of Yarepotamon Dai \& Türkay, 8841997 (Brachyura: Potamidae), freshwater crabs endemic to southern China, with descriptions 885 of two new genera and four new species. Journal of Crustacean Biology. rux120, 886 https://doi.org/10.1093/jcbiol/rux120

887 International Commission on Zoological Nomenclature (ICZN). 1991. Opinion 1640. Ranguna 888 Bott, 1966 and Larnaudia Bott, 1966 (Crustacea, Decapoda): Potamon rangoonensis

889 Rathbun, 1904 and Thelphusa larnaudii A. Milne-Edwards, 1869 confirmed as the respective 890 type species. Bulletin of Zoological Nomenclature 48: 171-172.

891 International Commission on Zoological Nomenclature (ICZN). 1999. International Code of 892 Zoological Nomenclature. Fourth Edition. Adopted by the XXI General Assembly of the 
893

894

895

896

897

898

899

900

901

902

903

904

905

906

907

908

909

910

911

912

913

914

915

916

$917 \mathrm{Ng}$ PKL. 1990. Comments on the proposed fixation of type species for Larnaudia and Ranguna

918 Bott, 1966 (Crustacea, Decapoda). Bulletin of Zoological Nomenclature 47: 45-46.

919

920

921

International Union of Biological Sciences. International Trust for Zoological Nomenclature, in association with the British Museum (Natural History), London.

Kemp S. 1913. Crustacea Decapoda. Records of the Indian Museum 8: 289-310, pls. 17-21.

Kunming Institute of Zoology, CAS, 1999. Wildlife in Yunnan. Beijing: Chinese Forestry Publishing House.

Lin GH, Cheng YZ, Chen SH. 2012. A new species of genus Nanhaipotamon (Decapoda: Potamidae) from China. Chinese Journal of Parasitology \& Parasitic Diseases 30(6):434437. (In Chinese with English summary and figure legends)

Lin GH, Cheng YZ, Chen SH. 2013. A new species of the genus Nanhaipotamon (Decapoda: Potamidae) serving as intermediate host of Paragonmus skrjabini. Chinese Journal of Parasitology \& Parasitic Diseases 31(1):39-42. (In Chinese with English summary and figure legends)

Naiyanetr P. 2001. Potamon bhumibol n. sp., a new giant freshwater crab from Thailand (Decapoda, Brachyura, Potamidae). Crustaceana 74(3): 309-316.

Naruse T, Yeo DCJ, Zhou X. 2008. Five new species of freshwater crabs (Crustacea: Decapoda: Brachyura: Potamidae) from China. Zootaxa 1812:49-68.

Naruse T, Quynh NX, Yeo DCJ. 2011. Three new species of Indochinamon (Crustacea: Decapoda: Potamidae: Potamiscinae) from Vietnam, with a redescription of Ranguna (Ranguna) kimboiensis Dang, 1975. Zootaxa 2732:33-48.

Naruse T, Zhu C, Zhou X. 2013. Two new species of freshwater crabs of the genus Heterochelamon Türkay \& Dai, 1997 (Crustacea: Decapoda: Brachyura: Potamidae) from Guangxi Zhuang Autonomous Region, southern China. Zootaxa 3647(4):567-576.

Ng PKL. 1988. The freshwater crabs of Peninsular Malaysia and Singapore. Singapore: Shinglee Press.

$\mathrm{Ng}$ PKL. 1991. A note on the taxonomy of two Malayan freshwater crabs, Stoliczia rafflesi (Roux, 1936) and Stoliczia changmanae Ng, 1988 (Crustacea: Decapoda: Brachyura: Potamidae). Verhandlungen der Naturforschenden Gesellschaft Basel 100: 91-97. 
922 Ng PKL, Naiyanetr P. 1993. New and recently described freshwater crabs (Crustacea: Decapoda: 923 Brachyura: Potamidae, Gecarcinucidae and Parathelphusidae) from Thailand. Zoologische $924 \quad$ Verhandelingen Leiden 284: 1-117.

925 Ng PKL, Guinot D, Davie PJF. 2008. Systema Brachyurorum: Part I. An annotated checklist of 926 extant brachyuran crabs of the world. Raffles Bulletin of Zoology, Supplement 17:1-286.

927 Ng PKL. 2017. Descriptions of two new cavernicolous species of Chinapotamon Dai \&

928 Naiyanetr, 1994 (Crustacea: Brachyura: Potamidae) from China. Crustacean Research 46: 1929 16. DOI: $10.18353 /$ crustacea.46.0_1

930 Pretzmann G. 1966. Einige neue Potamoniden (Crustacea) des Himalaya-Gebietes (Vorläufige 931 Mitteilung). Entomologisches Nachrichtenblatt, Wien 13: 4-6.

932 Rathbun MJ. 1904-1906. Les crabes d'eau douce (Potamonidae). Nouvelles Archives du Muséum 933 d'Histoire naturelle Paris, 4e série, 6: 225-312, pls. 9-18; 7: 159-322; 8: 33-122.

934 Türkay M, Naiyanetr P. 1987. The identity of Potamon rangoonense Rathbun, 1904 and

935 Thelphusa larnaudii A. Milne-Edwards, 1869, with introduction of Neolarnaudia botti n. g. n. 936 sp. (Crustacea: Decapoda: Potamidae). Senckenbergiana Biologica 67: 389-396.

937 Türkay M, Naiyanetr P. 1989. Case 2624. Ranguna Bott, 1966 and Larnaudia Bott, 1966

938 (Crustacea: Decapoda): propsed fixation of Thelphusa longipes A. Milne-Edwards, 1869 and

939 Thelphusa larnaudii A. Milne-Edwards, 1869 as the respective types. Bulletin of Zoological $940 \quad$ Nomenclature 46: 101-103.

941 Wood-Mason J. 1871. Contributions to Indian Carcinology: On Indian and Malayan

942 Telphusidae, Part I. Journal of the Asiatic Society of Bengal 40(2):189-207, 449-454, pls.

$943 \quad 11-14,27$.

944 Yang Y, Tian K, Hao J, Pei S, Yang Y. 2004. Biodiversity and biodiversity conservation in

945 Yunnan, China. Biodiversity \& Conservation 13(4):813-826.

946 Yeo DCJ, Ng PKL. 1998. Freshwater crabs of the Potamon tannanti species group (Crustacea,

947 Decapoda, Brachyura, Potamidae) of northern Indochina. Raffles Bulletin of Zoology

$948 \quad 46(2): 627-650$.

949 Yeo DCJ, Ng PKL. 2003. Recognition of two subfamilies in the Potamidae Ortmann, 1896

950 (Brachyura, Potamidae) with a note on the genus Potamon Savigny, 1816. Crustaceana

951 76(10):1219-1235. DOI: 10.1163/156854003773123456 
952 Yeo DCJ, Naruse T. 2007. A revision of the freshwater crab genus Hainanpotamon Dai, 1995

953 (Crustacea: Decapoda: Brachyura: Potamidae: Potamiscinae) with a redescription of Potamon

954 (Potamon) orientale (Parisi, 1916) and descriptions of three new species. Zoological Science

$955 \quad 24: 1143-1158$.

956 Yeo DCJ, Ng PKL. 2007. On the genus "Potamon" and allies in Indochina (Crustacea:

957 Decapoda: Brachyura: Potamidae). Raffles Bulletin of Zoology, Supplement 16:273-308.

958 Yeo DCJ. 2010. A new species of Eosamon from southern Vietnam (Brachyura, Potamidae),

959 with notes on E. brousmichei (Rathbun, 1904). In: Fransen CHJM, De Grave S, Ng PKL, eds.

960 Studies on Malacostraca: Lipke Bijdeley Holthuis Memorial Volume. Crustaceana

961 Monographs. Fransen CHJM, von Vaupel Klein JC, series eds. Vol. 14. Leiden: Brill, 747-

962754.

963 Zhu C, Naruse T, Zhou X. 2010. Two new species of freshwater crabs of the genus

964 Sinolapotamon Tai \& Sung, 1975 (Decapoda, Brachyura, Potamidae) from Guangxi zhuang

965 autonomous region, China. Crustaceana 83(2):245-256.

966 DOI: 10.1163/001121609X12603430877199 
968 Figure legends

969 Fig. 1. Map showing Yunnan Province, China, and collection localities of seven new species

970 described in this study.

971 Ia, Indochinamon ahkense sp. n.; Ip, I. parpidum sp. n.; It, I. tujiense sp. n.; Il, I. lui sp. n.; Prh,

972 Pararanguna hemicyclius sp. n.; Pvd, Parvuspotamon dixuense sp. n.; Pof, Potamiscus

973 fumariatus sp. $\mathrm{n}$. This map is modified from Baidu Map with permission.

974

975 Fig. 2. Indochinamon ahkense sp. n. (Holotype, male, NCU MCP 2013.0003, $41.3 \times 32.0$ mm).

976 A, habitus, dorsal view; B, cephalothorax, anterior view. Photo credit: Tohru Naruse.

977

978 Fig. 3. Indochinamon ahkense sp. n. (Holotype, male, NCU MCP 2013.0003, $41.3 \times 32.0$ mm).

979 A, cephalothorax, ventral view; B, left chela, outer view. Photo credit: Tohru Naruse.

980

981 Fig. 4. Indochinamon ahkense sp. n. (Holotype, male, NCU MCP 2013.0003, $41.3 \times 32.0 \mathrm{~mm}$ ).

982 A-C, left G1; A, ventral view; B, enlarged view of distal portion, ventral view; C, dorsal view;

983 D, left G2, dorsal view. Scales $=3 \mathrm{~mm}$. Drawing credit: Jing En Chia.

984

985 Fig. 5. Indochinamon ahkense sp. n. (Paratype, female, ZRC 2013.0551, $43.1 \times 33.2 \mathrm{~mm}$ ).

986 Thoracic sternum with vulvae. Photo credit: Tohru Naruse.

987

988 Fig. 6. Dorsal views of habitus(A-E) and ventral views of G1s (F-J) of comparative 989 Indochinamon species.

990 A, F, I. gengmaense (Dai, 1995) (Holotype, CB05192 YN6491119A); B, G, I. chinghungense

991 (Dai, Song, He, Cao, Xu and Zhong, 1975) (Holotype, CB05166 YN 637507); C, H, I.

992 boshanense (Dai \& Chen, 1985) (Holotype, CB05160 HD8183031); D, I, I. jianchuanense (Dai

993 \& Chen, 1985) (Holotype, CB005159 HD 8183030); E, J, I. menglaense (Dai \& Cai, 1998)

994 (Holotype, CB05168 YN-9496196A). Photo credit: Chunchao Zhu and Jiexin Zou.

995

996 Fig. 7. Indochinamon parpidum sp. n. (Holotype, male, NCU MCP 2013.0015, 47.1 × 36.5 mm).

997 A, habitus, dorsal view; B, cephalothorax, anterior view. Photo credit: Tohru Naruse. 
999 Fig. 8. Indochinamon parpidum sp. n. (Holotype, male, NCU MCP 2013.0015, 47.1 × $36.5 \mathrm{~mm}$ ).

1000 A, cephalothorax, ventral view; B, right chela, outer view. Photo credit: Tohru Naruse.

1001

1002 Fig. 9. Indochinamon parpidum sp. n. (Holotype, male, NCU MCP 2013.0015, 47.1 × 36.5 mm).

1003 A-D, left G1; A, ventral view; B, enlarged view of distal portion, ventral view; C, dorsal view;

1004 D, enlarged view of distal portion, dorsal view; E, left G2, ventral view. Scales $=3 \mathrm{~mm}$. Drawing 1005 credit: Jing En Chia (A-D) and Tohru Naruse (E).

1006

1007 Fig. 10. Indochinamon parpidum sp. n. (Paratype, female, ZRC 2013.0558, $33.0 \times 24.7 \mathrm{~mm}$ ).

1008 Thoracic sternum with vulvae. Photo credit: Tohru Naruse.

1009

1010 Fig. 11. Indochinamon tujiense sp. n. (Holotype, male, NCU MCP 2013.0005, 45.3 × $33.2 \mathrm{~mm}$ ).

1011 A, habitus, dorsal view; B, cephalothorax, anterior view. Photo credit: Tohru Naruse.

1012

1013 Fig. 12. Indochinamon tujiense sp. n. (Holotype, male, NCU MCP 2013.0005, 45.3 × $33.2 \mathrm{~mm}$ ).

1014 A, cephalothorax, ventral view; B, right chela, outer view. Photo credit: Tohru Naruse.

1015

1016 Fig. 13. Indochinamon tujiense sp. n. (Holotype, male, NCU MCP 2013.0005, 45.3 × $33.2 \mathrm{~mm}$ ).

1017 A-D, left G1; A, ventral view; B, enlarged view of distal portion, ventral view; C, dorsal view;

1018 D, enlarged view of distal portion, dorsal view; E, right G2, ventral view. Scales $=3 \mathrm{~mm}$.

1019 Drawing credit: Jing En Chia (A-D) and Tohru Naruse (E).

1020

1021 Fig. 14. Indochinamon tujiense sp. n. (Paratype, NCU MCP 2013.0006, $35.6 \times 26.7$ mm).

1022 Thoracic sternum with vulvae. Photo credit: Tohru Naruse.

1023

1024 Fig. 15. Indochinamon lui sp. n. (Holotype, male, NCU MCP 2013.0010, $43.0 \times 32.9$ mm).

1025 A, habitus, dorsal view; B, cephalothorax, anterior view. Photo credit: Tohru Naruse.

1026

1027 Fig. 16. Indochinamon lui sp. n. (Holotype, male, NCU MCP 2013.0010, $43.0 \times 32.9$ mm).

1028 A, cephalothorax, ventral view; B, right chela, outer view. Photo credit: Tohru Naruse. 
1030 Fig. 17. Indochinamon lui sp. n. (Holotype, male, NCU MCP 2013.0010, $43.0 \times 32.9 \mathrm{~mm}$ ).

1031 A-D, left G1; A, ventral view; B, enlarged view of distal portion, ventral view; C, dorsal view;

1032 D, enlarged view of distal portion, dorsal view; E, right G2, ventral view. Scales $=3 \mathrm{~mm}$.

1033 Drawing credit: Jing En Chia (A-D) and Tohru Naruse (E).

1034

1035 Fig. 18. Indochinamon lui sp. n. (Paratype, RUMF-ZC- 2369, $34.8 \times 26.2 \mathrm{~mm}$ ).

1036 Thoracic sternum with vulvae. Photo credit: Tohru Naruse.

1037

1038 Fig. 19. Dorsal views of habitus (A-D) and ventral views of G1s (E-H) of comparative species.

1039 A, E, Pararanguna semilunata (Dai \& Chen, 1984) (Holotype, CB05191 HD8183034); B, F,

1040 Parvuspotamon yuxiense Dai \& Bo, 1994 (Holotype, CB05138 YN 9091116A); C, G,

1041 Potamiscus motuoensis Dai, 1990 (Holotype, CB05157 XZ6389084); D, H. Potamiscus

1042 yongshengensis Dai \& Chen, 1985 (Holotype, CB05149 HD 8183035). Photo credit: Chunchao

1043 Zhu and Jiexin Zou.

1044

1045 Fig. 20. Pararanguna hemicyclia sp. n. (Holotype, male, NCU MCP 2013.0017, 14.3 × 12.5

$1046 \mathrm{~mm})$.

1047 A, habitus, dorsal view; B, cephalothorax, anterior view. Photo credit: Tohru Naruse.

1048

1049 Fig. 21. Pararanguna hemicyclia sp. n. (Holotype, male, NCU MCP 2013.0017, $14.3 \times 12.5$

$1050 \mathrm{~mm})$.

1051 Cephalothorax, ventral view. Photo credit: Tohru Naruse.

1052

1053 Fig. 22. Pararanguna hemicyclia sp. n. (Holotype, male, NCU MCP 2013.0017, $14.3 \times 12.5$

$1054 \mathrm{~mm})$.

1055 A-C, right G1; A, ventral view; B, dorsal view; C, lateral view; D, right G2, dorsal view. Scale =

$10561 \mathrm{~mm}$. Drawing credit: Jing En Chia.

1057

1058 Fig. 23. Pararanguna hemicyclia sp. n. (Paratype, female, NCU MCP 2013.0018, 15.9 x 13.4

$1059 \mathrm{~mm})$.

1060 Thoracic sternum with vulvae. Photo credit: Tohru Naruse. 
1061

1062 Fig. 24. Parvuspotamon dixuense sp. n. (Holotype, male, NCU MCP 2013.0020, $25.7 \times 20.0$ $1063 \mathrm{~mm})$.

1064 A, habitus, dorsal view; B, cephalothorax, anterior view. Photo credit: Tohru Naruse.

1065

1066

Fig. 25. Parvuspotamon dixuense sp. n. (Holotype, male, NCU MCP 2013.0020, $25.7 \times 20.0$

$1067 \mathrm{~mm}$ ).

1068 A, cephalothorax, ventral view; B, right chela, outer view. Photo credit: Tohru Naruse.

1069

1070 Fig. 26. Parvuspotamon dixuense sp. n. (Holotype, male, NCU MCP 2013.0020, $25.7 \times 20.0$ $1071 \mathrm{~mm})$.

1072 A-D, right G1; A, ventral view; B, enlarged view of distal portion, ventral view; C, dorsal view;

1073 D, enlarged view of distal portion, dorsal view; E, right G2, dorsal view. Scales $=1 \mathrm{~mm}$.

1074 Drawing credit: Jing En Chia.

1075

1076 Fig. 27. Parvuspotamon dixuense sp. n. (Paratype, female, NCU MCP 2013.0021, $23.1 \times 17.8$

$1077 \mathrm{~mm})$.

1078 Thoracic sternum with vulvae. Photo credit: Tohru Naruse.

1079

1080 Fig. 28. Potamiscus fumariatus sp. n. (Holotype, male, NCU MCP 2013.0024, $24.1 \times 20.1 \mathrm{~mm}$ ).

1081 A, habitus, dorsal view; B, cephalothorax, anterior view. Photo credit: Tohru Naruse.

1082

1083 Fig. 29. Potamiscus fumariatus sp. n. (Holotype, male, NCU MCP 2013.0024, $24.1 \times 20.1 \mathrm{~mm}$ ).

1084 A, cephalothorax, ventral view; B, right chela, outer view. Photo credit: Tohru Naruse.

1085

1086 Fig. 30. Potamiscus fumariatus sp. n. (Holotype, male, NCU MCP 2013.0024, $24.1 \times 20.1 \mathrm{~mm}$ ).

1087 A-D, left G1; A, ventral view; B, enlarged view of distal portion, ventral view; C, dorsal view;

1088

D, enlarged view of distal portion, dorsal view; E, left G2, dorsal view. Scales $=1 \mathrm{~mm}$. Drawing

1089 credit: Jing En Chia.

1090

1091 Fig. 31. Potamiscus crassus sp. n. (Holotype, male, NCU MCP 2013.0025, $28.0 \times 23.6$ mm). 
1092 A, habitus, dorsal view; B, cephalothorax, anterior view. Photo credit: Tohru Naruse.

1093

1094 Fig. 32. Potamiscus crassus sp. n. (Holotype, male, NCU MCP 2013.0025, $28.0 \times 23.6$ mm).

1095 A, cephalothorax, ventral view; B, left chela, outer view. Photo credit: Tohru Naruse.

1096

1097 Fig. 33. Potamiscus crassus sp. n. (Holotype, male, NCU MCP 2013.0025, $28.0 \times 23.6$ mm).

1098 A-D, right G1; A, ventral view; B, enlarged view of distal portion, ventral view; C, dorsal view;

1099 D, enlarged view of distal portion, dorsal view; E, right G2, dorsal view. Scales $=3 \mathrm{~mm}$.

1100 Drawing credit: Jing En Chia.

1101

1102 Fig. 34. Potamiscus crassus sp. n. (Paratype, female, ZRC 2013.0562, $22.7 \times 18.2$ mm).

1103 Thoracic sternum with vulvae. Photo credit: Tohru Naruse. 


\section{Figure 1}

Map showing Yunnan Province, China, and collection localities of seven new species described in this study.

Ia, Indochinamon ahkense sp. n.; Ip, I. parpidum sp. n.; It, I. tujiense sp. n.; II, I. lui sp. n.; Prh, Pararanguna hemicyclius sp. n.; Pvd, Parvuspotamon dixuense sp. n.; Pof, Potamiscus fumariatus sp. $\mathrm{n}$. 


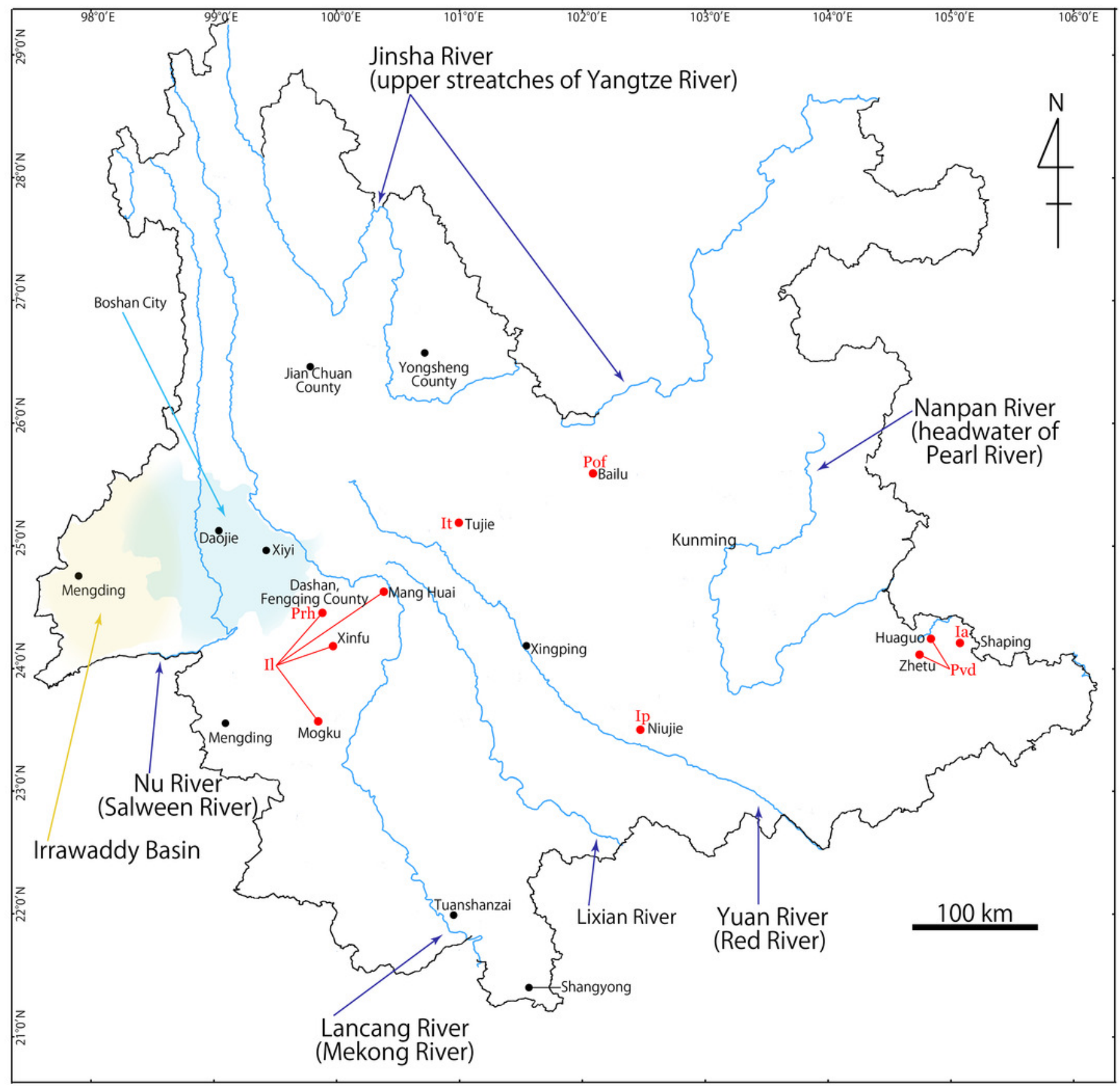




\section{Figure 2}

Indochinamon ahkense sp. n. (Holotype, male, NCU MCP 2013.0003, $41.3 \times 32.0$ mm).

A, habitus, dorsal view; B, cephalothorax, anterior view.

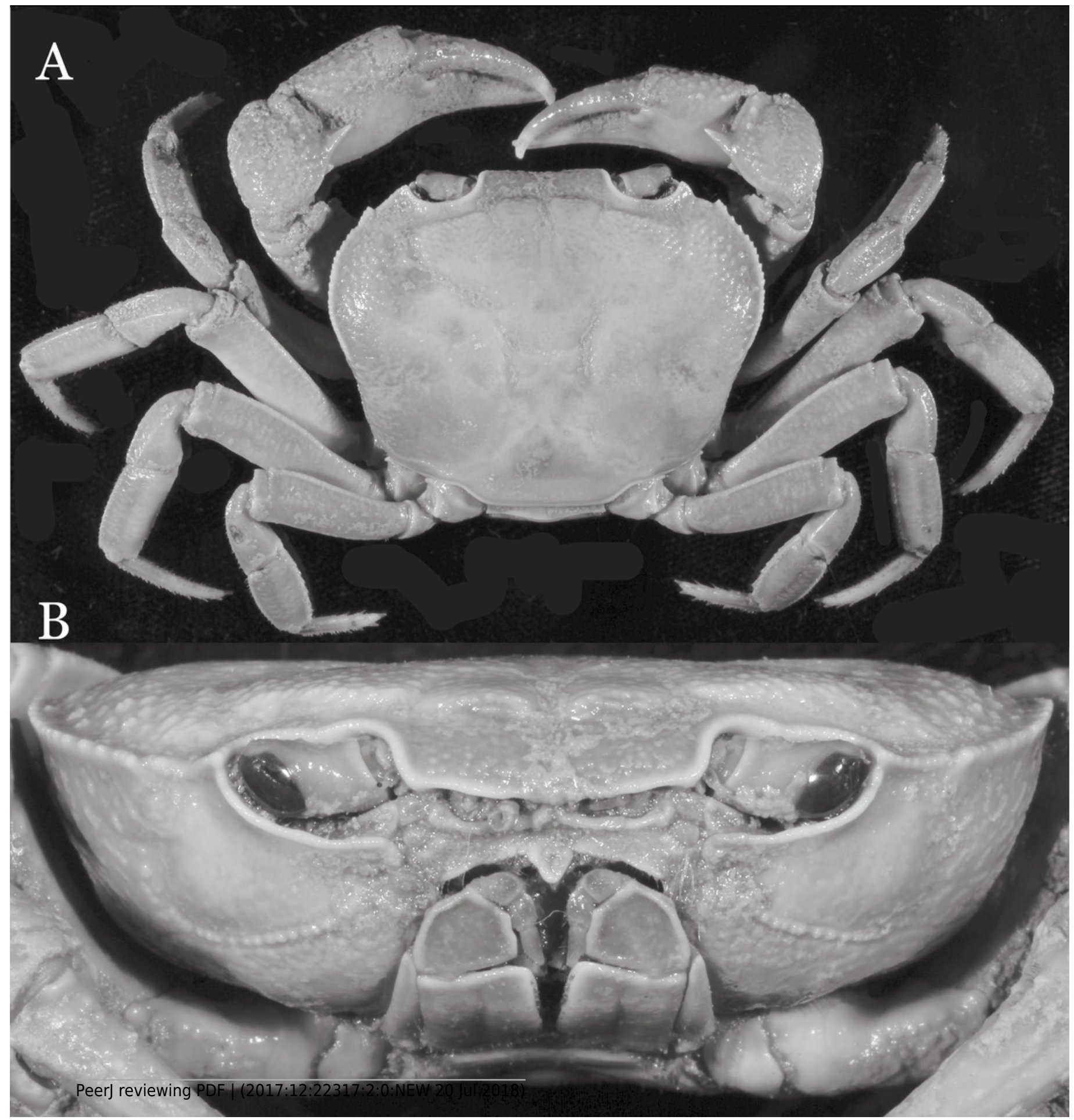


Figure 3

Indochinamon ahkense sp. n. (Holotype, male, NCU MCP 2013.0003, $41.3 \times 32.0$ mm).

A, cephalothorax, ventral view; B, left chela, outer view. 


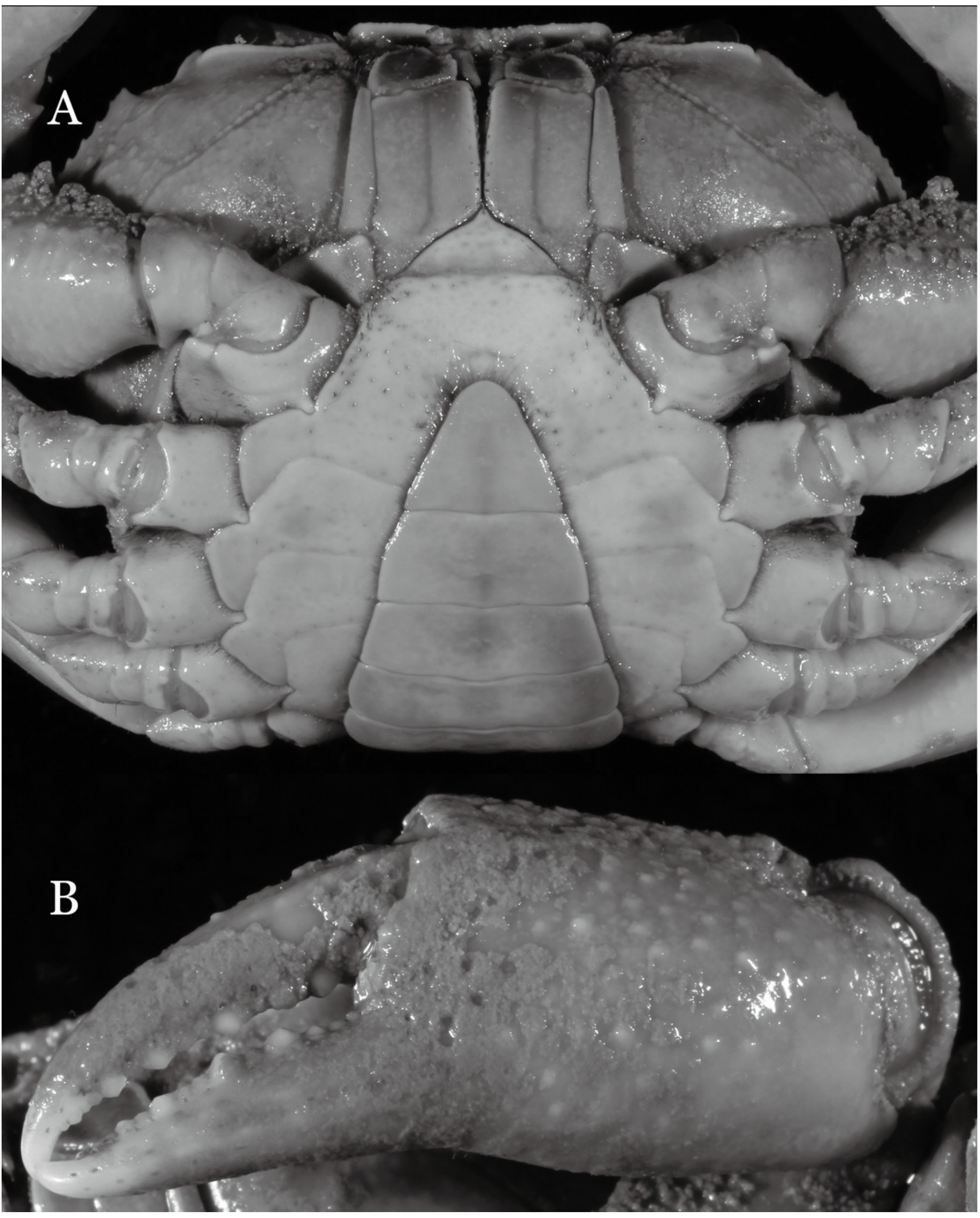


Figure 4

Indochinamon ahkense sp. n. (Holotype, male, NCU MCP 2013.0003, $41.3 \times 32.0$ mm).

A-C, left G1; A, ventral view; B, enlarged view of distal portion, ventral view; C, dorsal view;

$D$, left $\mathrm{G} 2$, dorsal view. Scales $=3 \mathrm{~mm}$.

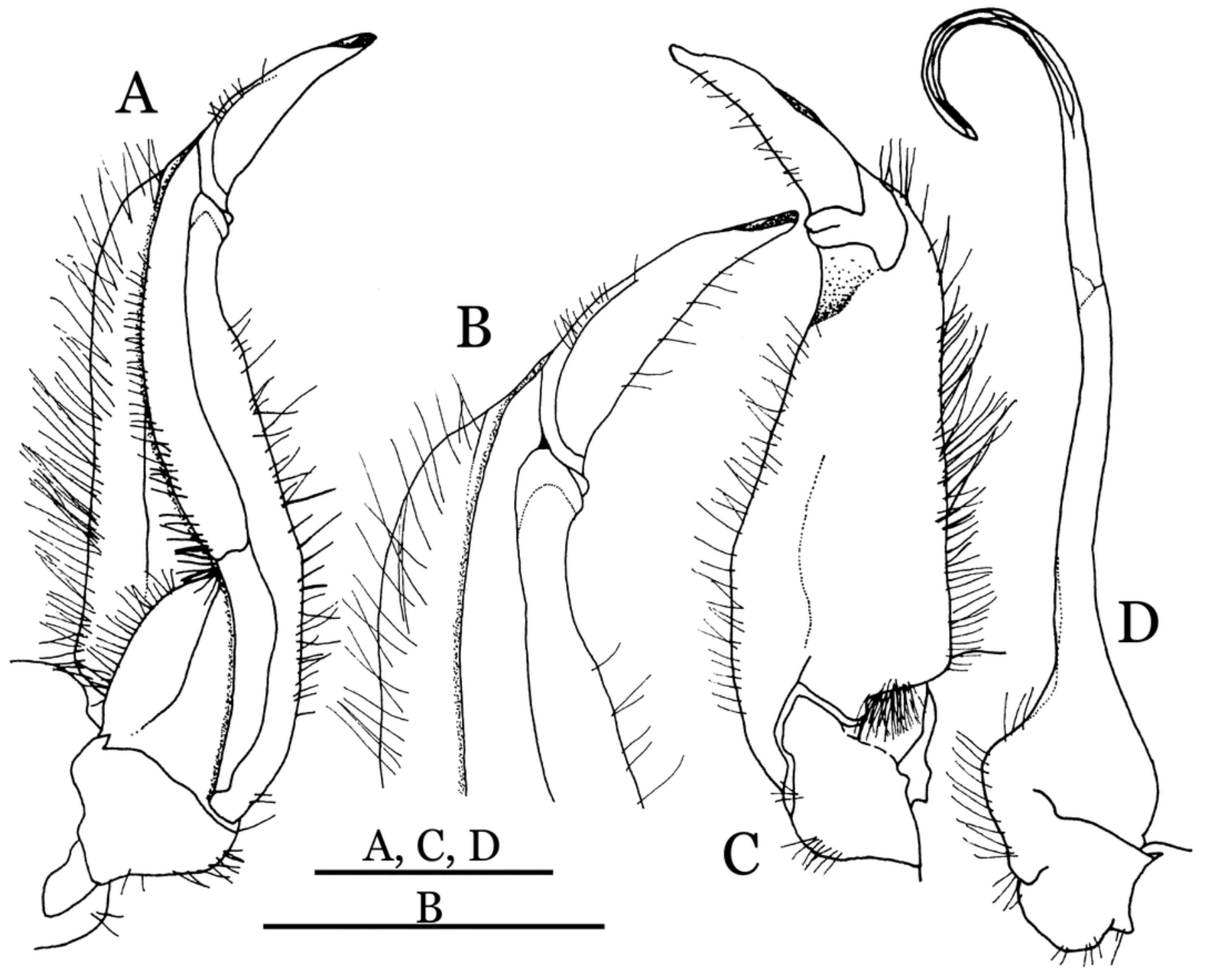




\section{Figure 5}

Indochinamon ahkense sp. n. (Paratype, female, ZRC 2013.0551, $43.1 \times 33.2 \mathrm{~mm}$ ).

Thoracic sternum with vulvae.

*Note: Auto Gamma Correction was used for the image. This only affects the reviewing manuscript. See original source image if needed for review.

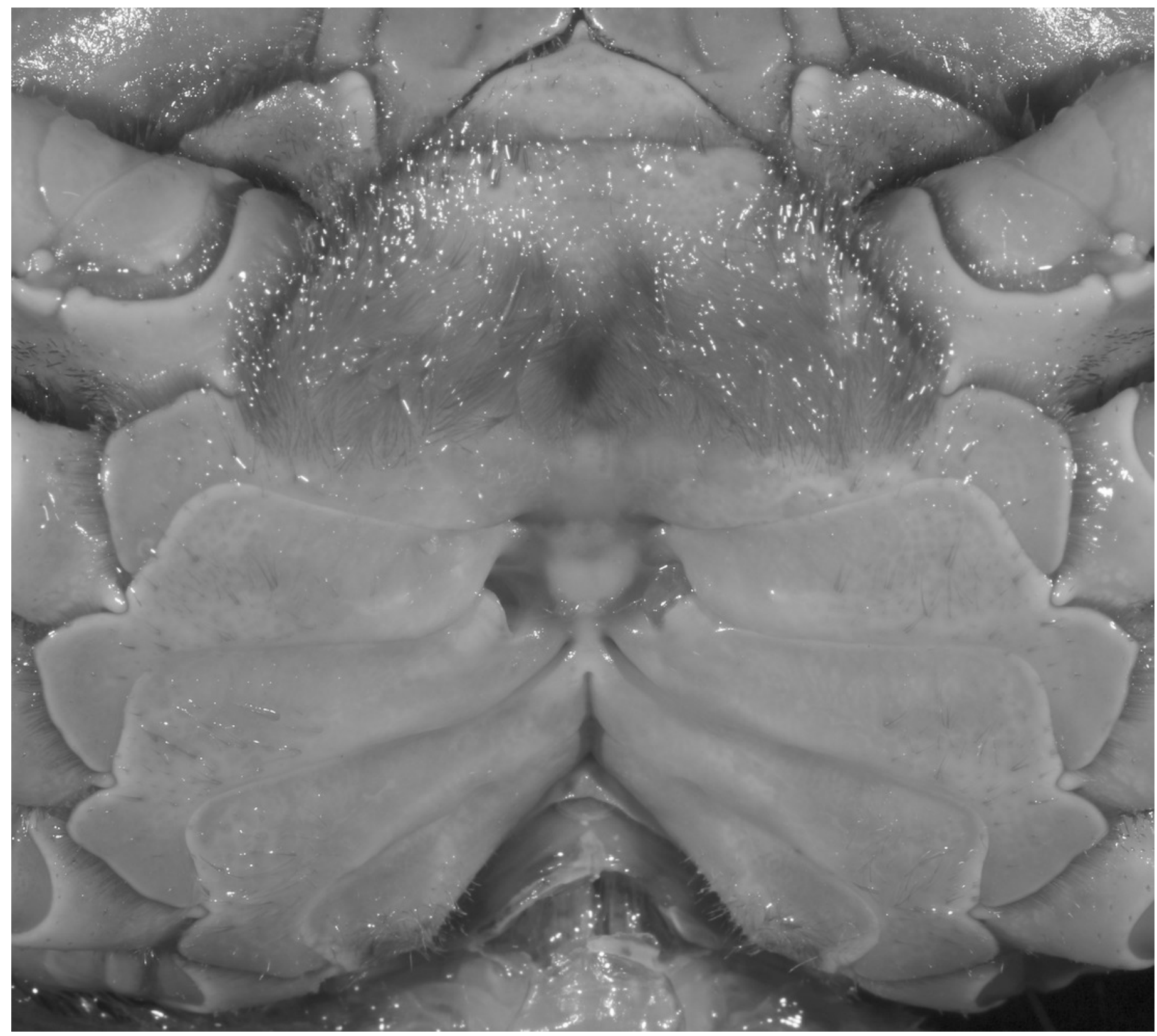




\section{Figure 6}

Dorsal views of habitus(A-E) and ventral views of G1s (F-J) of comparative Indochinamon species.

A, F, I. gengmaense (Dai, 1995) (Holotype, CB05192 YN6491119A); B, G, I. chinghungense (Dai, Song, He, Cao, Xu and Zhong, 1975) (Holotype, CB05166 YN 637507); C, H, I. boshanense (Dai \& Chen, 1985) (Holotype, CB05160 HD8183031); D, I, I. jianchuanense (Dai $\&$ Chen, 1985) (Holotype, CB005159 HD 8183030); E, J, I. menglaense (Dai \& Cai, 1998) (Holotype, CB05168 YN-9496196A).

*Note: Auto Gamma Correction was used for the image. This only affects the reviewing manuscript. See original source image if needed for review. 


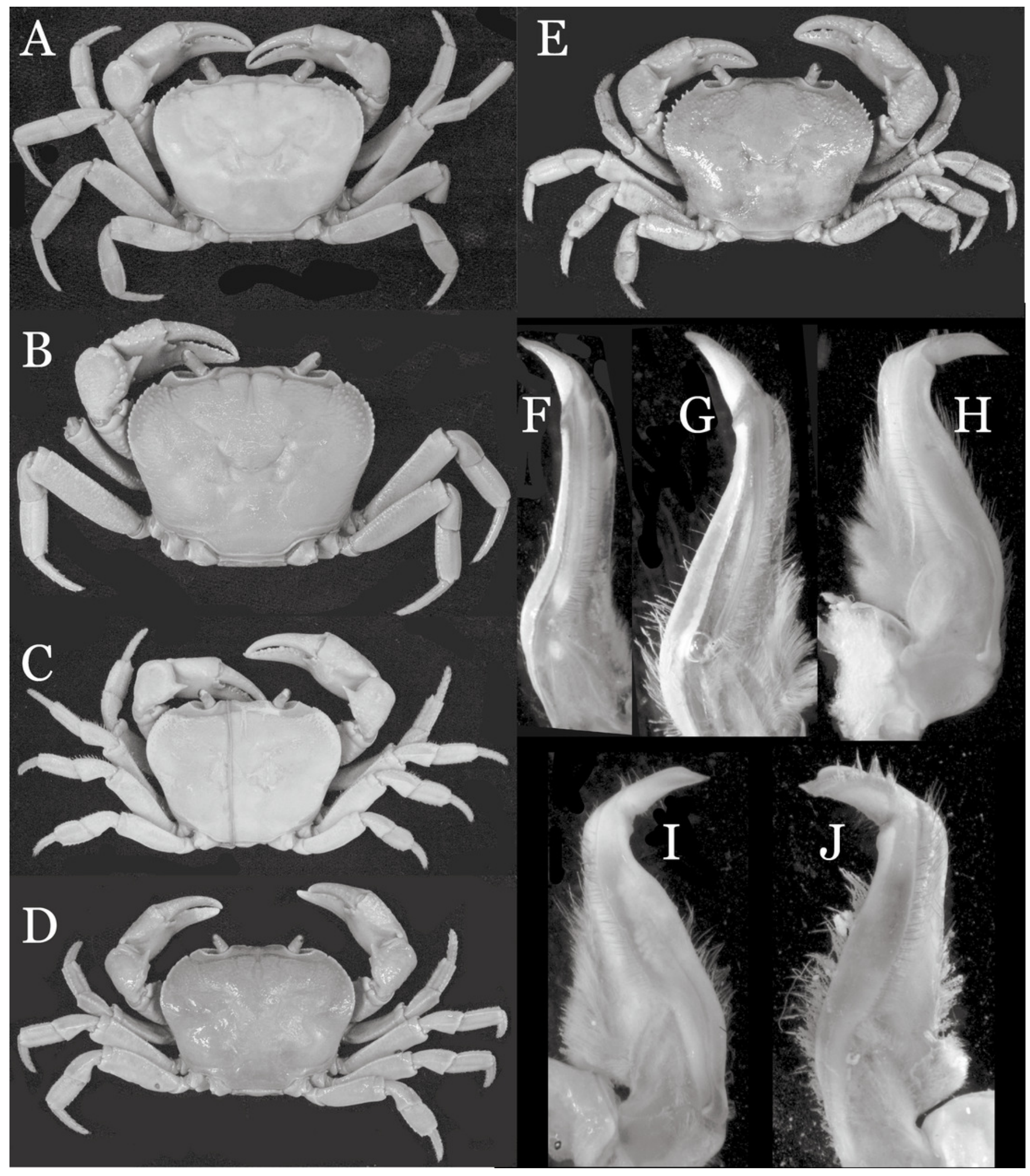


Figure 7

Indochinamon parpidumsp. n. (Holotype, male, NCU MCP 2013.0015, $47.1 \times 36.5$ mm).

A, habitus, dorsal view; B, cephalothorax, anterior view.

*Note: Auto Gamma Correction was used for the image. This only affects the reviewing manuscript. See original source image if needed for review.

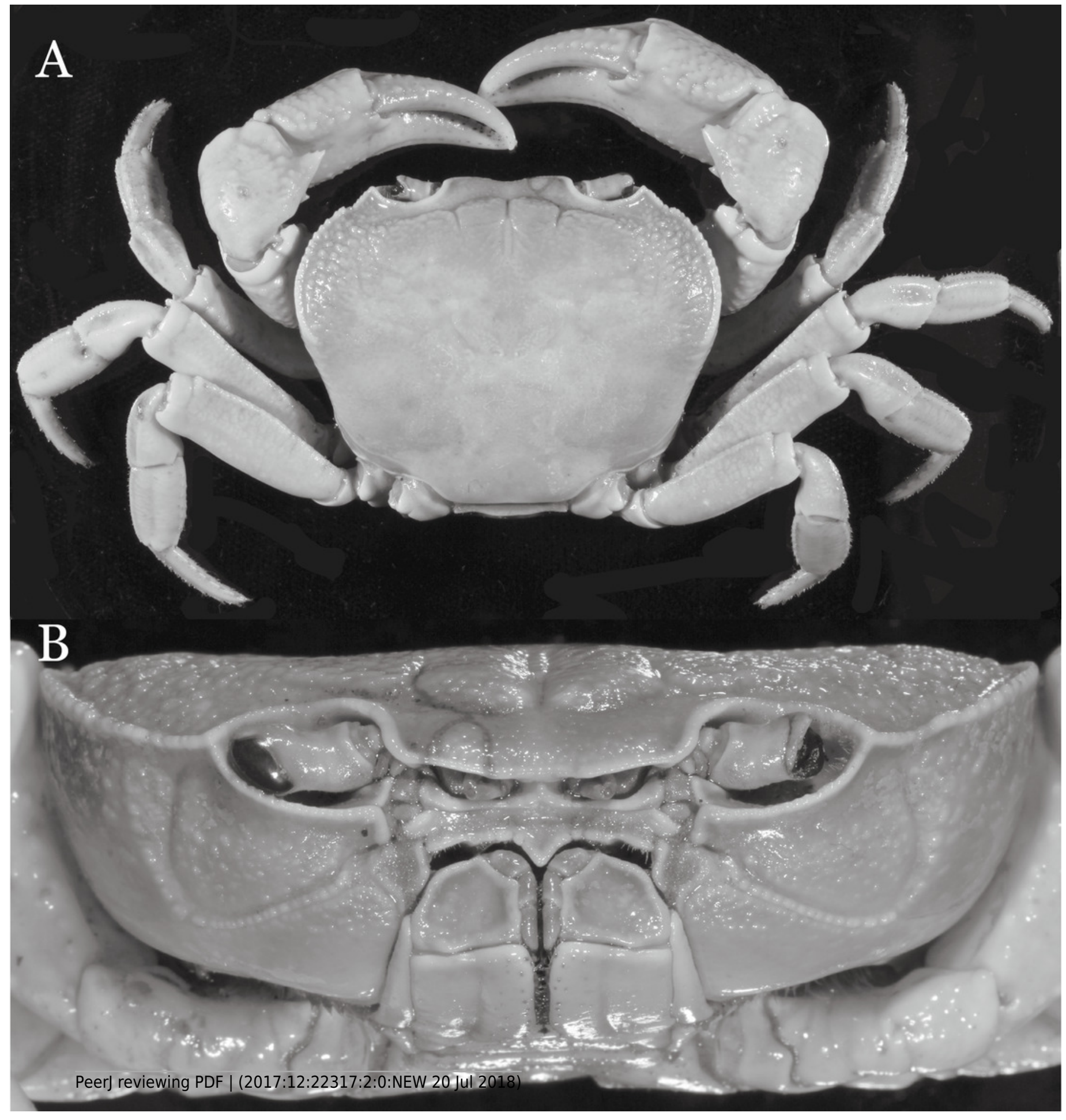


Figure 8

Indochinamon parpidumsp. n. (Holotype, male, NCU MCP 2013.0015, $47.1 \times 36.5$ mm).

A, cephalothorax, ventral view; $B$, right chela, outer view. 


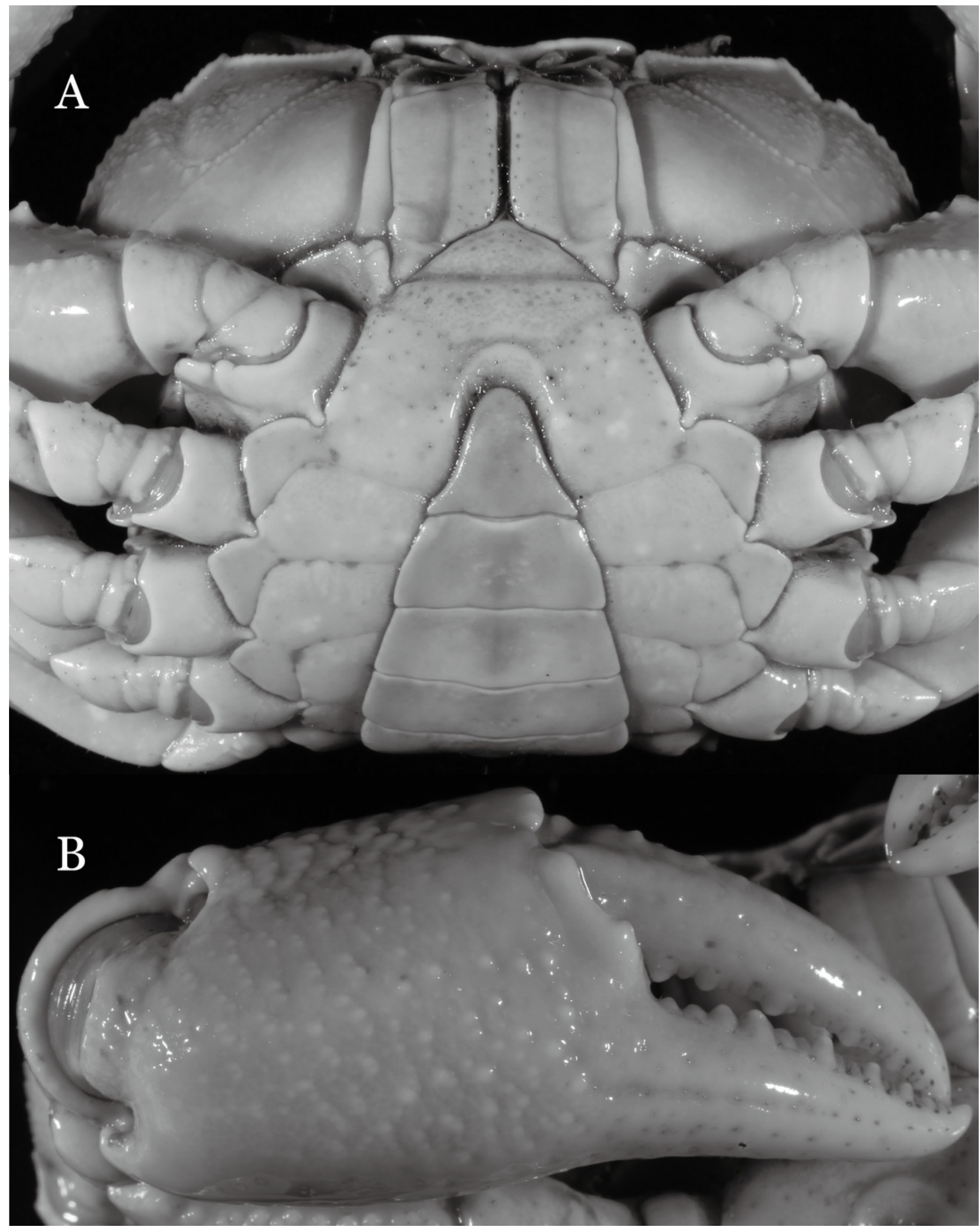


Figure 9

Indochinamon parpidumsp. n. (Holotype, male, NCU MCP 2013.0015, $47.1 \times 36.5$ mm).

A-D, left G1; A, ventral view; B, enlarged view of distal portion, ventral view; C, dorsal view;

$D$, enlarged view of distal portion, dorsal view; E, left G2, ventral view. Scales $=3 \mathrm{~mm}$.

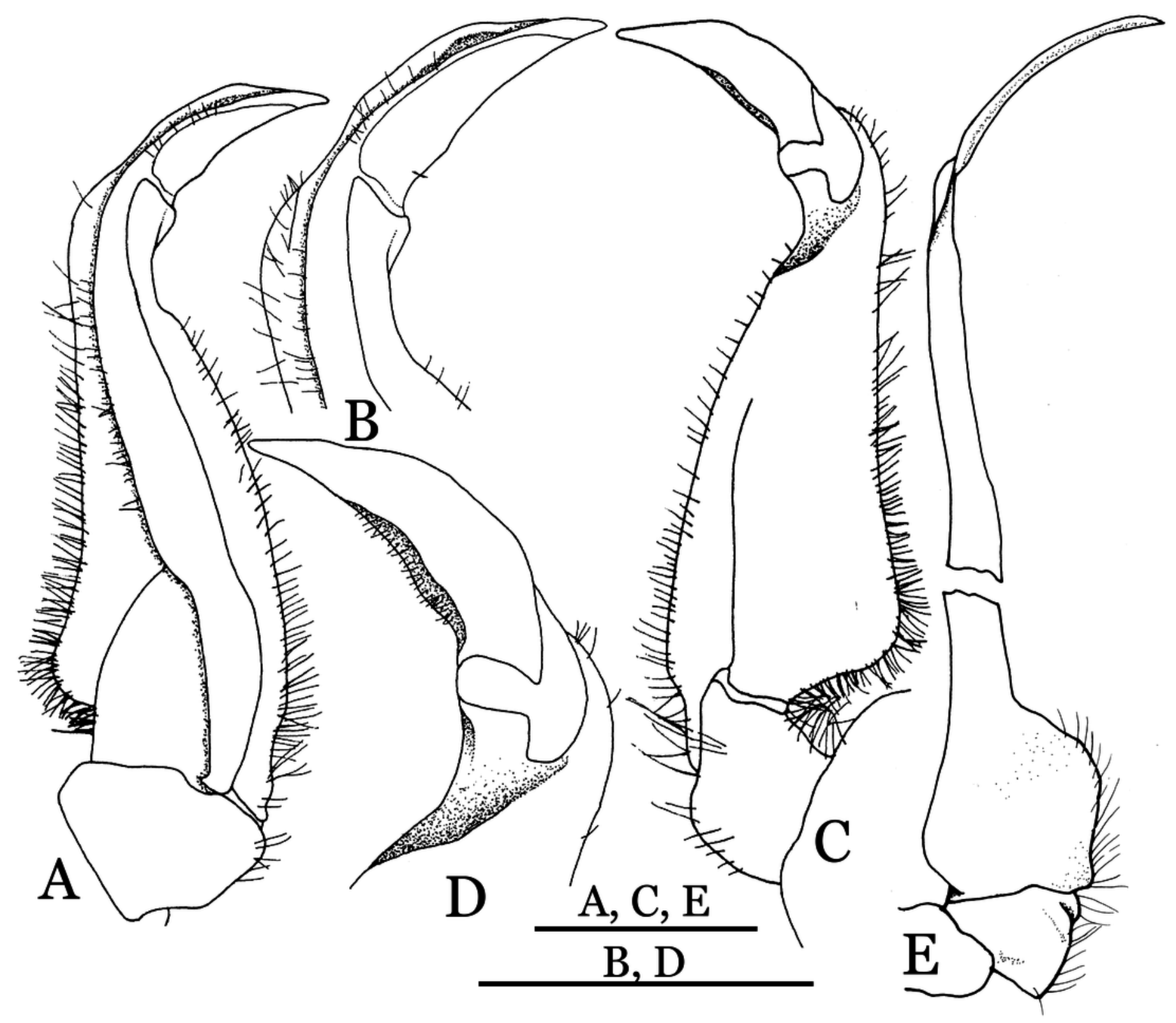




\section{Figure 10}

Indochinamon parpidum sp. n. (Paratype, female, ZRC 2013.0558, $33.0 \times 24.7 \mathrm{~mm}$ ).

Thoracic sternum with vulvae.

*Note: Auto Gamma Correction was used for the image. This only affects the reviewing manuscript. See original source image if needed for review.

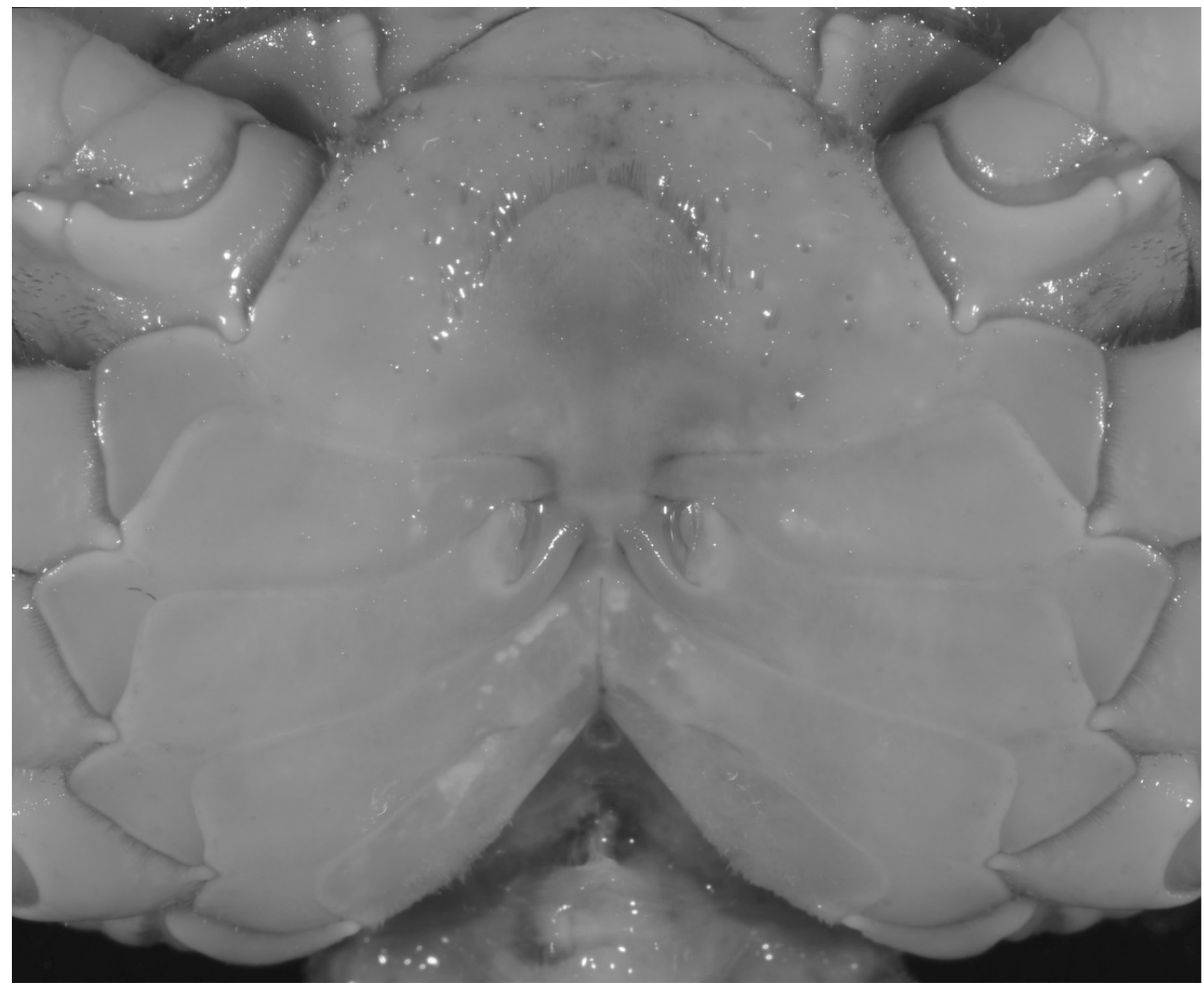




\section{Figure 11}

Indochinamon tujiensesp. n. (Holotype, male, NCU MCP 2013.0005, $45.3 \times 33.2 \mathrm{~mm}$ ).

A, habitus, dorsal view; B, cephalothorax, anterior view.

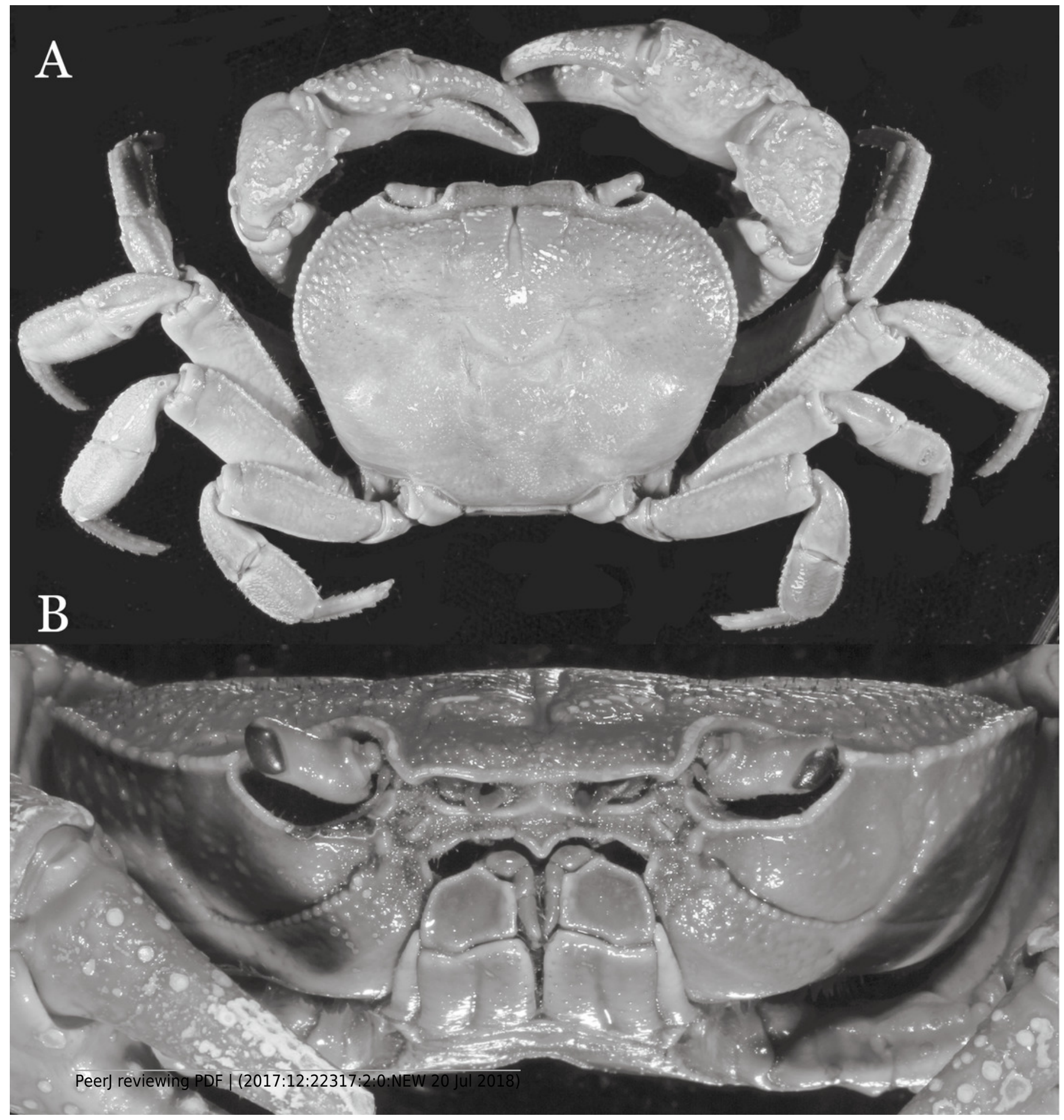


Figure 12

Indochinamon tujiense sp. n. (Holotype, male, NCU MCP 2013.0005, $45.3 \times 33.2 \mathrm{~mm}$ ).

A, cephalothorax, ventral view; B, right chela, outer view. 


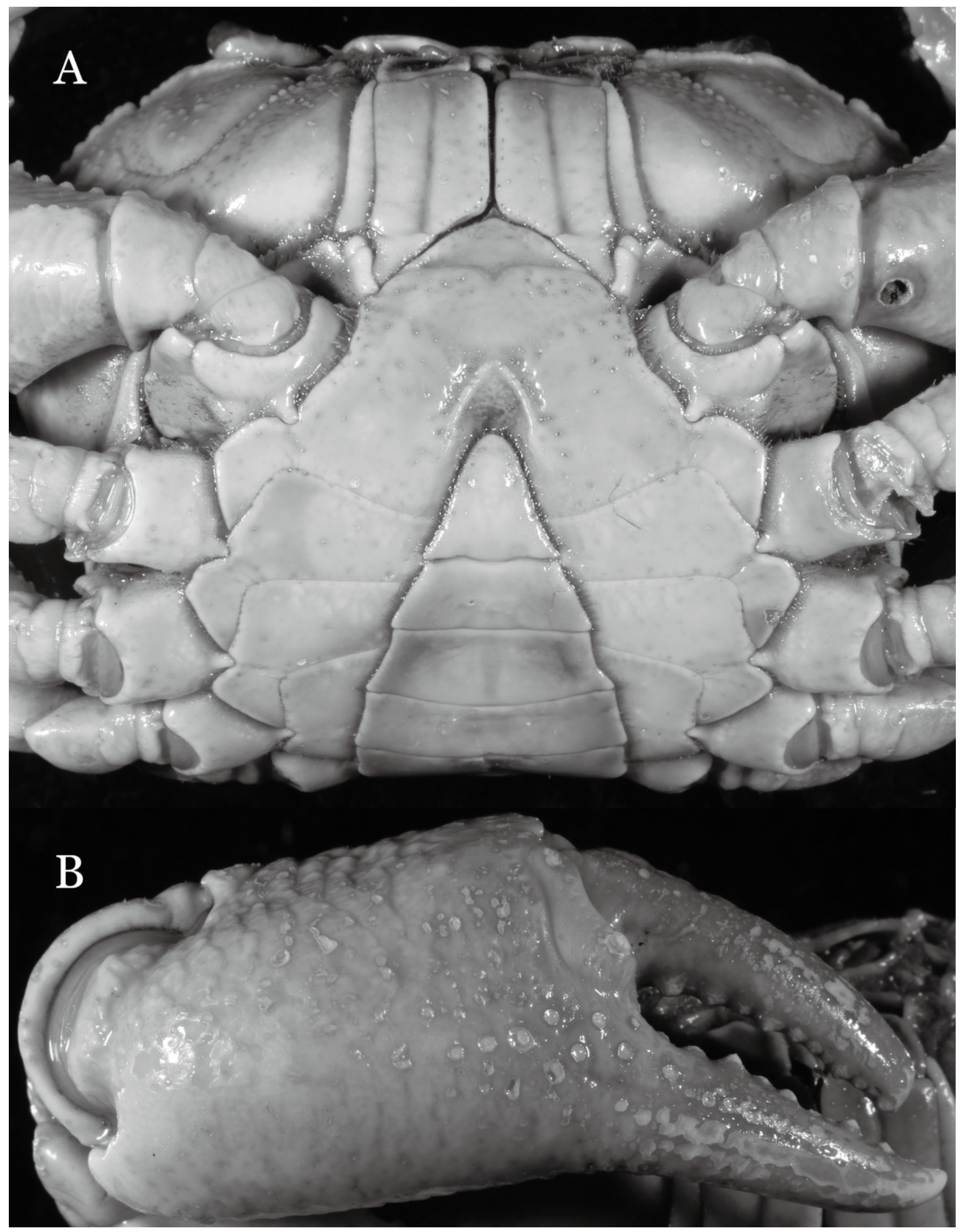


Figure 13

Indochinamon tujiense sp. n. (Holotype, male, NCU MCP 2013.0005, $45.3 \times 33.2 \mathrm{~mm}$ ).

A-D, left G1; A, ventral view; B, enlarged view of distal portion, ventral view; C, dorsal view;

$D$, enlarged view of distal portion, dorsal view; $E$, right $G 2$, ventral view. Scales $=3 \mathrm{~mm}$.

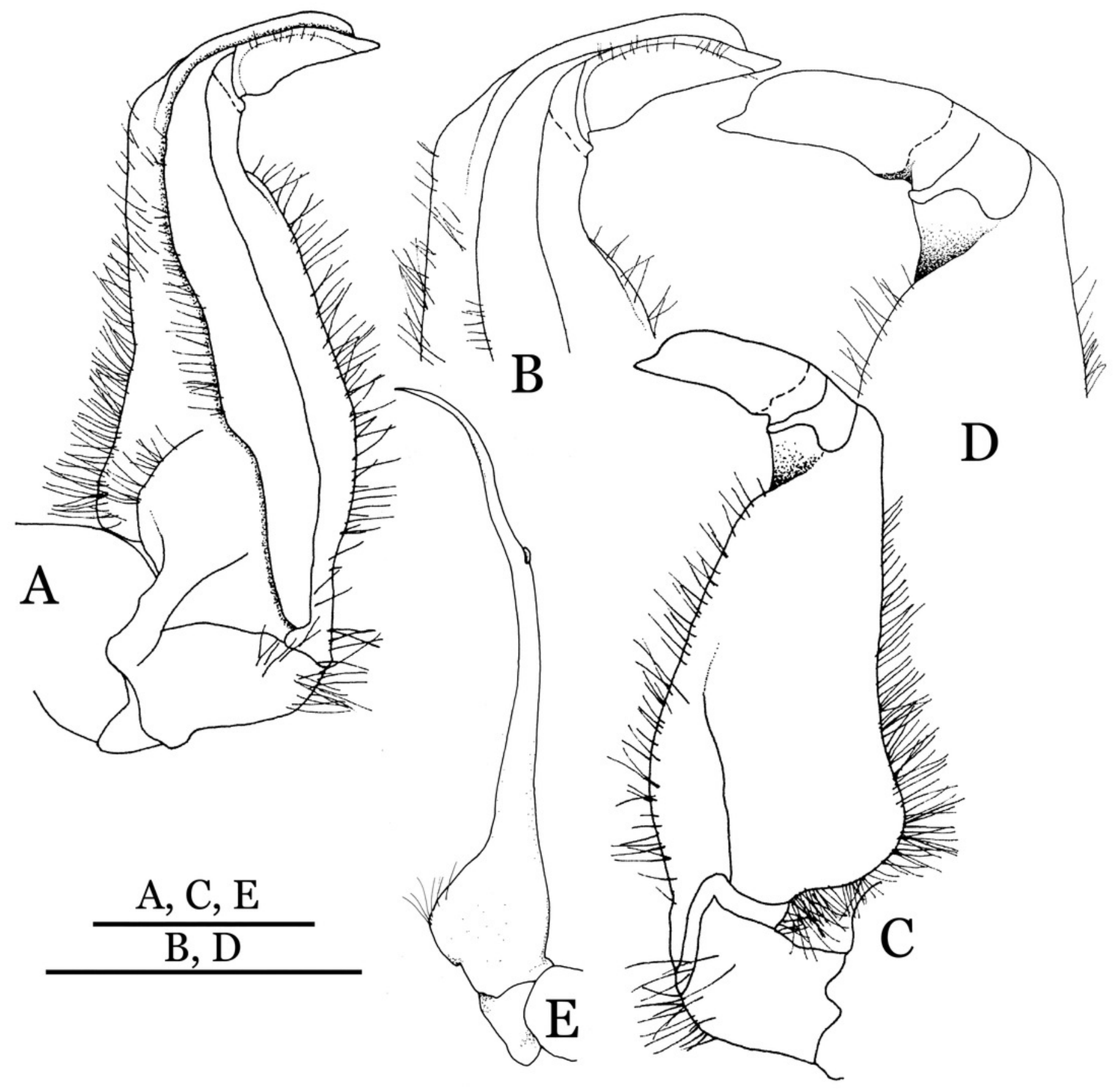




\section{Figure 14}

Indochinamon tujiense sp. n. (Paratype, NCU MCP 2013.0006, 35.6 × $26.7 \mathrm{~mm}$ ).

Thoracic sternum with vulvae.

*Note: Auto Gamma Correction was used for the image. This only affects the reviewing manuscript. See original source image if needed for review.

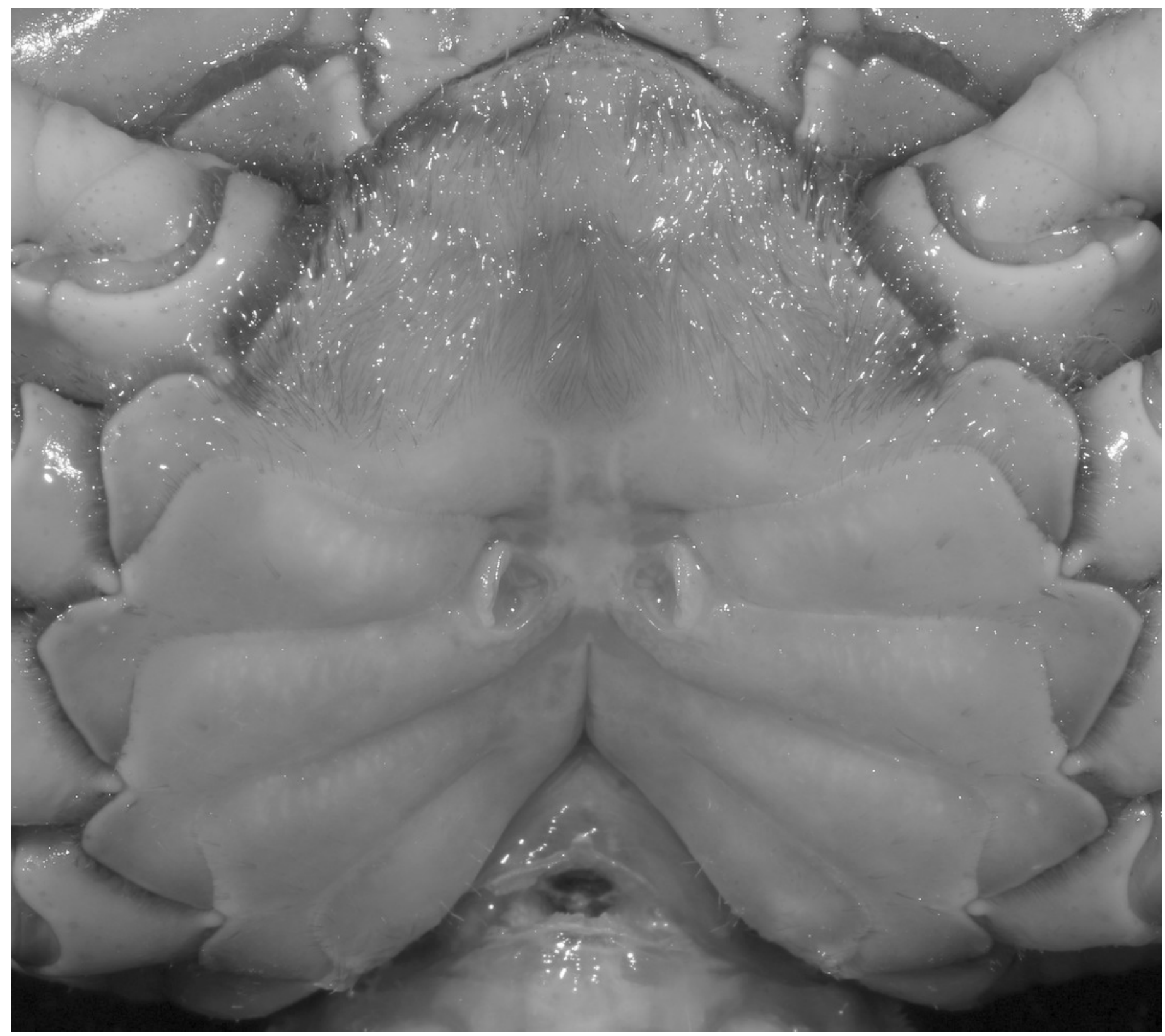




\section{Figure 15}

Indochinamon lui sp. n. (Holotype, male, NCU MCP 2013.0010, $43.0 \times 32.9$ mm).

A, habitus, dorsal view; B, cephalothorax, anterior view.

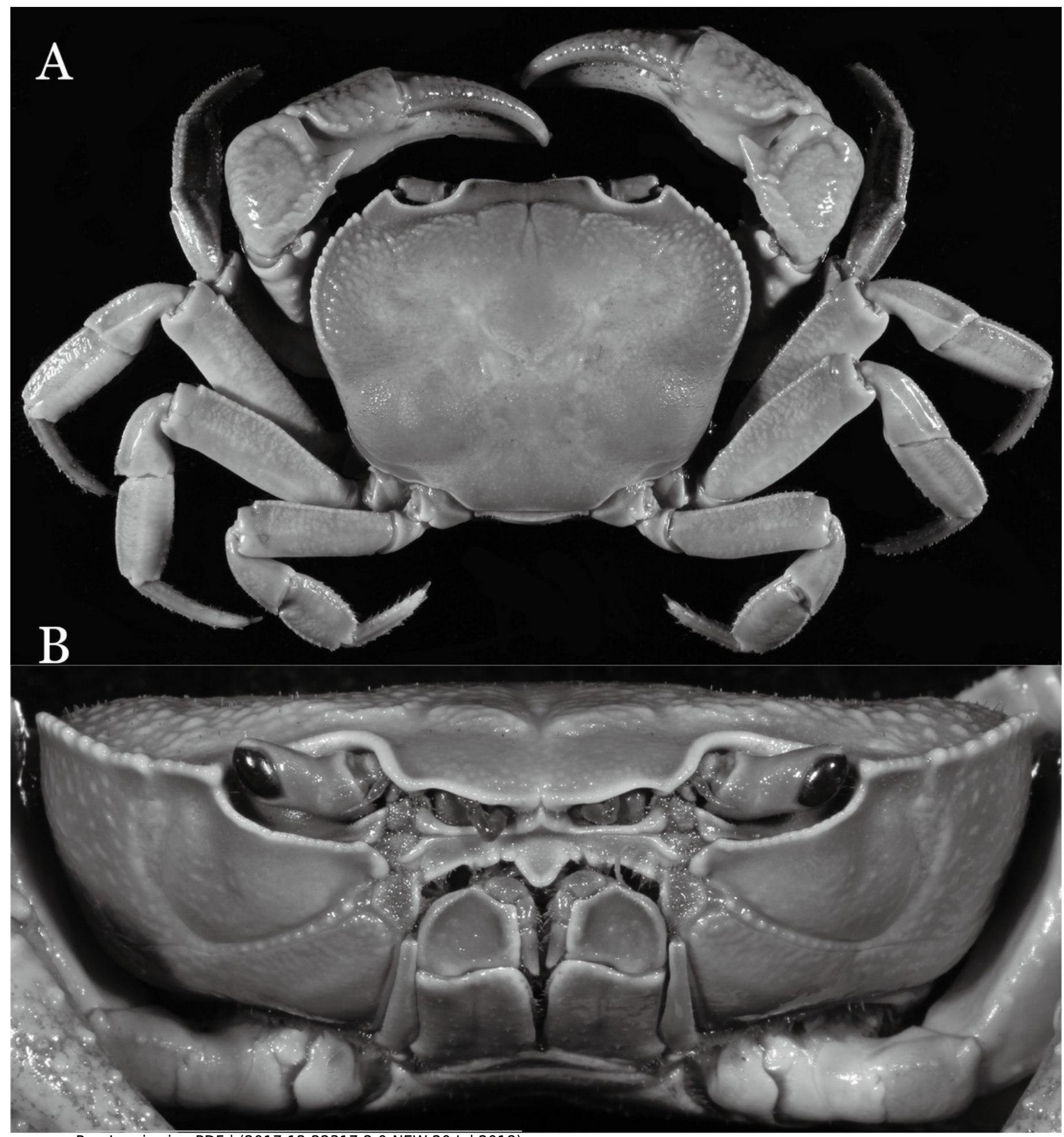


Figure 16

Indochinamon lui sp. n. (Holotype, male, NCU MCP 2013.0010, $43.0 \times 32.9$ mm).

A, cephalothorax, ventral view; B, right chela, outer view. 


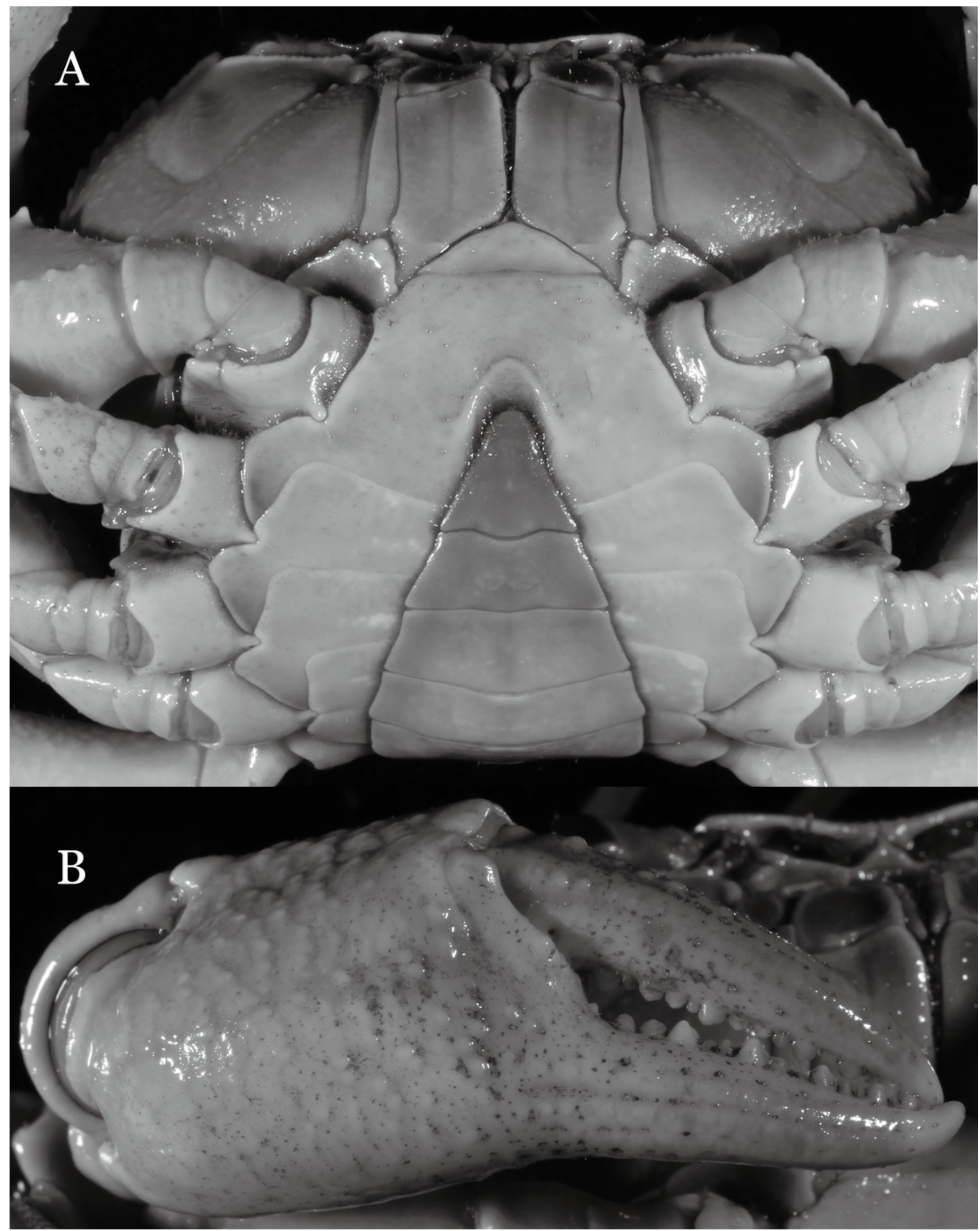


Figure 17

Indochinamon lui sp. n. (Holotype, male, NCU MCP 2013.0010, $43.0 \times 32.9$ mm).

A-D, left G1; A, ventral view; B, enlarged view of distal portion, ventral view; C, dorsal view;

$D$, enlarged view of distal portion, dorsal view; $E$, right $G 2$, ventral view. Scales $=3 \mathrm{~mm}$.

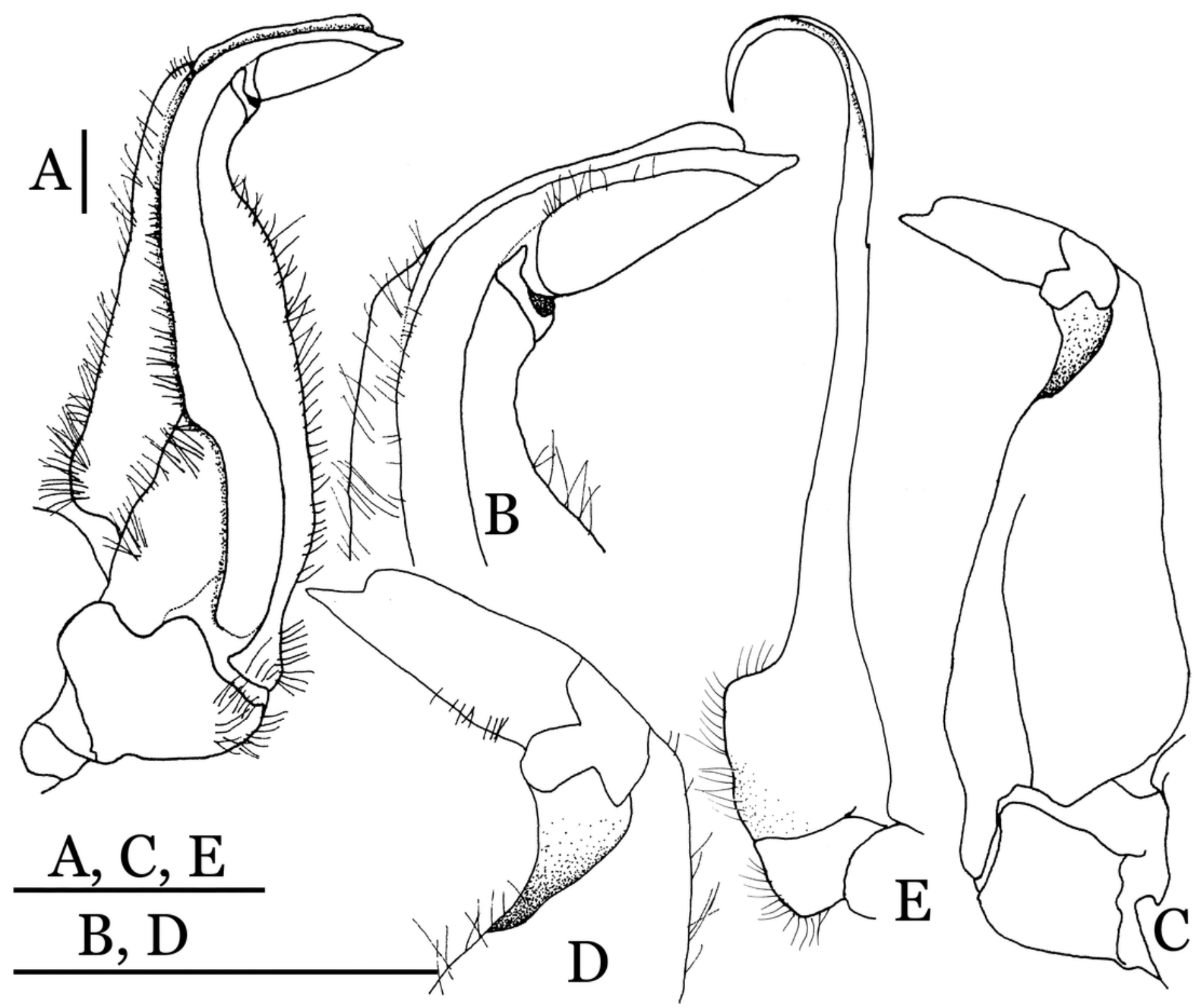




\section{Figure 18}

Indochinamon lui sp. n. (Paratype, RUMF-ZC- 2369, $34.8 \times 26.2 \mathrm{~mm}$ ).

Thoracic sternum with vulvae.

*Note: Auto Gamma Correction was used for the image. This only affects the reviewing manuscript. See original source image if needed for review.

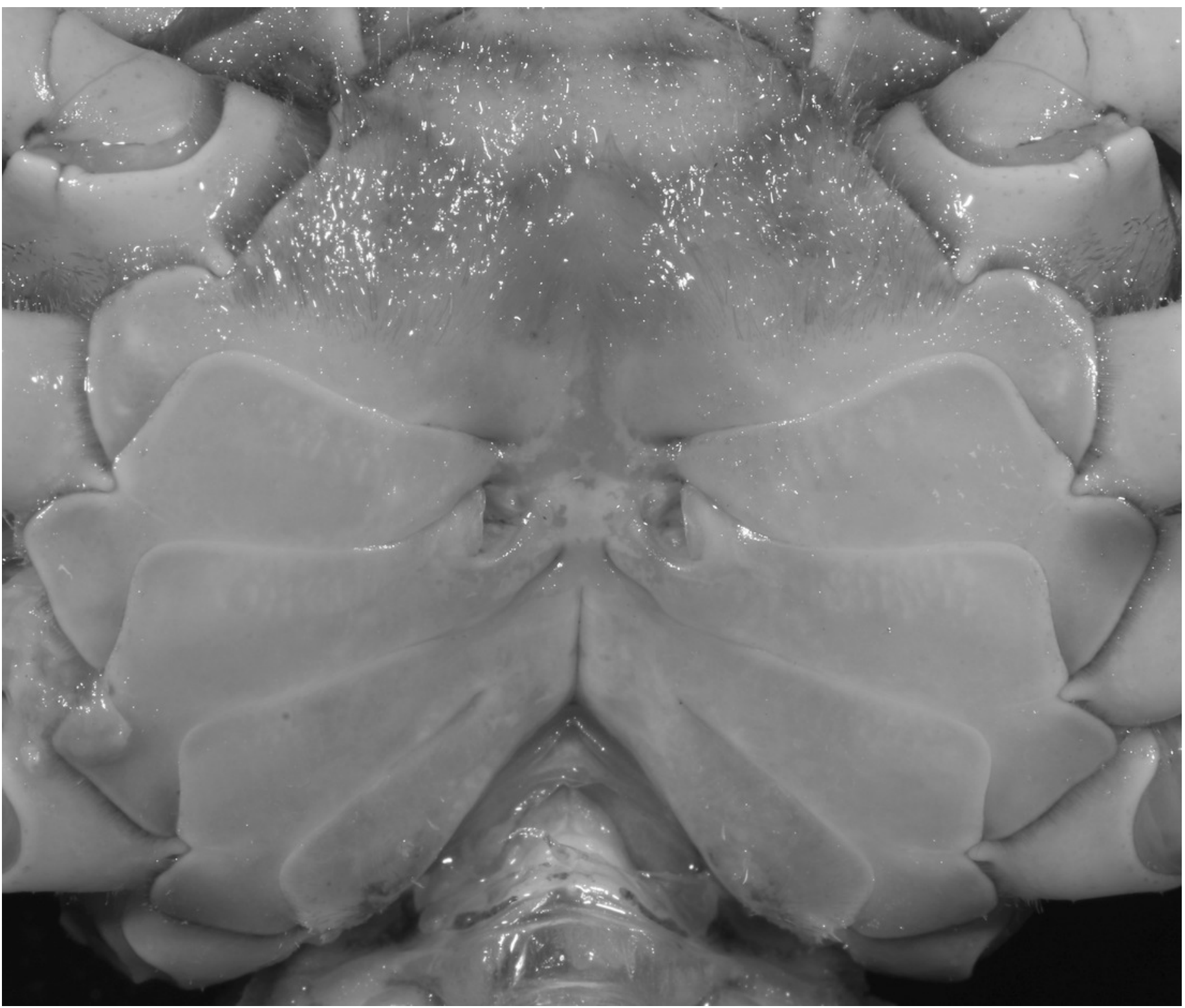




\section{Figure 19}

Dorsal views of habitus (A-D) and ventral views of Gls $(\mathrm{E}-\mathrm{H})$ of comparative species.

A, E, Pararanguna semilunata(Dai \& Chen, 1984) (Holotype, CB05191 HD8183034); B, F, Parvuspotamon yuxienseDai \& Bo, 1994 (Holotype, CB05138 YN 9091116A); C, G, Potamiscus motuoensisDai, 1990 (Holotype, CB05157 XZ6389084); D, H. Potamiscus yongshengensisDai \& Chen, 1985 (Holotype, CB05149 HD 8183035). Photo credit: Chunchao Zhu and Jiexin Zou.

*Note: Auto Gamma Correction was used for the image. This only affects the reviewing manuscript. See original source image if needed for review. 


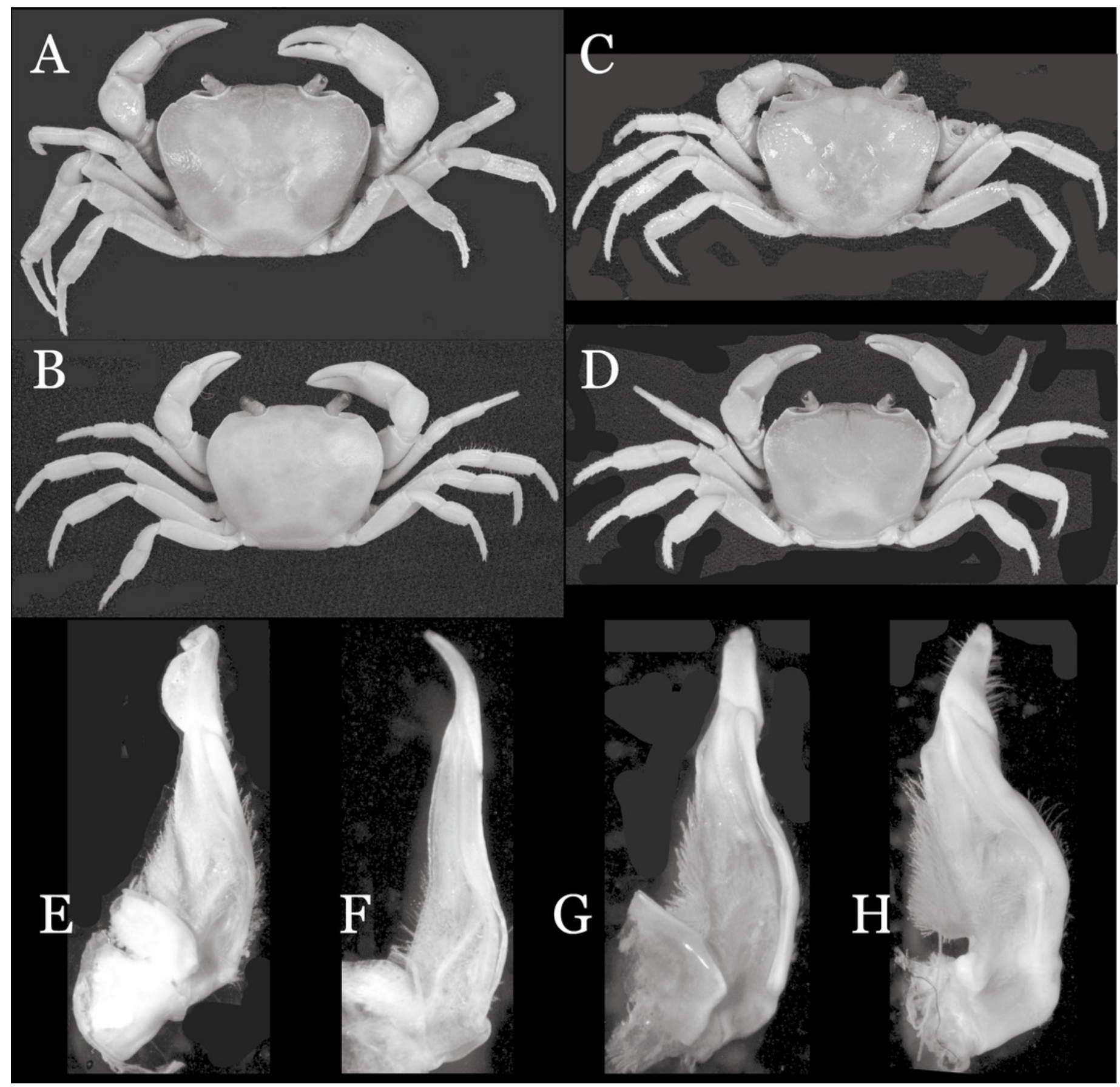




\section{Figure 20}

Pararanguna hemicycliasp. n. (Holotype, male, NCU MCP 2013.0017, $14.3 \times 12.5$ mm).

A, habitus, dorsal view; B, cephalothorax, anterior view. Photo credit: Tohru Naruse

*Note: Auto Gamma Correction was used for the image. This only affects the reviewing manuscript. See original source image if needed for review.

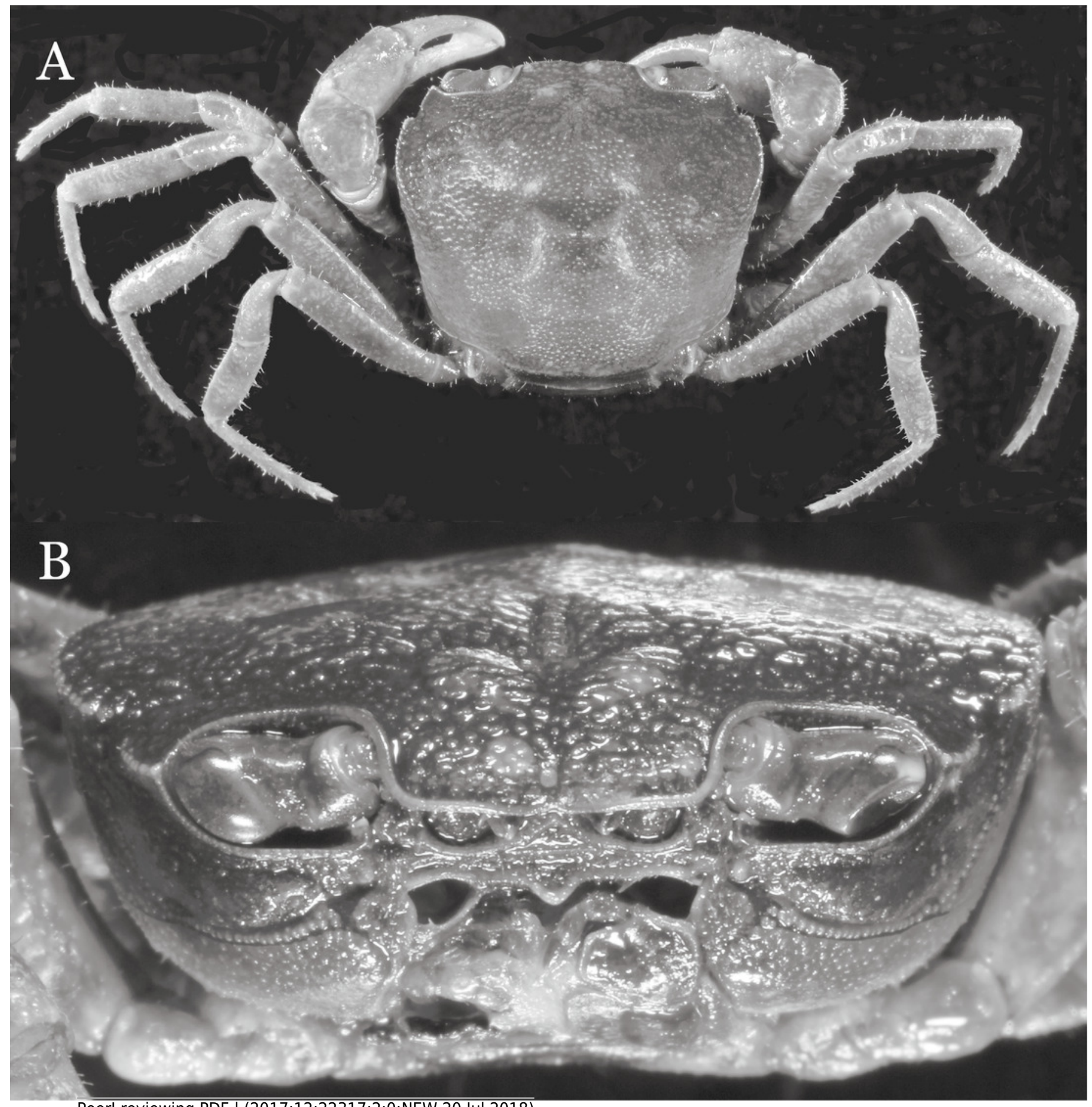




\section{Figure 21}

Pararanguna hemicycliasp. n. (Holotype, male, NCU MCP 2013.0017, $14.3 \times 12.5 \mathrm{~mm}$ ).

Cephalothorax, ventral view. Photo credit: Tohru Naruse.

*Note: Auto Gamma Correction was used for the image. This only affects the reviewing manuscript. See original source image if needed for review.

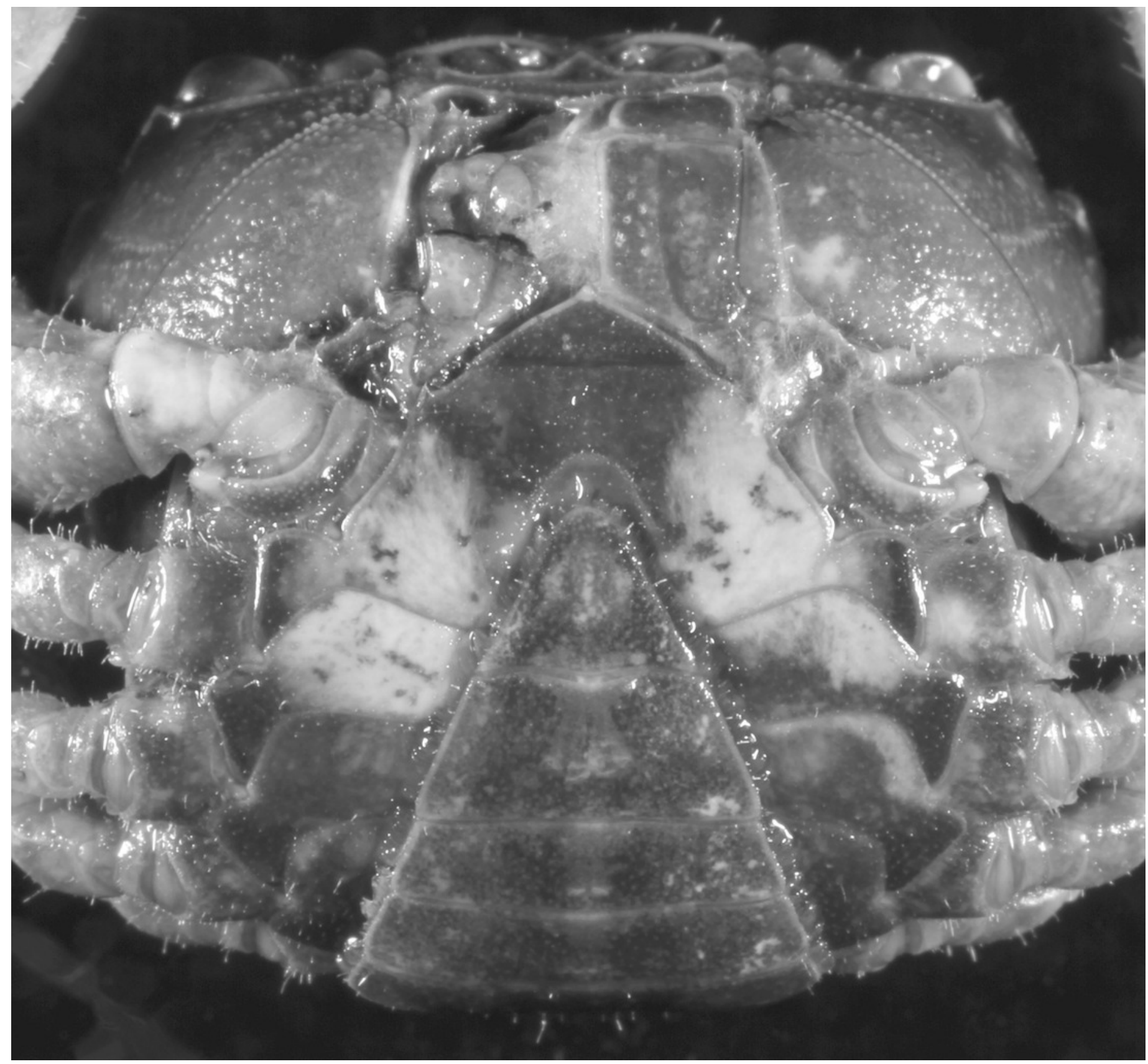


Figure 22

Pararanguna hemicycliasp. n. (Holotype, male, NCU MCP 2013.0017, $14.3 \times 12.5$ mm).

$\mathrm{A}-\mathrm{C}$, right $\mathrm{G} 1 ; \mathrm{A}$, ventral view; $\mathrm{B}$, dorsal view; $\mathrm{C}$, lateral view; $\mathrm{D}$, right $\mathrm{G} 2$, dorsal view. Scale $=$ $1 \mathrm{~mm}$. Drawing credit: Jing En Chia.
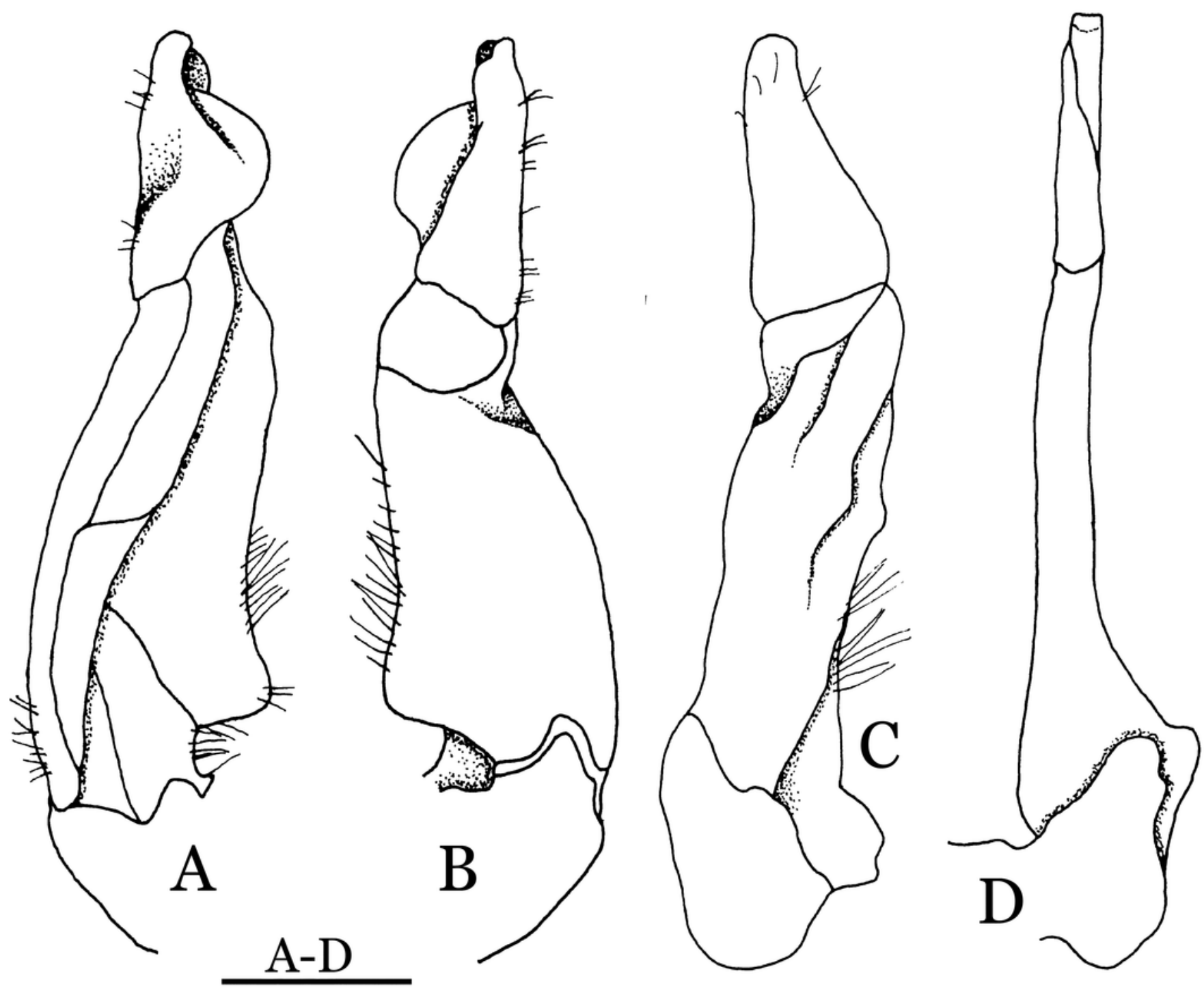


\section{Figure 23}

Pararanguna hemicycliasp. n. (Paratype, female, NCU MCP 2013.0018, $15.9 \times 13.4 \mathrm{~mm}$ ).

Thoracic sternum with vulvae. Photo credit: Tohru Naruse.

*Note: Auto Gamma Correction was used for the image. This only affects the reviewing manuscript. See original source image if needed for review.

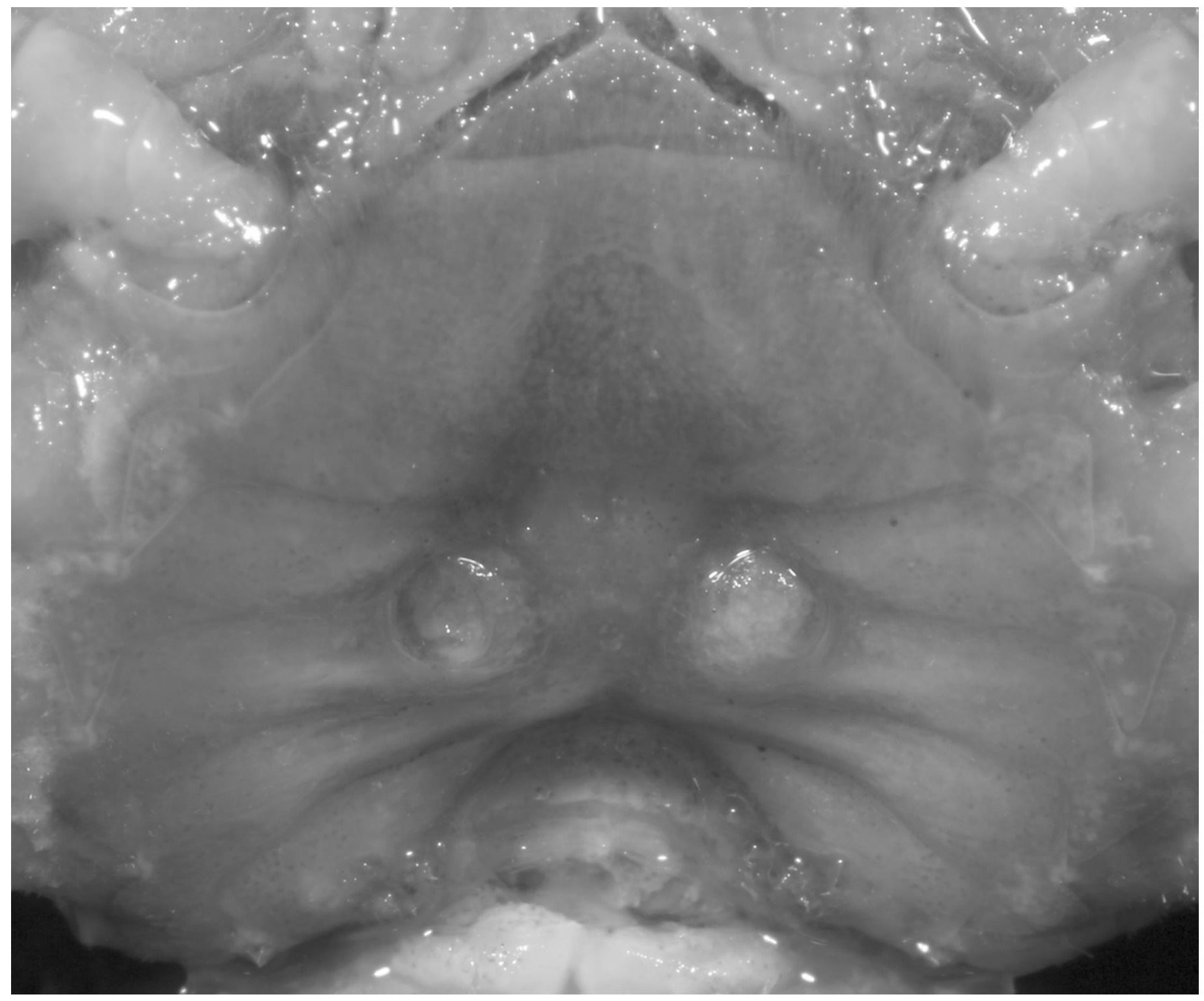




\section{Figure 24}

Parvuspotamon dixuense sp. n. (Holotype, male, NCU MCP 2013.0020, $25.7 \times 20.0$ $\mathrm{mm})$.
A, habitus, dorsal view; B, cephalothorax, anterior view.

*Note: Auto Gamma Correction was used for the image. This only affects the reviewing manuscript. See original source image if needed for review. 


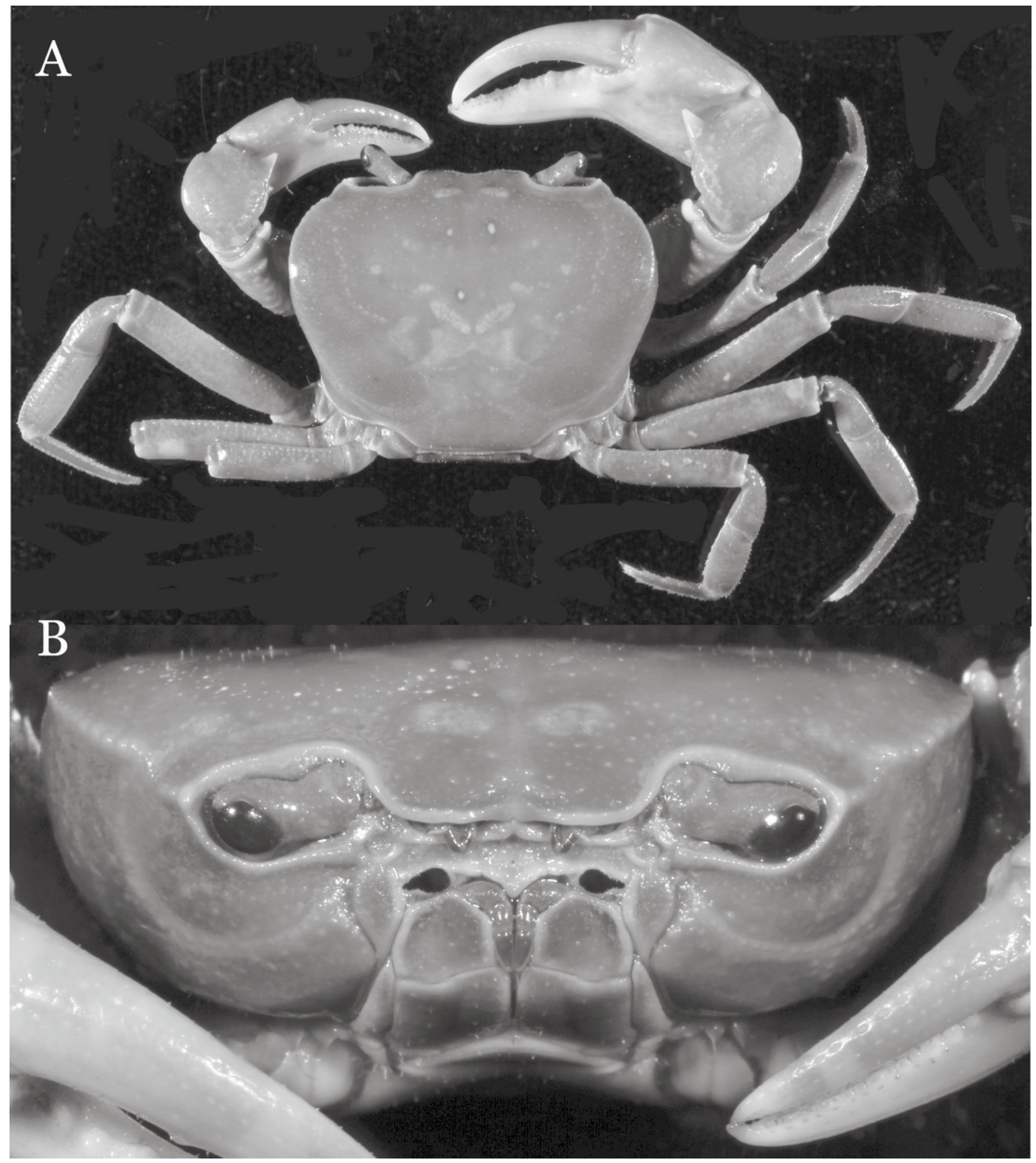




\section{Figure 25}

Parvuspotamon dixuense sp. n. (Holotype, male, NCU MCP 2013.0020, $25.7 \times 20.0$ $\mathrm{mm})$.

A, cephalothorax, ventral view; B, right chela, outer view.

*Note: Auto Gamma Correction was used for the image. This only affects the reviewing manuscript. See original source image if needed for review. 


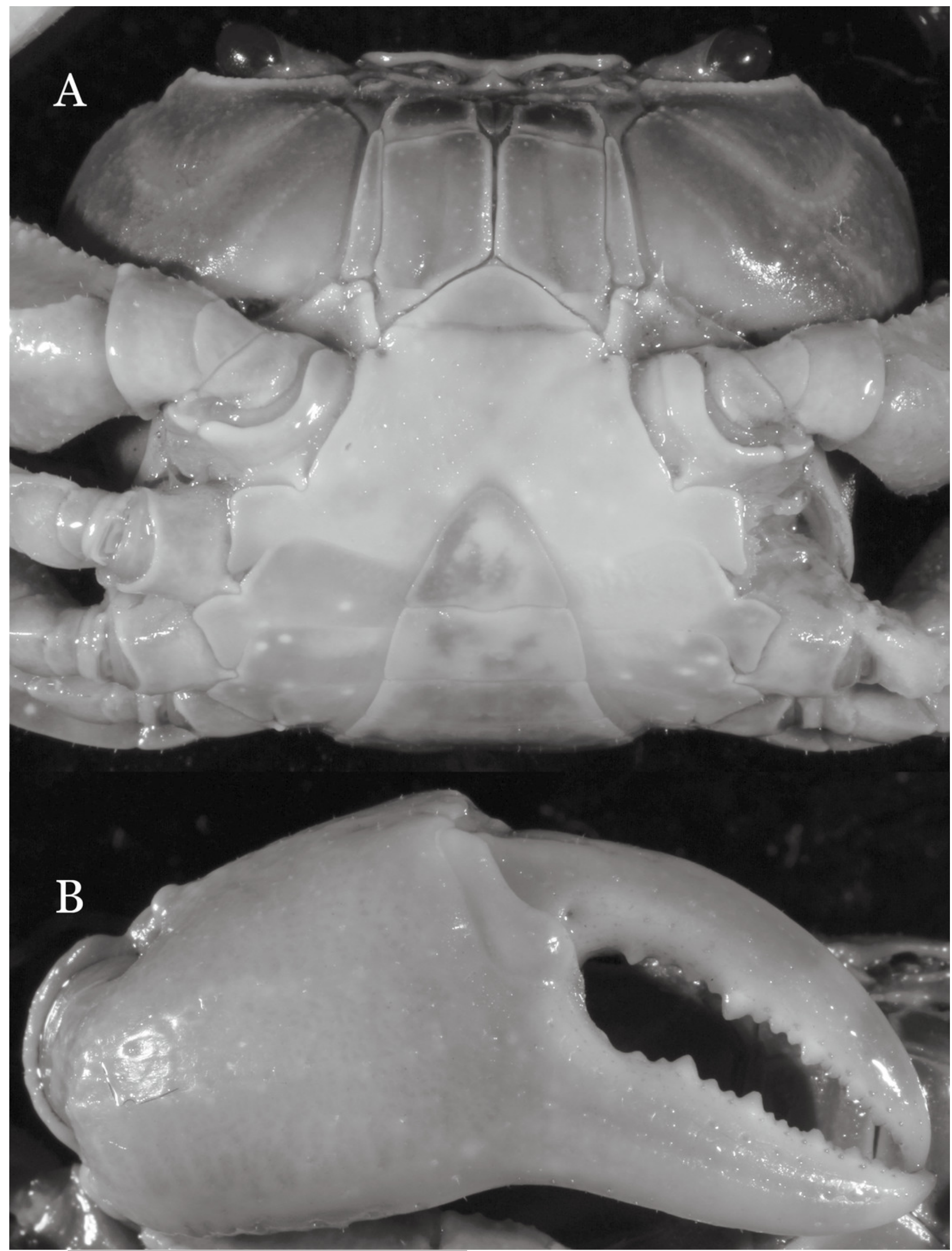


Figure 26

Parvuspotamon dixuense sp. n. (Holotype, male, NCU MCP 2013.0020, $25.7 \times 20.0$ $\mathrm{mm})$.

$A-D$, right $G 1 ; A$, ventral view; $B$, enlarged view of distal portion, ventral view; $C$, dorsal view;

$D$, enlarged view of distal portion, dorsal view; $E$, right $\mathrm{G} 2$, dorsal view. Scales $=1 \mathrm{~mm}$.
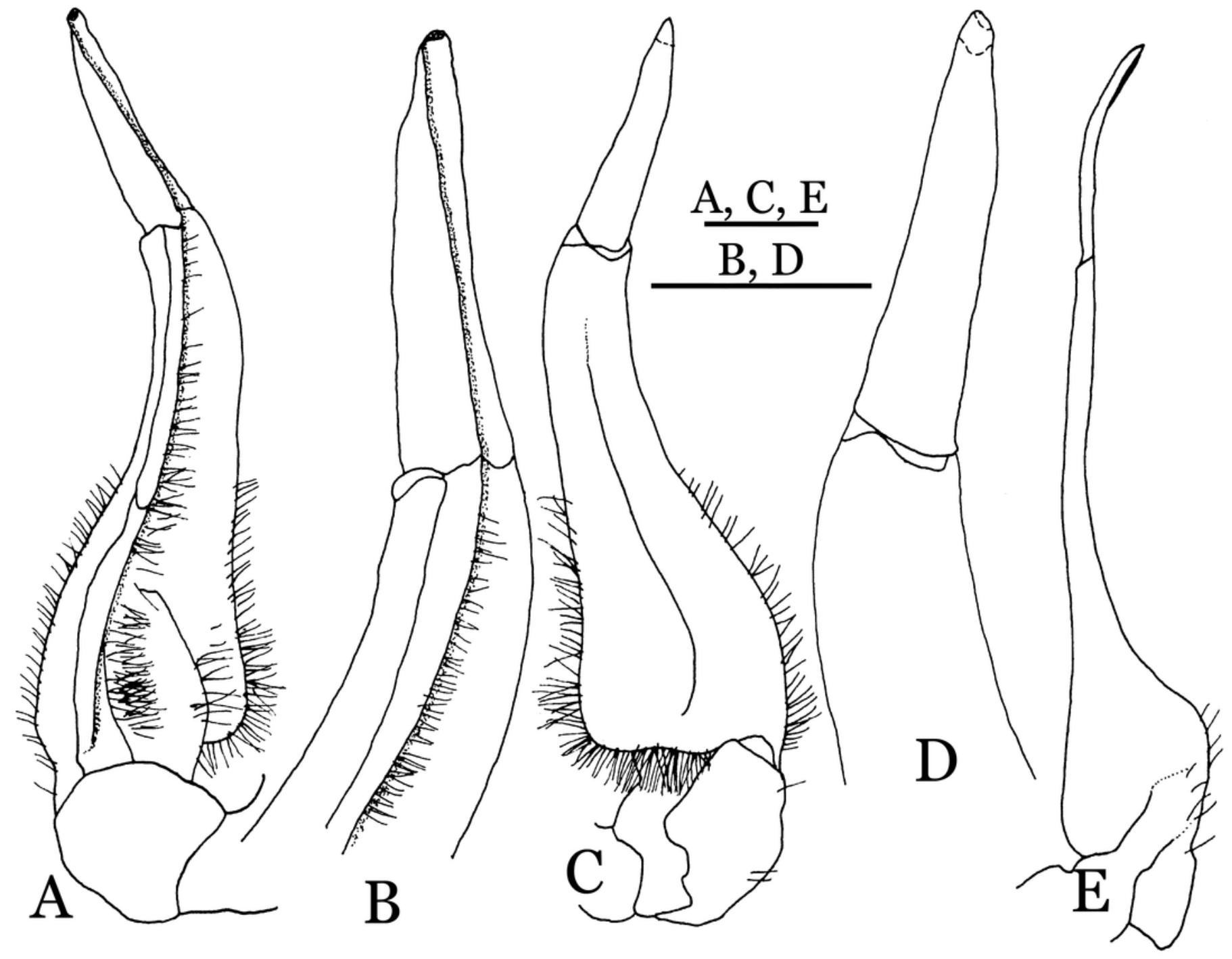


\section{Figure 27}

Parvuspotamon dixuense sp. n. (Paratype, female, NCU MCP 2013.0021, $23.1 \times 17.8$ $\mathrm{mm})$.

Thoracic sternum with vulvae.

*Note: Auto Gamma Correction was used for the image. This only affects the reviewing manuscript. See original source image if needed for review.

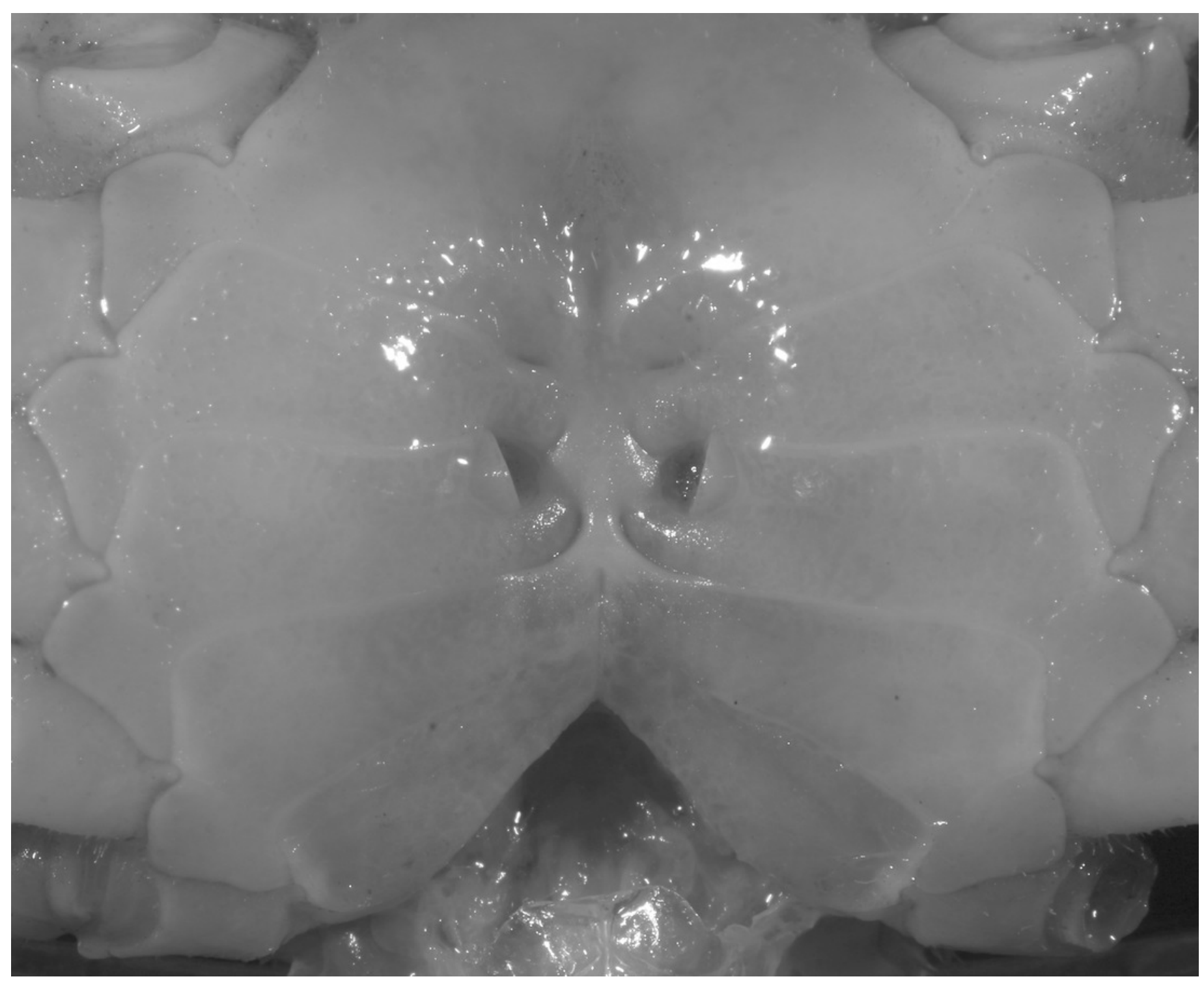




\section{Figure 28}

Potamiscus fumariatus sp. n.(Holotype, male, NCU MCP 2013.0024, $24.1 \times 20.1 \mathrm{~mm}$ ).

A, habitus, dorsal view; B, cephalothorax, anterior view.

*Note: Auto Gamma Correction was used for the image. This only affects the reviewing manuscript. See original source image if needed for review. 

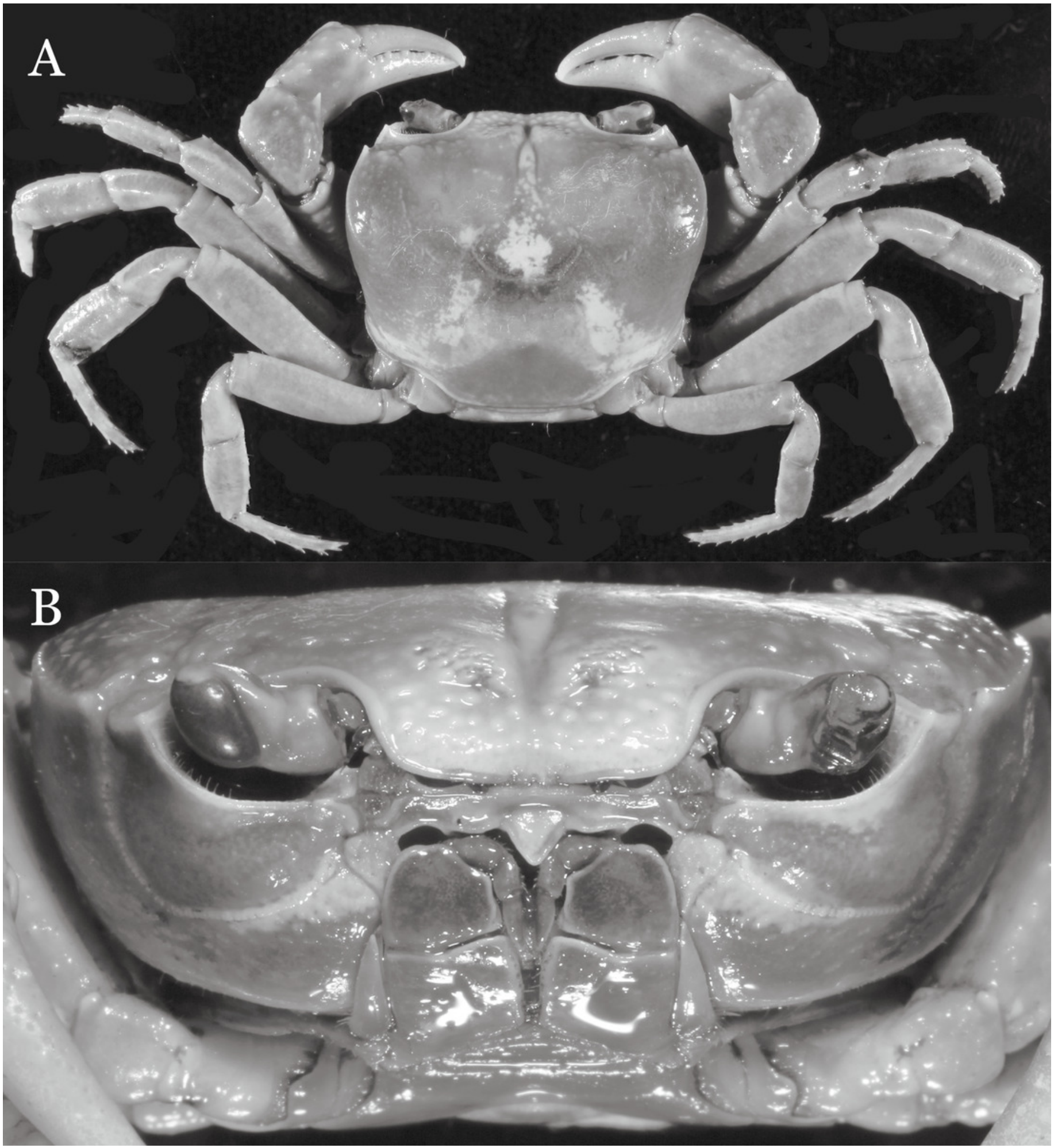
Figure 29

Potamiscus fumariatus sp. n.(Holotype, male, NCU MCP 2013.0024, $24.1 \times 20.1 \mathrm{~mm}$ ).

A, cephalothorax, ventral view; B, right chela, outer view. 


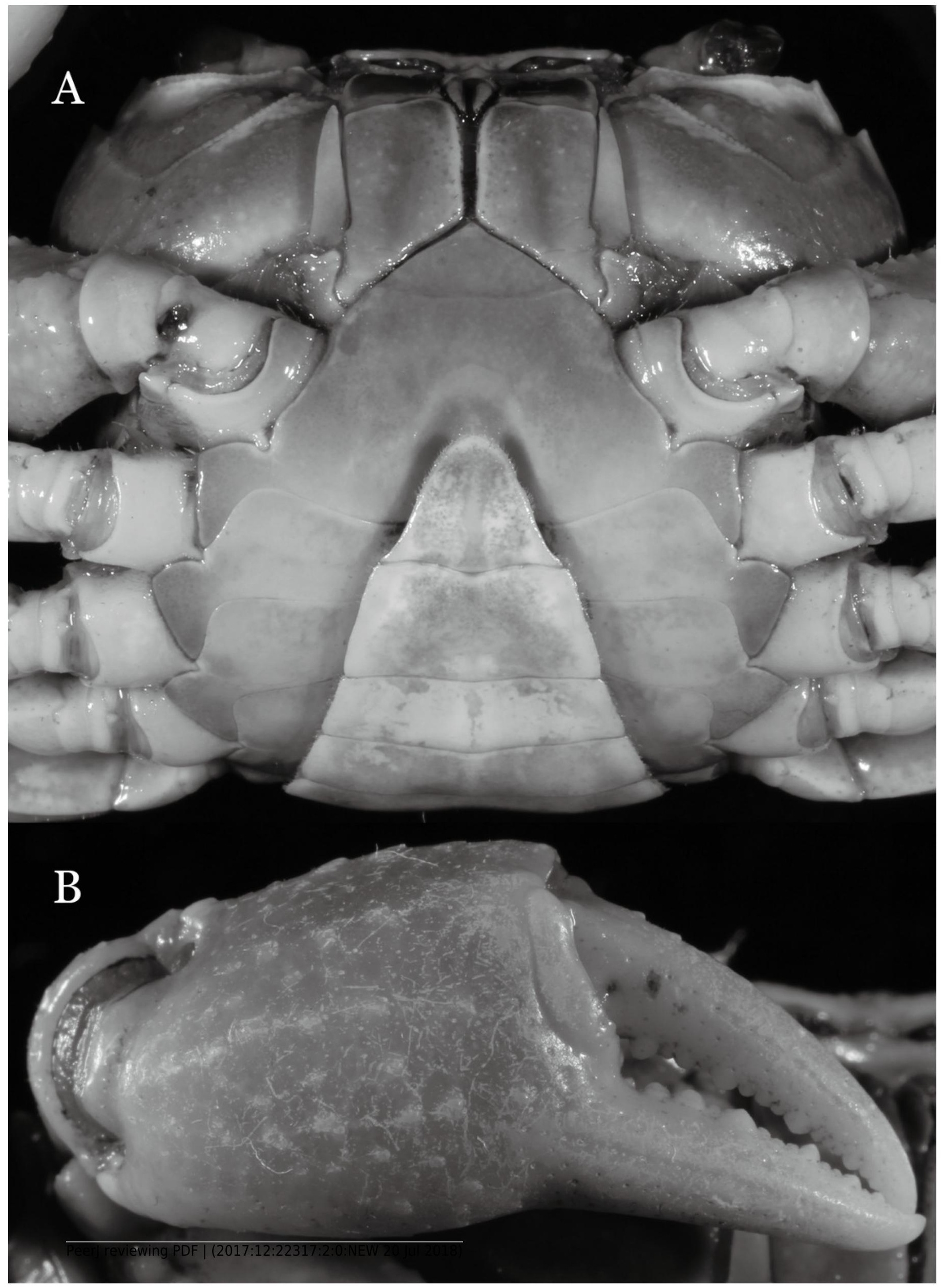


Figure 30

Potamiscus fumariatus sp. n.(Holotype, male, NCU MCP 2013.0024, $24.1 \times 20.1 \mathrm{~mm}$ ).

A-D, left G1; A, ventral view; B, enlarged view of distal portion, ventral view; C, dorsal view;

$D$, enlarged view of distal portion, dorsal view; E, left G2, dorsal view. Scales $=1 \mathrm{~mm}$.

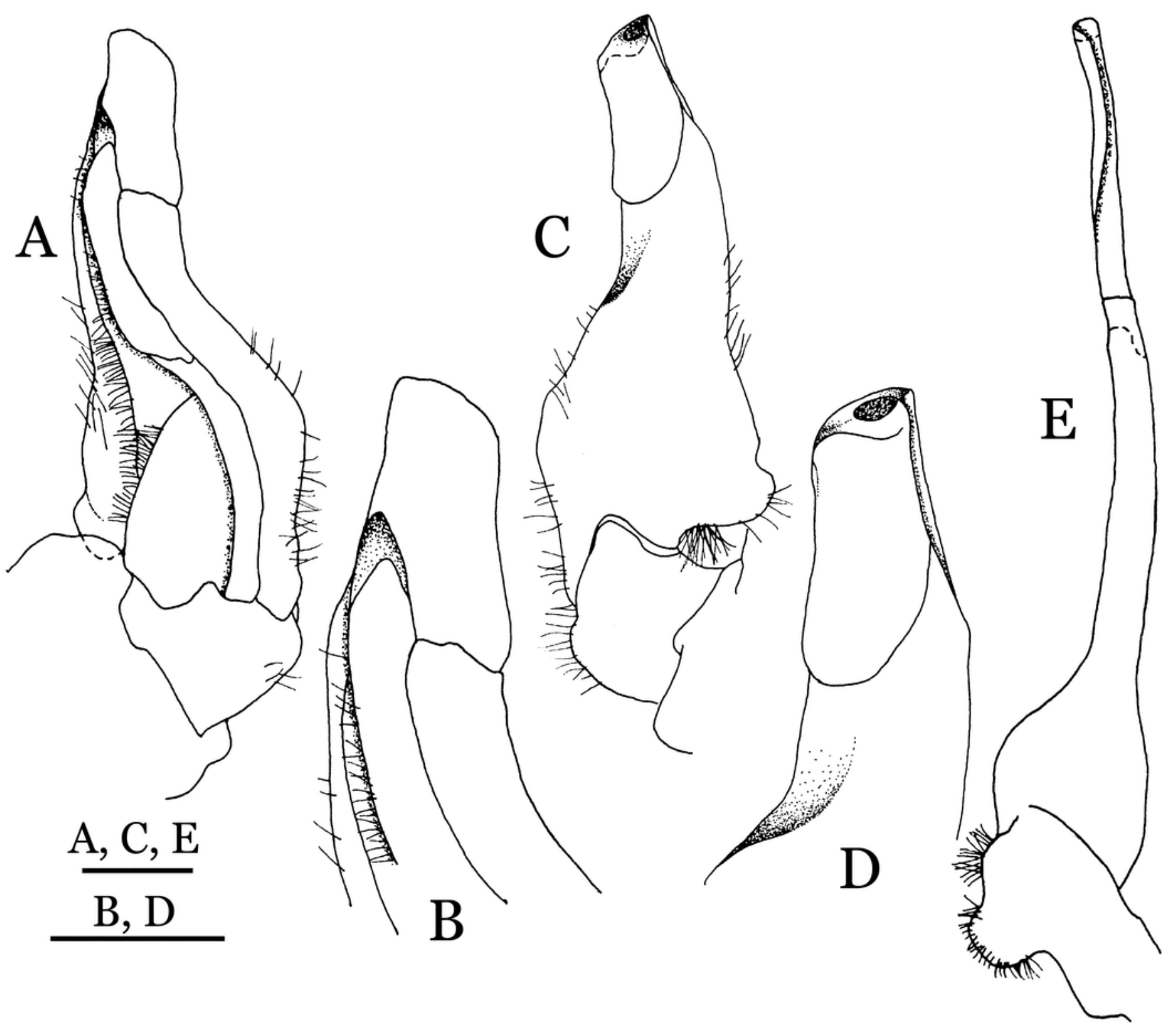




\section{Figure 31}

Potamiscus crassus sp. n. (Holotype, male, NCU MCP 2013.0025, $28.0 \times 23.6$ mm).

A, habitus, dorsal view; B, cephalothorax, anterior view.

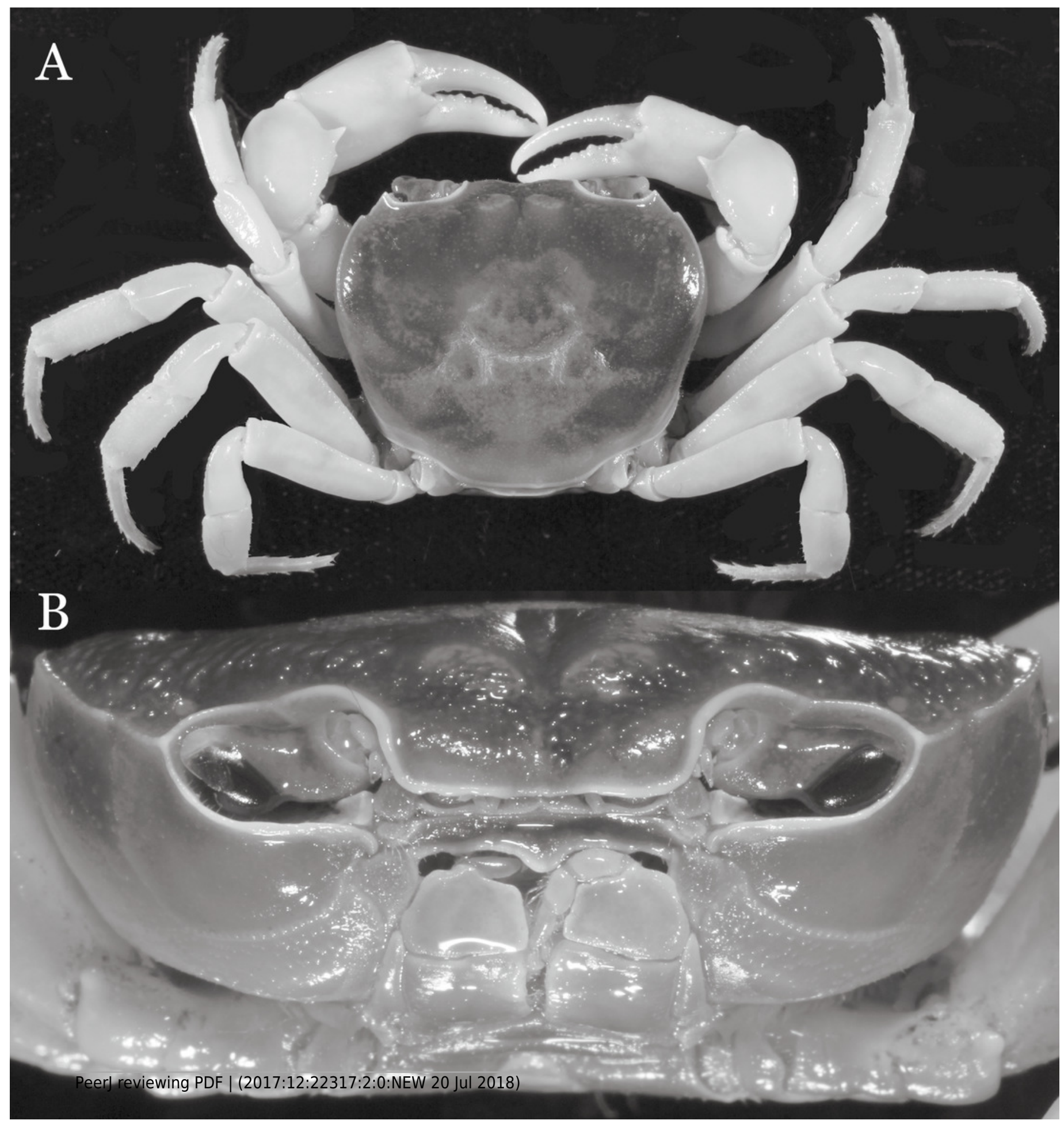


Figure 32

Potamiscus crassus sp. n. (Holotype, male, NCU MCP 2013.0025, $28.0 \times 23.6 \mathrm{~mm}$ ).

A, cephalothorax, ventral view; B, left chela, outer view. 


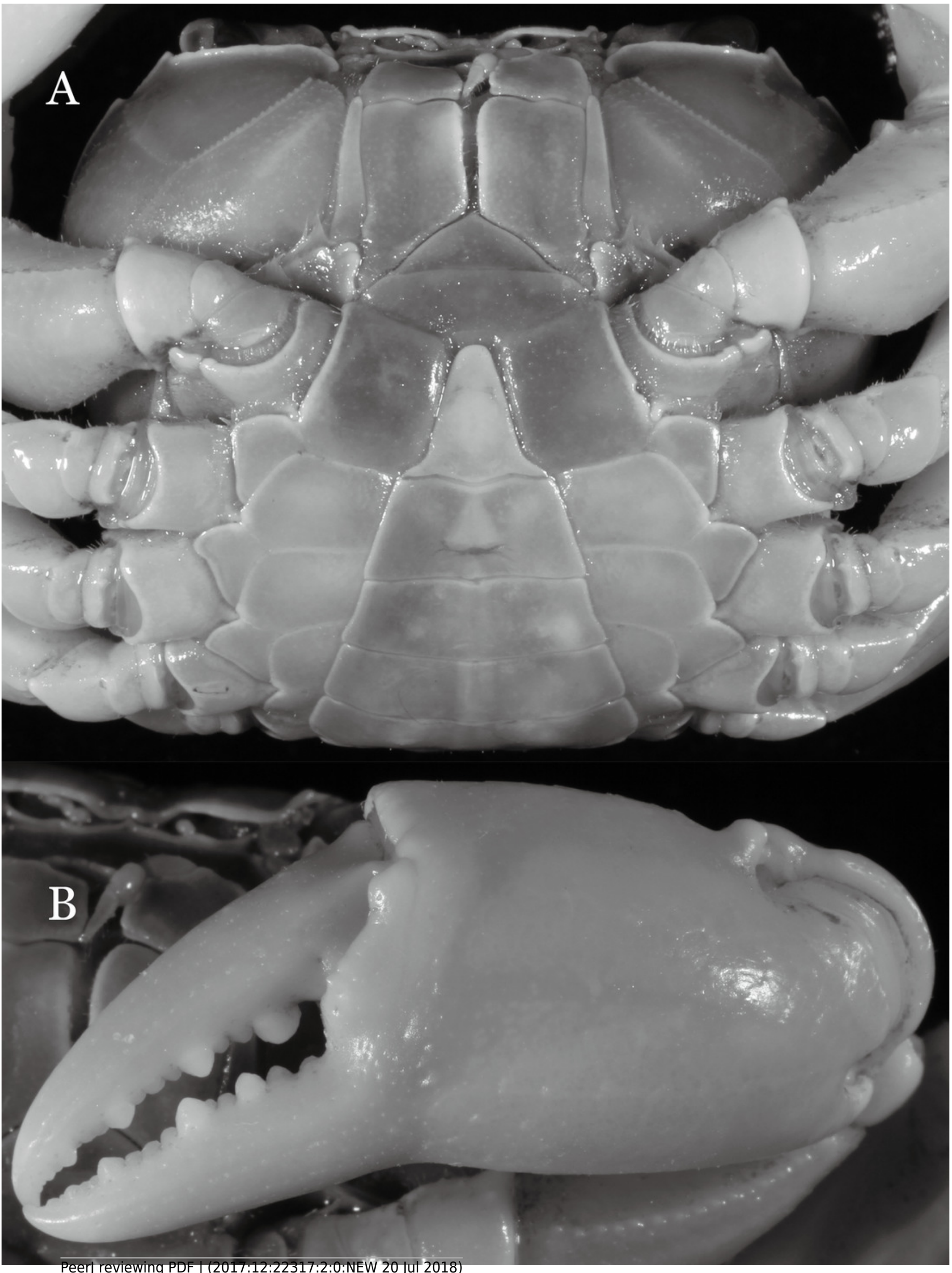


Figure 33

Potamiscus crassus sp. n. (Holotype, male, NCU MCP 2013.0025, $28.0 \times 23.6$ mm).

$A-D$, right $G 1 ; A$, ventral view; $B$, enlarged view of distal portion, ventral view; C, dorsal view;

$D$, enlarged view of distal portion, dorsal view; $E$, right $G 2$, dorsal view. Scales $=3 \mathrm{~mm}$.

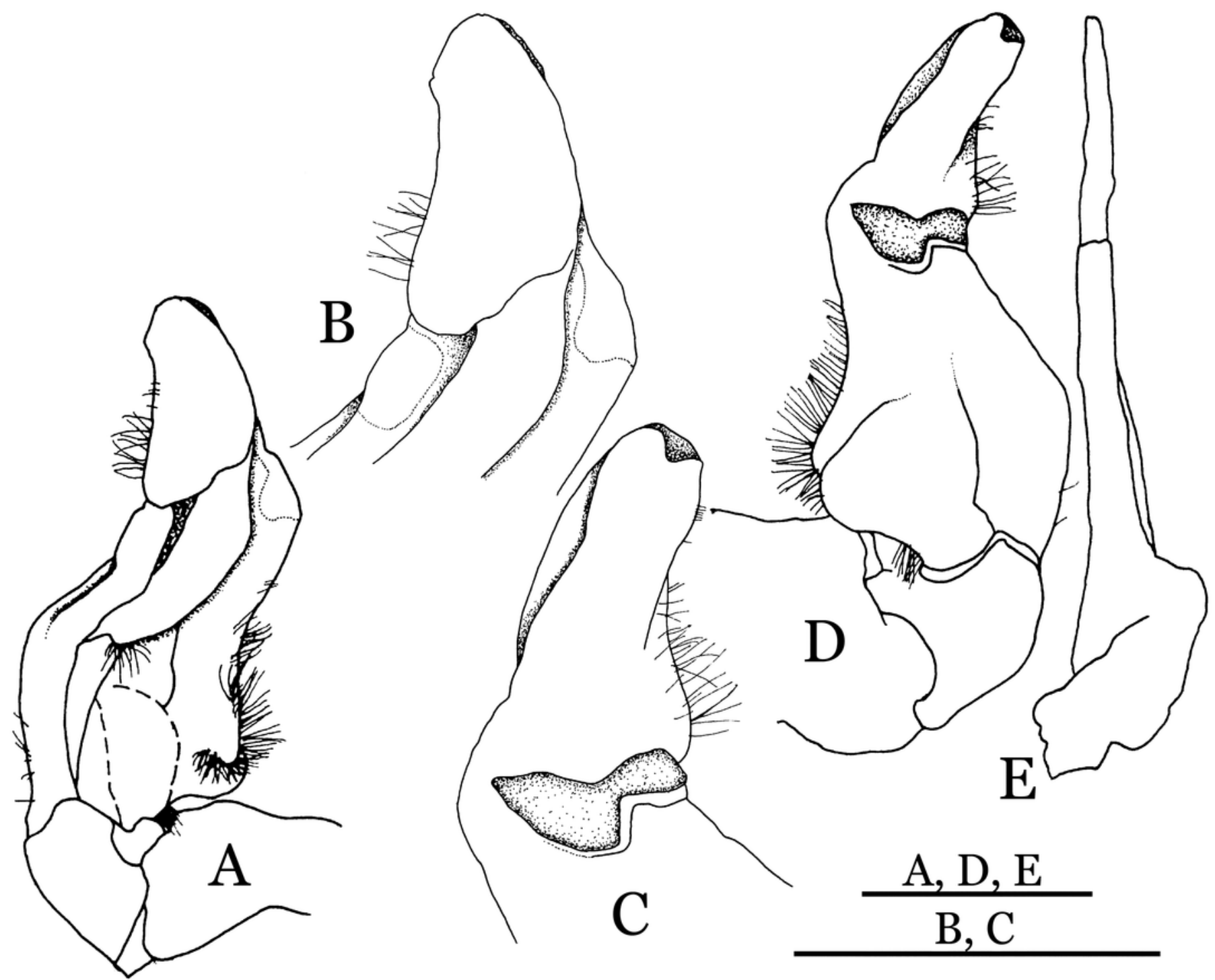




\section{Figure 34}

Potamiscus crassus sp. n. (Paratype, female, ZRC 2013.0562, $22.7 \times 18.2 \mathrm{~mm}$ ).

Thoracic sternum with vulvae.

*Note: Auto Gamma Correction was used for the image. This only affects the reviewing manuscript. See original source image if needed for review.

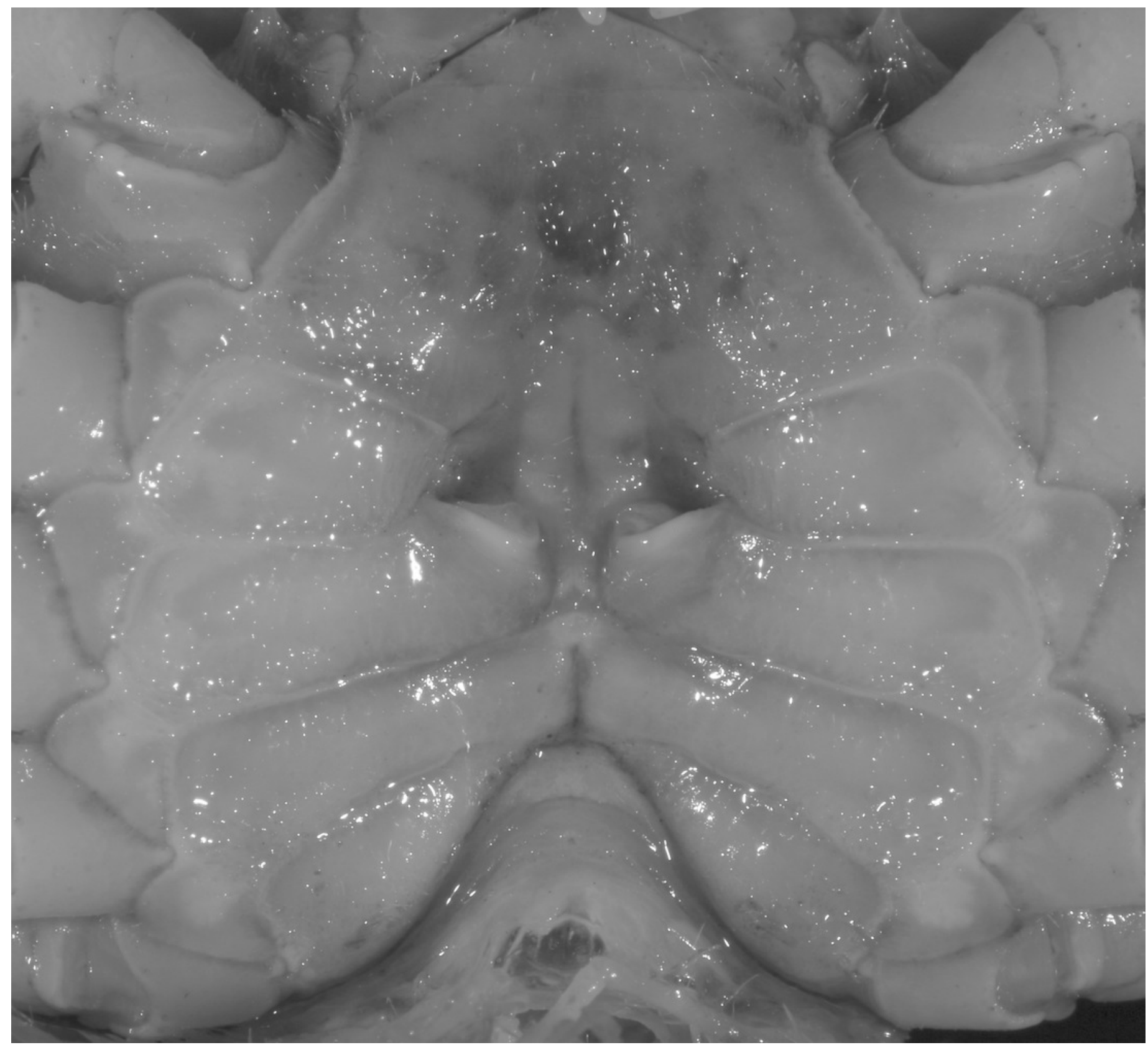

